OPEN ACCESS

Edited by:

Roberto Paganelli,

University of Studies G. d'Annunzio

Chieti and Pescara, Italy

Reviewed by:

Amit P. Bhavsar

University of Alberta, Canada

Palmiro Poltronieri,

Italian National Research Council, Italy

Alexandre Rossi Paschoal,

Federal Technological University of

Paraná, Brazil

${ }^{*}$ Correspondence:

Alessio Naccarati

alessio.naccarati@iigm.it

†These authors have contributed equally to this work

${ }^{\ddagger}$ Present Address:

Mihnea P. Dragomir,

Institute of Pathology, CharitéUniversitätsmedizin Berlin, Corporate Member of Freie Universität Berlin, Humboldt-Universität zu Berlin and Berlin Institute of Health, Berlin, Germany

Specialty section: This article was submitted to Translational Pharmacology, a section of the journal Frontiers in Pharmacology

Received: 11 January 2021 Accepted: 07 June 2021 Published: 06 July 2021

Citation:

Sabo AA, Dudau M, Constantin GL, Pop TC, Geilfus C-M, Naccarati $A$ and Dragomir MP (2021) Two Worlds Colliding: The Interplay Between Natural Compounds and Non-Coding

Transcripts in Cancer Therapy. Front. Pharmacol. 12:652074. doi: 10.3389/fphar.2021.652074

\section{Two Worlds Colliding: The Interplay Between Natural Compounds and Non-Coding Transcripts in Cancer Therapy}

\author{
Alexandru A. Sabo ${ }^{1 \dagger}$, Maria Dudau ${ }^{2,3 \dagger}$, George L. Constantin ${ }^{4 \dagger}$, Tudor C. Pop ${ }^{5}$, \\ Christoph-M. Geilfus ${ }^{6}$, Alessio Naccarati ${ }^{7,8 *}$ and Mihnea P. Dragomir ${ }^{9 \neq}$ \\ ${ }^{1}$ Pediatrics 2 (General and Special Pediatrics), Klinikum Stuttgart, Olgahospital, Zentrum für Kinder, Jugend- und Frauenmedizin, \\ Stuttgart, Germany, ${ }^{2}$ Biochemistry-Proteomics Department, Victor Babes National Institute of Pathology, Bucharest, Romania, \\ ${ }^{3}$ Department of Cellular and Molecular Biology and Histology, Carol Davila University of Medicine and Pharmacy, Bucharest, \\ Romania, ${ }^{4}$ Division of Soil Science and Site Science, Thaer-Institute of Agricultural and Horticultural Sciences, Humboldt- \\ Universitätzu Berlin, Berlin, Germany, ${ }^{5}$ Department of Pediatrics, Marie Curie Emergency Clinical Hospital for Children, Bucharest, \\ Romania, ${ }^{6}$ Division of Controlled Environment Horticulture, Thaer-Institute of Agricultural and Horticultural Sciences, Humboldt- \\ Universität zu Berlin, Berlin, Germany, ${ }^{7} / / G M$ Italian Institute for Genomic Medicine, Turin, Italy, ${ }^{8}$ Candiolo Cancer Institute, FPO- \\ IRCCS, Turin, Italy, ${ }^{9}$ Department of Surgery, Fundeni Clinical Hospital, Carol Davila University of Medicine and Pharmacy, \\ Bucharest, Romania
}

Cancer is a devastating disease and has recently become the leading cause of death in western countries, representing an immense public health burden. When it comes to cancer treatment, chemotherapy is one of the main pillars, especially for advanced stage tumors. Over the years, natural compounds have emerged as one of the most valuable resources for new chemotherapies. It is estimated that more than half of the currently used chemotherapeutic agents are derived from natural compounds. Usually, natural compounds are discovered empirically and an important limitation of introducing new anti-cancer natural products is lack of knowledge with regard to their mechanism of action. Recent data has proven that several natural compounds may function via modulating the expression and function of non-coding RNAs (ncRNAs). NcRNAs are a heterogenous class of RNA molecules which are usually not translated into proteins but have an important role in gene expression regulation and are involved in multiple tumorigenic processes, including response/resistance to pharmacotherapy. In this review, we will discuss how natural compounds function via ncRNAs while summarizing the available data regarding their effects on over 15 types of cancer. Moreover, we will critically analyze the current advances and limitations in understanding the way natural compounds exert these health-promoting effects by acting on ncRNAs. Finally, we will propose several hypotheses that may open new avenues and perspectives regarding the interaction between natural compounds and ncRNAs, which could lead to improved natural compound-based therapeutic strategies in cancer.

Keywords: natural compounds, non-coding RNAs, cancer, chemotherapy, drug resistance 


\section{INTRODUCTION}

\section{MicroRNAs and Long Non-Coding RNAs in Humans}

Almost 2 decades have passed since it has been discovered that about $98-99 \%$ of the human DNA is not following the central dogma of molecular biology (i.e., only about $1 \%$ of the DNA is actively transcribed into proteins) (The ENCODE Project Consortium, 2012). Part of the non-protein-coding genome, which was initially considered "junk DNA", was later on discovered to be pervasively transcribed (Palazzo and Lee, 2015) into RNA molecules, and the quest of revealing its functions was started.

Nowadays, a plethora of physiological and pathological functions of the non-coding RNA (ncRNA) are known. Thousands of papers describe the new functions of these previously ignored transcripts (Dragomir M. P. et al., 2018). Based on their size, using an arbitrary selected length of 200 nucleotides, ncRNAs have been divided into small non-coding RNAs (sncRNAs) (<200 nt) and long non-coding (>200 nt) (lncRNAs). The most studied class of ncRNAs is a particular subtype of sncRNAs called microRNAs (miRNAs). MiRNAs, approximately $22 \mathrm{nt}$ in length, typically bind the 3' untranslated region (3'UTR) of mRNAs, further inhibiting their translation into proteins. Worth mentioning is also that most mRNAs are targeted by multiple miRNAs and each miRNA can target several mRNAs, forming complex regulatory networks (Dragomir M. et al., 2018). An additional layer of complexity to these regulatory networks is the involvement of lncRNAs (or other non-coding genes) that can bind and sponge miRNAs, interfering with their canonical function of mRNA suppression. Hence, it seems that there is a pool of miRNAs that can bind both other ncRNAs and mRNAs, and everything depends on the stoichiometry of these molecules. Interestingly, this observation was first made in plants. In Arabidopsis thaliana, high levels of the non-coding transcript IPS1 lead to the sequestration of miR-399, which consequently induces the upregulation of its target, PHO2 mRNA (Franco-Zorrilla et al., 2007). This interplay is perceived as a unifying theory, connecting the non-coding world and the coding world, being plausible especially in plants (Paschoal et al., 2018).

In the past decade, we have also witnessed some atypical miRNA mechanisms of action. For example, some miRNAs bind to their target mRNAs, inducing their translation rather than inhibiting it, while other miRNAs activate Toll-like receptors (TLRs) (Dragomir M. P. et al., 2018). Therefore, an altered miRNA transcriptome will generate an altered proteome. Moreover, miRNAs, in a similar way as small hormones, can function in intercellular signaling pathways in a paracrine or endocrine fashion, being packed into exosomes or bound to proteins/lipids for short and long-distance transport (Pardini and Calin, 2019). These "traveling miRNAs" can be altered in various pathological states and reflect most of the circulating ncRNA transcriptome.

A special subtype of sncRNAs are those arising from introns, which act as non-canonical miRNAs and were therefore termed "mirtrons". Deregulation of these mirtrons is involved in various human pathologies. Also, in plants, these molecules might have miRNA regulatory roles. MirtronDB is an initiative of collecting available data on these molecules (Da Fonseca et al., 2019).

LncRNAs, as mentioned, are $>200 \mathrm{nt}$ in length, but can also be several kilobases long. They have a complex secondary structure including double stem loops and cloverleaf elements, being polymorphic in form, which enables them to carry out a wide range of functions (Novikova et al., 2012). LncRNAs are capable of regulating gene transcription, directly binding proteins and RNA molecules, acting as posttranscriptional regulators and signaling regulators (Statello et al., 2021). LncRNAs also influence chromatin remodeling (Dragomir et al., 2020a). Surprisingly, in recent years, it was observed that numerous lncRNAs, circular RNAs and a few miRNA precursors are translated into functional micropeptides that play a role in immunity, development and cancer (Dragomir et al., 2020b; Othoum et al., 2020). From a phylogenetic standpoint, lncRNAs can be extremely conserved, being termed "transcribed ultraconserved regions" or they can be primate-specific, often harboring short repetitive regions called pyknons (Rigoutsos et al., 2017; Dragomir et al., 2020a). Over the years, other forms of ncRNAs with various functions have been described and new ones are currently under investigation. For more information about other classes and the main functions of ncRNAs, we refer to Cech and Steitz (2014) and Pardini et al. (2019).

The role of ncRNAs in cancer is one of the most extensively studied fields of non-coding transcripts. Currently, we can consider that ncRNAs play functional roles in all 12 canonical hallmarks of cancer, but also in emerging cancer traits like oncogenic neurogenesis (Amit et al., 2020). For example, the super-oncogenic miR-21 is overexpressed in several types of cancer and induces proliferation, migration, invasion, and metastasis (Javanmardi et al., 2017) and the super-tumor suppressor miR-34 family members are dysregulated in a plethora of cancers and are known to inhibit metastasis by blocking epithelial-mesenchymal transition (EMT) (Zhang L. et al., 2019). An important role in deciphering the function of ncRNAs are the multiple databases that provide crucial information regarding their interacting molecules, structure, function etc. (Maracaja-Coutinho et al., 2019). For example, a better understanding of the role of ncRNAs in cancer will stem from the analysis of their secondary structure, which will provide additional mechanistic insights. A tentative to provide a curated resource on this topic has been recently done by the RNAcentral Consortium which provides the largest database regarding ncRNA spatial organization for $>13$ million molecules (RNAcentral Consortium et al., 2021).

While we continue to understand more and more about the role of specific ncRNAs in different types of cancer, from a translational perspective, these molecules have a promising future as diagnostic biomarkers and therapeutic tools in cancer (Petrescu et al., 2019). Additionally, we observe that the timeline of miRNA discoveries is related to the plant world and oncology (Dragomir M. P. et al., 2018; Li J. et al., 2019), providing a new understanding about potential new plant based therapeutic tools in cancer therapy (Figure 1). 


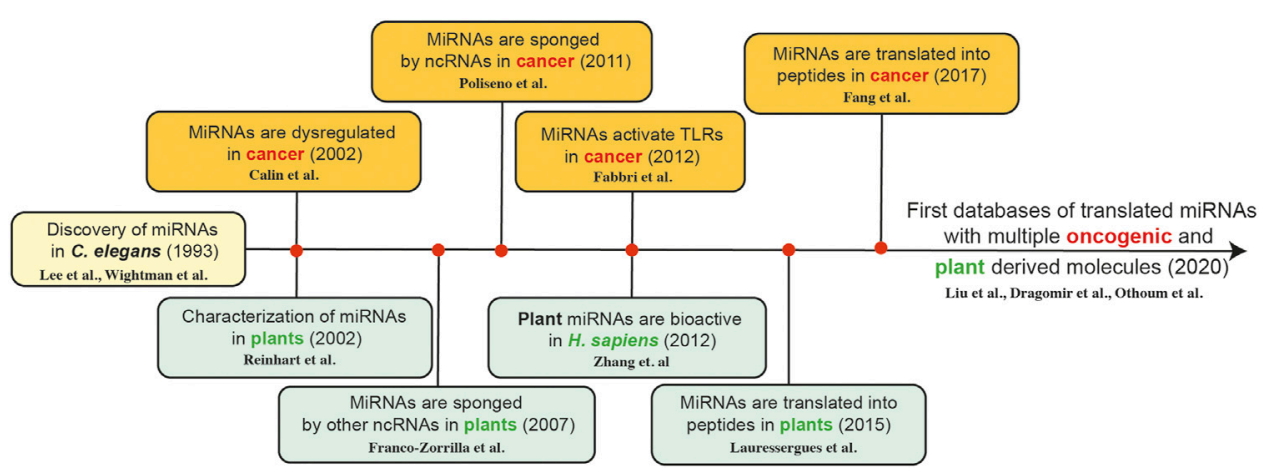

FIGURE 1 | The timeline of miRNA discoveries is related plant sciences and oncology; providing a new understanding about potential new plant based therapeutic tools in cancer therapy [Lee et al. (Lee et al., 1993), Wightman et al. (Wightman et al., 1993), Calin et al. (Calin et al., 2002), Reinhart et al. (Reinhart et al., 2002), FrancoZorilla et al. (Franco-Zorrilla et al., 2007), Poliseno et al. (Poliseno et al., 2010), Fabbri et al. (Fabbri et al., 2012), Zhang et al. (Zhang et al., 2012), Lauressergues et al. (Lauressergues et al., 2015), Fang et al. (Fang J. et al., 2017), Liu et al. (Liu H. et al., 2020), Dragomir et al. (Dragomir et al., 2020b), and Othoum et al. (Othoum et al., 2020)].

\section{From Plants to Chemotherapy}

Serendipity, which represents the "finding of interesting or valuable things by chance", together with recurrent efforts, are the best words to historically describe the discovery of most chemotherapeutic compounds (Mann, 2002). In the first half of the 20th century, the main cancer treatment dogma was based on radiation and surgery. Research into usage of chemicals as anticancer agents emerged based on empirical observations. For example, spilled mustard gas from a bombed ship in Bari in World War II induced extreme leukopenia, as observed in depleted bone marrow and lymph nodes of exposed individuals. At the same time, the dietary effects of folic acid were discovered, subsequently leading to the development of folate antagonists as therapeutic agents. Such discoveries opened the first avenues to chemotherapy. Among them, the most notable is methotrexate. In addition, the discovery of the effects of thiopurines and 5-fluorouracil (5-FU) in cancer induced a shift of paradigm in cancer treatment, marking the transition from surgical treatment to the modern "chemotherapy". An important landmark that needs to be mentioned was the foundation of the "Cancer Chemotherapy National Service" in 1955 in the United States, which started a new era of substance research, where natural compounds where screened and then tested (DeVita and Chu, 2008).

Plants are the main source of natural compounds discussed in this review. We will use the term "phytochemicals" to refer to plant secondary metabolites that fulfill a broad range of functions e.g., in the defense against herbivores and pathogens, in the interaction with pollinators, in plant-plant chemical communication or in the protection against high light or UV radiation, drought or other abiotic threats. Since plants cannot actively change their location, they have to overcome inconvenient conditions rather than switching to more convenient places. Being embedded in such complex ecological relationships, plants evolved a staggering diversity of chemical compounds enabling them to optimize their sessile lifestyle to withstand specific pressures. This gave rise to a huge source of molecules, including some with potential health benefits to humans. Knowing that compounds with potential uses in cancer therapy are the result of a stress-induced shift in plant metabolism toward a defense reaction, appropriate techniques can be used in controlled horticulture and agriculture to enrich crops with these bioactive compounds. Exposing the plant to a short and controlled stress treatment will stimulate biosynthesis of these compounds without reducing yield (Geilfus, 2019).

The structure and relative quantity of phytochemicals vary not only between species but even among different populations of the same species and tissues therein (Moore et al., 2014). In the context of medical research generally and cancer research specifically, plant genetic diversity and ecological diversity, the main drivers of chemical diversity in secondary metabolites, are thus invaluable resources.

With the development of adequate models for testing these compounds, more and more natural products from a variety of sources, belonging to a wide range of chemical classes have been screened in order to find new agents. This way, the functions of phytochemicals previously used in traditional medicine have been explained. These findings laid the ground for improvement, as starting from the original molecules found in nature, more potent and effective chemical analogs have been synthesized by techniques such as combinatorial chemistry (Cragg and Pezzuto, 2016).

Since the second half of the 20th century, the approach on oncologic treatment has changed, as more and more natural products known from traditional medicine were shown to be effective in treating or at least slowing down cancer. The precursors of the podophyllins which are used today, with etoposide and teniposide being the most representative ones, stem from the mayapple plant (Podophyllum peltatum L.), which Native Americans have been using in the treatment of skin warts. Likewise, Catharanthus roseus (L.) G. Don (syn. Vinca rosea L.), a plant that has been used as a remedy in traditional Asian medicine, yields potent anti-cancer drugs nowadays. The isolation of paclitaxel from the Pacific yew tree (Taxus brevifolia Nutt.) and, later on, of the more efficient analog docetaxel from the European yew (Taxus baccata L.), revolutionized the standard approaches of oncologic care, as 
they have been shown to be efficient against breast, pancreatic and lung cancer. Likewise, the topoisomerase inhibitors topotecan and irinotecan are also of plant origin, derived from Camptotheca acuminata Decne., a tree species native to China, and are part of standard treatment protocols of different cancers. At the same time, research initiatives also focused on discovering chemotherapeutic agents from other sources besides plants. For example, two of the chemotherapeutical agents frequently used-mitomycin and doxorubicin-are derived from microbial sources. Likewise, cytosine arabinoside (cytarabine), commonly used in pediatric cancers, is derived from a marine sponge (Mann, 2002).

While for many well-stablished natural compounds the main mechanism of action in cancer is already known, for newer compounds the mechanisms still need to be elucidated. Additionally, alternate mechanisms are being investigated. New discoveries over the last 2 decades proved that older and newer natural products convey their functions in cancer treatment via modulating ncRNA expression (Izzotti et al., 2012). In this review, we sum up recent literature focused on investigating the effects of natural compounds/phytochemicals through ncRNAs on different cancers, discussing both cancers of the adult age and pediatric cancers. From this, we have identified both open fields for research and putative phytochemicals whose potential for human health promotion might be worth pursuing in depth. As most studies regarding phytochemicals and cancer have focused on miRNAs and lncRNAs, we will only focus on these two classes of ncRNAs.

\section{Sources and Classes of Natural Compounds}

A natural compound is any organic product that is synthesized by a living organism. As stated above, the main sources of natural compounds are terrestrial plants, marine macroorganisms and microorganisms (both terrestrial and marine). In this section, chemicals derived from each of these sources will be briefly addressed.

In terms of their role in human diets, phytochemicals are defined as bioactive substances found in fruits, leaves, stems, tubers, roots and other parts of the plant, providing beneficial health effects. Unlike other human nutrients such as proteins, fats or minerals, most phytochemicals are not indispensable for human life, but, among other beneficial properties, they have considerable value in cancer prevention, and as adjuvants in cancer therapy (Gullett et al., 2010; Sak, 2012).

Beside the terrestrial plant kingdom, marine life is also a major source for a variety of bioactive agents. These can be extracted from marine macroorganisms like tunicates, sponges, soft corals, and mollusks. Noteworthy examples would be cytarabine and vidarabine, two agents widely used in chemotherapy (Montaser and Luesch, 2011; Victor and Sharma, 2015).

Likewise, microbes produce a wide range of potentially useful compounds. Bacterial proteins and peptides and, more recently, chemicals isolated from marine sediment bacteria include promising natural compounds that show an anti-proliferative activity and could be employed as anti-cancer agents. Antibiotics, bacteriocins, enzymes, non-ribosomal peptides (NRPs) and toxins are the main groups of bacteria-derived chemicals (Karpinski and Adamczak, 2018).

Natural compounds can be classified into different groups based on their chemical structure and biological characteristics including phenolic compounds, terpenes, carotenoids, saponins, alkaloids and organosulfur compounds, among others (Budisan et al., 2017). Table 1 offers an overview of the chemical classes and subclasses encompassing the natural products discussed in this review, which are almost exclusively of plant origin. It should be stressed that this is not an exhaustive table attempting to categorize the entire spectrum of known natural compounds, but only a selection relevant in the context of ncRNA-mediated anticancer effects. The reader may also acknowledge that there are also disciplines that favor a different way of classification or grouping. In the next section, we will present recent findings about specific natural compounds in the context of ncRNA modulation and cancer therapy, following the order used in Table 1.

\section{PHENOLIC COMPOUNDS}

Plant phenolic compounds are secondary metabolites bearing structures with one or more hydroxyl groups attached to at least one aromatic ring. They are generally known for their antioxidative properties, with the number and position of the hydroxyl groups leading to a variation in their bioactivity, e.g., in the antioxidative potential. In plants, they represent precursors of cell wall components and fulfill a multitude of other functions including the response to different biotic and abiotic stressors. For instance, phenolic substances are known to have repellent properties against herbivores, diminish herbivore digestive ability, protect against fungal and bacterial infections and are involved in the response to wounding, drought, salinity and modified or stressful light exposure (Bhattacharya et al., 2010; Geilfus, 2019).

Very often, phenolic compounds extracted from plants are referred to as "polyphenols", both in commercial and in scientific communication. However, this term is sometimes misused to even include compounds featuring a single hydroxylated aromatic ring, which would be correctly referred to as monophenols. In this review, we use definitions and classifications proposed by Quideau et al. (2011) as guiding principles for presenting plant phenolic compounds in a systematic fashion. This can be a challenging task, since common classifications of plant phenolic compounds based on biogenetic aspects yield categories that cannot be globally considered monophenols or polyphenols, despite this being a very common practice. For instance, flavonoids, curcuminoids and stilbenoids are commonly referred to as "polyphenolic compounds", even though these classes also contain compounds with less than two hydroxylated benzene rings. For this reason, we will discuss these classes of phytochemicals directly under the umbrella term of "phenolic compounds", while only using the term "polyphenols" when all criteria proposed by Quideau et al. (2011) are met. These authors define polyphenols 
TABLE 1 | Major classes and subclasses of organic chemicals, and their specific natural compounds, whose potential role in cancer therapy has been summarized in this review. N/A, not available.

Major compound classes

Phenolic compounds

Terpenoids and meroterpenoids

Subclasses
Phenolic acids and other monophenols
Flavonoids: Flavones, flavanones, isoflavones, flavanols, chalcones
Curcuminoids
Stilbenoids
Tannins: Proanthocyanidins
Related compounds: Lignans, flavaglines
Monoterpenoids, diterpenoids and triterpenoids
Carotenoids
Saponins
Polyprenylated acylphloroglucinols
Cannabinoids
N/A
N/A
N/A

Alkaloids

Polysaccharides

Organosulfur compounds to treat nephroblastoma tumor cell lines. Apoptosis was promoted, cleaved caspase -3 and -9 levels were elevated, p53 and p21 expression was increased and decreased expression of vimentin, matrix metalloproteinase 2 (MMP-2) and cyclin D1 was observed. The phosphorylation levels of p65, Iк-Ba, PI3K, AKT and mTOR were increased in treated cells, while transfection with miR-891b up-regulated cyclin D1 and down-regulated p53 and p21. Salidroside was presumed to inhibit growth and migration through down-regulation of miR-891b, leading to inactivation of $\mathrm{PI} 3 \mathrm{~K} / \mathrm{AKT} / \mathrm{mTOR}$ and NF- $\mathrm{kB}$ signaling pathways, but the direct molecular targets await clarification (Li H. et al., 2019).

Paeonol is a simple phenol found in peonies (Paeonia spp.) and other plants, that is used in traditional Chinese medicine (TCM). In a study on chondrosarcoma cells, Horng et al. (2014) showed that although paeonol did not decrease cell viability nor induce apoptosis, it exhibited anti-proliferative effects as evidenced by reduced protein-kinase $\mathrm{C}$ delta and $\mathrm{c}$-Src phosphorylation activity. MiR-141 levels were elevated in treated cells while its suppression decreased the effects of paeonol. However, no mechanistic links were revealed between miR-141 and the protein-kinase C delta and c-Src pathways.

Shikonin is a naphthoquinone found in the purple gromwell plant (Lithospermum erythrorhizon Siebold and Zucc.), whose dried roots are used in TCM. Shikonin was found to reduce retinoblastoma cell proliferation by up-regulating miR-34a and miR-202, both well-known anti-oncogenic miRNAs. There is evidence for the inhibited proliferation being connected with miR-34a and miR-202 repressing the oncogene protein MYCN (Su et al., 2018). The inhibitory relationship between MYCN and miR-34a has been evaluated in lung cancer, where miR-34a increased chemosensitivity to cisplatin via inhibition of MYCN (Song et al., 2017).

\section{Flavonoids}

Flavonoids are a wide family of phenolic compounds found in almost all plant organs including leaves, fruits or flowers. In addition to their role in the response against diverse biotic and abiotic stress factors, they are often responsible for the aroma and pigmentation of flowers and fruits (Erdman et al., 2007; Panche 
et al., 2016). This is to attract pollinators (in flowers) or to avoid being eaten by insects (in leaves). In terms of plant metabolism, these compounds have been described as hybrids, stemming from a combination of the phenylpropanoid and the polyketide pathways. For the synthesis of phenolic compounds, this is considered to be the most productive metabolic route in plants, with more than 8,000 compounds produced by different plant species being counted as belonging to the flavonoid family (Quideau et al., 2011). Flavonoids discussed in this review belong to several major flavonoid subclasses such as the flavones, flavanones, isoflavones, flavanols and chalcones.

In the case of flavones, there are multiple active chemicals that have been tested for anti-cancer properties. Among them, apigenin and luteolin are the most thoroughly studied.

Apigenin is a common flavone found in a range of plants, including Matricaria spp. (commonly known as chamomile), that displays important anti-tumor properties (Salehi et al., 2019). A study by Gao et al. (2018) found miR-520b, which physiologically acts as a tumor suppressor, to be up-regulated in apigenin treated hepatocellular carcinoma (HCC) cells. In turn, miR-520b targets ATG7, regulating autophagy and, in the cited study, leads to increased chemo-sensitivity to doxorubicin treatment. Apigenin treatment also showed increased miR-16 levels in glioma cell lines, which subsequently targeted and decreased BCL2 expression and down-regulated the NF-kB/MMP9 pathway (Chen X. J. et al., 2016).

As for luteolin, plants rich in this natural compound have been used in TCM for the treatment of hypertension, inflammatory skin diseases or cancer (Lin et al., 2008). In vitro and in vivo studies on hepatoma cells revealed that luteolin treatment promotes apoptosis and tumor suppression through up-regulation of miR-6809-5p which down-regulates Flotillin 1 by directly binding to the $3^{\prime}$ UTR of Flotillin-1 gene mRNA (Yang et al., 2019a). Flotillin 1 is a membrane receptor protein that is considered to promote metastasis and tumor invasion by influencing the Erk1/2, p38, JNK and NF- $\mathrm{BB} / \mathrm{p} 65$ signaling pathways (Lin C. et al., 2011; Cao et al., 2016).

In pancreatic cancer cells, luteolin treatment is associated with down-regulation of miR-301-3p, which directly targets caspase-8, an initiator of the extrinsic apoptosis pathway. Also, luteolin treatment and knockdown of miR-301-3p sensitized pancreatic cancer cells to the tumor necrosis factor (TNF)-related apoptosisinducing ligand (TRAIL) (Moeng et al., 2020). This is a potent apoptosis inducer of the TNF cytokine superfamily, which was also tested as a recombinant anti-cancer agent, but with reported high resistance rates after repeated treatments (Wong et al., 2019).

Mir-34a, which has a well-known tumor suppressor role, has been shown to be epigenetically down-regulated by aberrant $\mathrm{CpG}$ methylation of its promoter region in multiple cancers, including gastric cancer (Lodygin et al., 2008). In a study on gastric cancer cell lines, the reduced expression of miR-34a was reversed by treatment with luteolin. Mir-34a was then shown to target and reduce expression of the BCL-2 protein, leading to apoptosis induction (Wu et al., 2015a).

Moreover, pleiotrophin (PTN), a growth factor that is highly expressed in several cancers associated with poor prognosis (Jee et al., 2016; Ma et al., 2017), has been found to be modulated by luteolin in colorectal cancer (CRC) cells through the up-regulation of miR-384, which binds to PTN 3'-UTR (Yao et al., 2019).

In human glioma cells, treatment with luteolin increased miR124-3p expression, activated apoptosis through MAPK and the death receptor pathway. It also promoted autophagosome initiation following an increased ratio of LC3B II to LC3B I and decreased p62 levels. Although no mechanistic target was identified, the authors suggest PIM1 as a potential miR-124-3p target, an important protein for cell proliferation and apoptosis (Brasó-Maristany et al., 2016; Tursynbay et al., 2016; You et al., 2019).

Luteolin also showed synergistic effects with silibinin, a flavonolignan found in milk thistle seeds (Silybum marianum (L.) Gaertn.). In glioblastoma (GBM) cells, this specific cotreatment produced better results than conventional chemotherapy [bis-chloroethyl nitrosourea or temozolomide (TMZ)]. Co-treatment with these two flavonoid compounds increased apoptosis and reduced autophagy. This is owed to luteolin's capacity of inhibiting $\mathrm{PKCa}$ and up-regulating mTOR and p62, along with silibinin's ability to inhibit inducible nitric oxide synthase (iNOS). Their anti-oncogenic activity, regardless of p53 GBM status, is mediated by miR-71-3p overexpression. Mechanistically they showed that, miR-7-1$3 \mathrm{p}$ decreases in vivo the expression of XIAP, a potent antiapoptotic protein (Chakrabarti and Ray, 2016).

Baicalein is a flavone found in the roots of plants such as the Baikal skullcap (Scutellaria baicalensis Georgi). Zhang et al. treated osteosarcoma cell lines with baicalein and noted increased miR183 expression. The authors showed that this miRNA directly modulated the expression of Ezrin, an intracellular protein which connects the cell wall via the actin cytoskeleton. By decreasing Ezrin, baicalein treatment in this study led to decreased proliferation, invasion and migration (Zhang J. et al., 2018). These findings are additionally supported by another study of Zhang et al. (2014) who showed that Ezrin up-regulates $\mathrm{N}$-cadherin levels and ERK pathway activity to promote osteosarcoma invasion. This mechanism has also been highlighted in other studies on different osteosarcoma and gastric cancer cells respectively (Zhu et al., 2012; Cao et al., 2014).

Naringin is the glycosidic form of the flavanone naringenin and can be found in citrus fruits. This compound was used by Tan et al. in human chondrosarcoma cells lines. The authors observed an up-regulation of miR-126, which was shown to regulate the expression of vascular cell adhesion molecule-1 (VCAM-1), a protein involved in cell motility, which probably accounted for the observed repression of migration and proliferation in this study (Tan et al., 2014).

Formononetin, an isoflavone derived from red clover (Trifolium pratense L.), has been investigated by $\mathrm{Hu}$. et al., who used it to treat osteosarcoma cell lines and tumor bearing mice ( $\mathrm{Hu}$ and Xiao, 2015). This study noted decreased expression levels of miR-375 and an increased $\mathrm{Bax} / \mathrm{Bcl}-2$ ratio, which probably accounts for the observed apoptosis induction in vitro and for the tumor mass shrinkage in vivo. Notably, formononetin also acts as a phytoestrogen and has been shown to act on the estrogen receptor-beta $(\operatorname{ER} \beta)$ with anti-tumor effects on ER positive breast 
cancer cells (Chen et al., 2013). ER $\beta$ is known to have anti-tumor effects in various tumors including osteosarcoma (Yang et al., 2017; Yang Z. M. et al., 2019). In breast cancer cell lines, miR-375 is upregulated and inhibition resulted in decreased ERa signaling (de Souza Rocha Simonini et al., 2010).

The flavanols epigallocatechin gallate (EGCG) and (-)-epicatechin gallate (ECG) are important antioxidants from green tea and, as catechins, chemical precursors of condensed tannins (proanthocyanidins) (Quideau et al., 2011). In a study on osteosarcoma cell lines by Liangdong et al., EGCG increased apoptosis by cell cycle arrest in the G1 phase (Jiang L. et al., 2014). Arrest in the G1 phase was also observed in prostate cancer studies, without involvement of p53 (Gupta et al., 2003), while in leukemic cells the apoptotic effects were mediated through p53, p21 and Bax (which showed increased expression) and down-regulation of Bcl-2- $\alpha$ (Harakeh et al., 2008). Jiang et al. co-treated osteosarcoma cells with miR-126 and EGCG and showed that, in contrast to aforementioned findings, miR-126 did not interact with the mTOR pathway, without inducing the G1 phase arrest of the cell cycle. However, miR-126 enhanced the anti-tumoral effect of EGCG. Mechanistically, it remains unclear if EGCG can act as a miR126 inducer (Jiang L. et al., 2014). However, studies on gastric cancer cell lines (Liu et al., 2014) and endothelial cell lines (Sui et al., 2014) showed that miR-126 regulates PLK2, PI3KR2, Crk, PI3K and Akt, respectively, and these pathways may be dysregulated in osteosarcoma cells as well.

In neuroblastoma cell lines, treatment with EGCG and ECG increased several tumor-suppressive miRNAs such as miR-7-1, miR-34a and miR-99a and decreased a number of oncogenic miRNAs such as miR-92, miR-93 and miR-106b. Overexpression of miR-7-1 followed by co-treatment with EGCG and fenretinide, a synthetic retinol derivate, increased apoptosis by promoting activation of the caspase-3 and calpain pathways. In contrast, miR-93 overexpression reduced the efficacy of fenretinide-EGCG co-treatment, promoted proliferation, with decreased caspase-8, caspase-3, tBid and calpain levels and increased expression of the apoptosis inhibitor survivin (Chakrabarti et al., 2012; Chakrabarti et al., 2013). In nasopharyngeal carcinoma cells, EGCG modulated miR-296 and decreased cancer cell migration. This effect was associated with down-regulation of signal transducer and activator of transcription 3 (STAT3) activation mediated by miR-296 (Lin et al., 2020).

Xanthohumol is a chalcone found in hops (Humulus lupulus L.). Ho et al. treated a U87-MG GBM cell line with xanthohumol and observed reduced invasiveness induced by the downregulation of stromal interaction molecule 1 (STIM1). MiR4725-3p was up-regulated in treated cells and it was shown that the effects of xanthohumol were mediated via miR-4725-3p, which binds directly to the $3^{\prime}$-UTR of STIM1 (Ho et al., 2018). STIM1 is an important protein in cellular calcium metabolism, and inhibition of STIM1 has favorable effects on proliferation and apoptosis (Liu et al., 2011). Furthermore, Chen et al. also treated glioblastoma cells with xanthohumol and noted apoptosis induction, as well as mitochondrial dysfunction and generation of radical oxygen species. The group demonstrated that xanthohumol up-regulated miR-204-3p via ERK/c-Fos pathway and went on to hypothesize IGFBP2 (insulin-like growth factor binding protein 2) as a potential target of this miRNA. IGFBP2 is implicated in the regulation of proliferation by modulation of $\mathrm{AKT} / \mathrm{Bcl}-2$, and its down-regulation through miR-204-3p may account for the observed cytotoxicity (Chen P. H. et al., 2016).

\section{Curcuminoids}

Curcuminoids are phenolic compounds containing two benzene rings and are derived from the name-giving compound curcumin, featuring some variations in functional groups. Curcumin has been isolated from the turmeric plant (Curcuma longa L.) and is responsible for the distinctive bright yellow color of turmeric. Plants accumulate this insecticidal and fungicidal compound in the storage roots and other organs to protect them from being eaten or infected, respectively (Kim et al., 2003). A number of studies on different cancer cell lines reported curcumin downregulating miR-21 levels with pro-apoptotic and antiproliferative effects. In a diffuse large B-cell lymphoma cell line Liu et al. (Liu K. et al. (2017)) revealed VHL (Von Hippel-Landau), a tumor suppressor gene, as a target for miR21 . They then verified the involvement of curcumin by reversing all the salutary effects of this natural compound either through miR-21 overexpression or VHL siRNA transfection. In CRC, Mudduluru et al. (2011) showed that treatment of two CRC cell lines with curcumin down-regulated the miR-21 expression via regulation of activation protein 1 (AP-1) transcription factor. Subsequently, a known miR-21 target in CRC (Asangani et al., 2008), programmed cell death protein 4 (PDCD4) was shown to be up-regulated. Induction of cell cycle arrest in $\mathrm{G}_{2} / \mathrm{M}$, in vitro anti-proliferative effects and in vivo anti-metastatic effects by curcumin, might be a consequence of PDCD4 regulation via miR21. Additionally, PDCD4 locus is coding also for an antisense lncRNA and an intronic miRNA which could play an additional role in the regulatory pathway.

Studies on breast cancer (Wang X. et al., 2017; Esmatabadi et al., 2017) and glioma (Yeh et al., 2015) have also reported curcumin down-regulating miR-21 expression, but without proposing a specific mechanism by which it does so, or possible targets of miR-21. Working with a GBM model, Tan et al. (2018) designed a micelle loaded with curcumin and miR-21 antisense nucleotide and reported increased effects compared to both curcumin treatment and miR-21 antisense nucleotide treatment alone. This was found both in vitro and in vivo, as evidenced by increased apoptosis and lower tumor volume, respectively. Tan et al. did not test for any miR-21 targets in this experiment, but showed elevated levels of phosphatase and tensin homolog (PTEN) and PDCD4, two known targets of miR21 in other cancers (Cirino et al., 1991; Asangani et al., 2008).

In retinoblastoma cell lines, curcumin up-regulated miR-99a and reduced JAK/STAT activity in a miR-99a dependent manner, although the precise target of miR-99a was not identified (Li Y. et al., 2018). Sreenivasan et al. also treated retinoblastoma cells with curcumin and found that miR-22 was up-regulated and, upon subsequent transfection, cell migration was inhibited (Sreenivasan et al., 2012). This study, along with Patel et al. (2011) further showed that miR-22 negatively regulates Erbb3 which is up-regulated in various neoplasms including 
retinoblastoma (Chakraborty et al., 2007). Yu et al. (2015) showed that curcumin up-regulates miR-138 and down-regulates miR186 in osteosarcoma cells. Moreover, they revealed Smad4, NF$\mathrm{kB}$ p65 and Cyclin D3 as targets of miR-138 and demonstrated that curcumin inhibits these genes in a miR-138 dependent manner. It is also worth mentioning that miR-22 was also upregulated, but downstream exploration was not undertaken.

Curcumin was used by Yin et al. (2018), Tahmasebi Mirgani et al. (2014) and Wu et al. (2015b) on GBM cells. Yin revealed that miR-326 and curcumin had complementary effects, with curcumin increasing miR-326 expression and miR-326 augmenting curcumin's anti-tumor activity by increasing apoptosis, inhibiting proliferation and migration (Yin et al., 2018). Furthermore, an inhibition of the SHH/GLI1 signaling pathway was observed, a result also described by other studies employing curcumin (Du et al., 2013) or miR-326 (Jiang Z. et al., 2014). In addition, a combined therapy decreased tumor volume and increased survival in a glioma mouse model population. While no specific target of miR-326 was identified by Yin in this experiment, SMO was evidenced as a direct target of miR-326 in another experiment on glioma cells (Du et al., 2015). Mirgani et al. showed that curcumin increased miR-145 expression and subsequently down-regulated OCT4A, OCT4B1 and SOX-2 which are known targets of miR-145 (Chivukula and Mendell, 2009; Xu et al., 2009) and reduced cell viability by increasing apoptosis and cell cycle arrest (Tahmasebi Mirgani et al., 2014). Because GBM is known for resistance to therapy with temozolomide, a process mediated through NF-kB overexpression (Lavon et al., 2007), Wu et al. investigated whether a combination of curcumin and TMZ would improve GBM chemosensitivity. Combination therapy resulted in increased apoptosis compared to either TMZ or curcumin alone and in an up-regulation of miR-146a levels (Wu et al., 2015b). Inhibition of miR-146a, which has been shown to negatively regulate the NF-kB pathway (Crone et al., 2012; Sha et al., 2013), canceled curcumin's enhancing effect on TMZ treatment.

\section{Stilbenoids}

Stilbenoids, a family of non-flavonoid phenolic phytochemicals, mainly play a role in fungal and UV protection in plants (Akinwumi et al., 2018). In humans, they are known to modulate several signaling pathways involved in oxidative stress and inflammation, therefore these compounds could have applications in cardiovascular protection, insulin resistance, neurodegeneration and cancer prevention (Carter et al., 2014; Kosuru et al., 2016; Dvorakova and Landa, 2017). One of the richest sources of stilbenoids currently known is the genus Vitis, which includes the grapevine Vitis vinifera $\mathrm{L}$.

Resveratrol and its derivatives are the most extensively studied compounds in this class (Rivière et al., 2012) and can commonly be found in fruits such as red grapes and raspberries. In plants, they act as phytoalexins that play a role in the defense against bacterial and fungal pathogens (Tian and Liu, 2020). Xiao et al. investigated the relationship between miR-139-5p and resveratrol in osteosarcoma cells and discovered that resveratrol induces apoptosis and up-regulates miR-139-5p, with a synergistic relationship existing between the two molecules. While miR-139-5p mimics augment the effect of resveratrol, this effect is diminished by miR-139 inhibition. It was shown that miR-139-5p elicits an inhibitory effect on NOTCH1 by directly binding to the $3^{\prime}$ UTR (Xiao et al., 2020).

Yang et al. also treated osteosarcoma cells with resveratrol at non-cytotoxic concentrations and revealed that proliferation and invasiveness were inhibited in vitro and in vivo. Resveratrol upregulated miR-328 which in turn directly binds MMP-2 and reduced its expression (Yang et al., 2015). Additionally, in a different study it was further demonstrated by another research group that miR-328-3p directly targeted MMP-16 in osteosarcoma cells (Zhang M. et al., 2019).

In a GBM cell line, resveratrol was found to down-regulate miR-21, in connection with a subsequent decreased phosphorylation of the Inbitor of $\kappa \mathrm{B}$ (I $\kappa \mathrm{B}$ ) and $\mathrm{p} 50 / \mathrm{p} 65$ heterodimer. This has the effect of blocking their nuclear internalization and the inability to activate the NF-kB pathway leads to a reduction of cell viability ( $\mathrm{Li} \mathrm{H}$. et al., 2013).

MiR-15a and miR-16-1 are two anti-oncogenes that inhibit Bcl-2 and are known to be down-regulated in leukemia (Cimmino et al., 2005; Acunzo and Croce, 2016). Resveratrol exercised anti-tumor effects in T-cell and B-cell ALL cells by down-regulating miR-196b and miR-1290 which are known to be elevated in ALL lines (Zhou et al., 2017). Down-regulation of these miRNAs resulted in up-regulation of IGFBP3 (insulin-like growth factor binding protein 3 ), which was revealed to be lowered in ALL patients compared to healthy controls. Both miRNAs were found to bind to the $3^{\prime}$-UTR of the IGFBP3 gene with inhibitory effects.

Pterostilbene is an analog of resveratrol found in almonds, grapes and berries from the genus Vaccinium, with blueberries as the most noteworthy source. Huynh et al. investigated the effect of pterostilbene in CD133 + GBM stem cells with highly expressed GRP78 (Glucose-regulated protein 78), which are known for their resistance to therapy. Upon treatment with pterostilbene, an increase in miR-205, as well as a decrease in GRP78, c-Myc, TCF-4, GSK3 $\beta$ and vimentin levels were discovered. These modifications translated into the disruption of tumor sphere formation and radiation sensitization. The authors hypothesized that miR-205 is responsible for this down-regulation, as overexpression of miR-205 in monotherapy yielded the same results and combination therapy had a more pronounced effect. The findings were also confirmed in vivo, on xenograft mice (Huynh et al., 2015).

\section{Tannins}

Tannins are polyphenolic secondary metabolites that often have high molar masses (up to 20,000 D) and that are known for their ability to crosslink collagen chains, an effect that is used in the process of turning animal skins into leather ("tanning"). They are found in a wide range of higher plant families and are responsible for the astringent taste of many plants. Their biological role mainly consists in protecting the plant against bacterial or fungal infection or herbivory (acting as a repellent), therefore an increase in tannin production is found when plants respond to these particular situations (Khanbabaee and van Ree, 2001). Based on their structural characteristics, tannins can be divided into several 
major groups: gallotannins, ellagitannins (often collectively referred to as hydrolyzable tannins), condensed tannins and complex tannins. Among these, condensed tannins (also called proanthocyanidins), which are derived from the oligomerization or polymerization of flavanol units, have shown promising effects in cancer research.

Chakrabarti et al. (2016) treated GBM cells with grape seed proanthocyanidins (GSP) and with miR-30e. Both GSP and miR-30e in monotherapy decreased autophagy as evidenced by reduced levels of Beclin-1 and LC3 II and increased apoptosis by down-regulation of BIRC6 and AVEN, two important apoptosis inhibitors. The role of autophagy, which is a physiologic process implicated in the household of healthy cells, turns to protumoral in the context of hypoxia and starvation, by recycling proteins which contribute to the tumoral survival and proliferation. In the case of GSP and miR-30e, co-treatment showed synergistic results but with no evidence of a direct induction of miR-30e by GSP.

\section{Related Compounds}

This section presents two more compounds belonging to two phytochemical families (lignans and flavaglines) with precursors stemming from the phenylpropanoid metabolic network (Pan et al., 2013; El-Seedi et al., 2018). While these particular compounds contain aromatic rings lacking free hydroxyl groups, they are included here, since they are biogenetically related to plant phenolics discussed above.

Lignans are building blocks of the cell wall, but they can also inhibit germination of competitor plants and protect the plant through their antimicrobial activity (DellaGreca et al., 2013). One lignan that has been studied in cancer research is schisandrin, a compound extracted from the magnolia-vine (Schisandra chinensis (Turcz.) Baill.). Jiang et al. (2015) found schisandrin to have an inhibitory effect on the mTOR/MMP-9 pathway and to inhibit glioma metastasis. In another study by Jiang et al., in which glioma cell lines were treated with schisandrin, an increase in miR-125a-5p expression and a decrease in the expression of the lncRNA HOTAIR (HOX transcript antisense RNA) were observed. This modulation of miRNA and lncRNA was associated with a lowered mTOR protein expression. Upon transfection with a miR-125a-5p inhibitor, the effects of schisandrin were diminished, but no further mechanistic details were offered (Jiang Y. et al., 2017). However, a molecular mechanism was described by Tang et al., who identified CASP2 as a target of miR-125a-5p and found that knockdown of HOTAIR can induce cell apoptosis via CASP2/miR-125a-5p axis (Tang et al., 2016).

Another compound tested for its potential use in cancer therapies is silvestrol, a flavagline produced by trees of the genus Aglaia, which showed important anti-tumor effects in acute myeloid leukemia (AML) cell lines. After FLT3-ITD (FLT3 internal tandem duplication) and FLT3-wt cell lines were subjected to silvestrol treatment, a reduction of proliferation and colony forming capacity and an increase of apoptosis were obtained in both cell lines. FLT3-ITD protein and miR-155 levels were decreased by silvestrol. NF-kB protein levels were found to be also decreased, which could indicate that silvestrol down-regulates miR-155 through NF-kB (Alachkar et al., 2013).

\section{TERPENOIDS AND MEROTERPENOIDS}

Terpenoids are a group of molecules synthesized by all kinds of organisms (animals, plants, fungi, bacteria etc.) through either the mevalonate (MVA) or the methylerythritol phosphate (MEP) pathways, assuming a wide range of metabolic functions. They are particularly diverse in plants, with higher plants possessing a great number of enzymes specialized in terpenoid synthesis. In plants, some terpenoids can be classified as primary metabolites, as they contribute to essential cell functions like photosynthetic activity or membrane stability, while others that are involved in responses to environmental factors are counted as secondary metabolites (Bergman et al., 2019; Tetali, 2019). The latter category serves many functions similar to those previously presented for phenolic compounds: defense against pathogens and herbivores, attraction of pollinators or of natural enemies of herbivores, response to light stress etc. In fact, terpenoids form the most diverse group of secondary metabolites known from plants. A large number of terpenoids are used by humans for various reasons, including medical (e.g., as anti-malarial drugs or chemotherapy medication) or cosmetic purposes and in the food industry (Tetali, 2019).

Interestingly, in Arabidopsis thaliana (L.) Heynh., proper functioning of plant miRNAs in post-transcriptional gene silencing was shown to be dependent on terpenoid biosynthesis. As it has been suggested, this might be due to the need for a functional MVA pathway as a prerequisite for membrane association of Argonaute (AGO) proteins. As AGOs and, by extension, RNA-induced silencing complexes (RISC) are associated with membranes in both plants and animals, this might be an interesting example of phytochemicals influencing miRNA function through a common mechanism in both groups of organisms (Brodersen et al., 2012).

Terpenes represent the basic form of terpenoids. They are derived from isoprene precursors containing five carbon atoms and can be classified by the number of isoprene units they are composed of, e.g., hemiterpenes ( 1 unit-5 C), monoterpenes (2 units-10 C), diterpenes (4 units-20 C) up to polyterpenes that may consist of thousands to tens of thousands of isoprene units. The term terpenoids is used to designate a broader category which comprises terpenes and derived molecules containing additional functional groups. This section additionally includes terpenoid glycosides and molecules having at least a partial terpenoid structure (meroterpenoids), like terpenophenols or other prenylated compounds.

\section{Monoterpenoids, Diterpenoids and Triterpenoids}

$\boldsymbol{\alpha}$-pinene is an isomer of pinene, a monoterpene found in the resin of coniferous plants. Xu Q. et al. (2018) and Yang J. B. et al. (2016) showed that a-pinene induced G2/M phase cell cycle arrest and inhibited miR-221 expression with downstream upregulation of $\mathrm{CDKN} 1 \mathrm{~B} / \mathrm{P} 27$ and down-regulation of CDKN1C/ P57 in HCC cells. The mechanism through which miR-221 regulates $\mathrm{CDKN} 1 \mathrm{C} / \mathrm{P} 57$ and $\mathrm{CDKN} 1 \mathrm{~B} / \mathrm{P} 27$ was not elucidated in this study, but another study revealed that $\mathrm{CDKN} 1 \mathrm{~B} / \mathrm{P} 27$ is a direct target of miR-221 (Diaz-Moralli et al., 2013). 
Ailanthone is a pentacyclic diterpene lactone produced by the tree of heaven (Ailanthus altissima (Mill.) Swingle). This compound was used to treat a number of cancer cell lines with proapoptotic and anti-proliferative effects and showed regulatory activity on a number of different miRNAs. In a study on AML cell lines (Zhang Y. et al., 2019), ailanthone up-regulated miR-449a with inhibitory effects on the Notch and PI3K/AKT pathways, both of which were demonstrated to be downstream targets of miR-449a (Liu X. et al., 2018; Cheng et al., 2018). Similar proapoptotic and anti-proliferative effects were observed by Gao W. et al. (2019) in breast cancer cell lines, where ailanthone up-regulated miR-148a and inhibited the AMPK and Wnt/ $\beta$-catenin pathways in a miR-148adependent manner. For Hou et al. of course in a study on lung cancer cell lines, also showed that ailanthone blocked the PI3K/AKT pathway as well as the JAK/STAT3 pathway in a miR-195-dependent manner, miRNA levels being upregulated upon treatment (Hou et al., 2019). Yang et al. revealed that miR-21 was down-regulated by ailanthone in a schwannoma cell line with downstream inhibition of the Ras/ Raf/MEK/ERK and mTOR pathways. MiR-21 overexpression partly reversed ailanthone effects by increasing the expression of Ras, Raf, $p$-MEK, $p$-ERK, $p$-mTOR and p-p70S6K (Yang P. et al., 2018).

Carnosic acid is a diterpenoid found in rosemary (Salvia rosmarinus Spenn.) and sage (Salvia officinalis L.). Liu and colleagues induced G2/M phase cell cycle arrest and lowered proliferation in a chronic myeloid leukemia (CML) cell line through treatment with carnosic acid. MiR-708 was downregulated, but no downstream pathway mechanisms were explored (Liu D. et al., 2018). It is worth mentioning that miR-708 has been reported as both an oncogenic ( $\mathrm{Li} \mathrm{X}$. et al., 2013; Zhang Y. et al., 2017; Huang et al., 2018) and an antioncogenic (Baer et al., 2015; Wu et al., 2016; Monteleone and Lutz, 2020) miRNA in various other studies on leukemic and lung cancer cells. A study using rosemary extracts on colon and pancreatic cancer cells showed anti-cancer effects both in vitro and in vivo (colon cancer xenografts in treated nude mice showed reduced tumor size compared to untreated mice). In this study, the authors showed that carnosic acid down-regulates miR-15b, subsequently leading to overexpression of the GCNT3 gene. However, a direct interaction between this miRNA and GCNT3 was not identified (González-Vallinas et al., 2014).

Triptolide is a diterpenoid extracted from the Asian medicinal plant Tripterygium wilfordii Hook. f., which has been used in TCM against rheumatoid arthritis and psoriasis (Bao and Dai, 2011). This compound has shown anti-cancer effects in studies employing a variety of cancer cell lines.

In medulloblastoma cells treated with triptolide, miR-138 was increased and proliferation, viability and migration were inhibited. MiR-138 directly targets Cyclin Dependent kinase 6 (CDK6). Hence, a possible mechanistic explanation for the anticancer effect of triptolide is the inhibition of CDK6 via miR-138 (Zhang H. et al., 2018). Furthermore, triptolide also induced the apoptosis of osteosarcoma cells by inhibition of PTEN. MiR-181a was up-regulated by triptolide and directly inhibited PTEN mRNA translation (Jiang C. et al., 2017).
In CRC, treatment with triptolide down-regulated miR-191 and was associated with decreased activation of $\mathrm{Wnt} / \beta$-catenin and NFkB pathways. Treated cells showed increased apoptosis and reduced migration capabilities (Qi and Li, 2019). Nephroblastoma cells treated with triptolide showed a decrease in KLF-4 activity (an activator of p53) and down-regulation of PI3K/AKT and ERK pathways. KLF-4 activity was modulated by miR-193b-3p (Hang et al., 2019).

In ALL cell lines, 21 different miRNAs were modulated by triptolide. MiR-138-2* was the most significantly up-regulated and miR-16-1 was the most significantly down-regulated, supposedly accounting for the anti-proliferative effects of triptolide noted in this study (Meng et al., 2011). Furthermore, breast cancer cells showed decreased invasion and migration capacity after exposure to triptolide. Triptolide up-regulates miR146a, which mechanistically down-regulates the expression of Rasrelated $\mathrm{C} 3$ botulinum toxin substrate 1 (RAC1), an important cellular switch which is altered in cancerous states (Liu Q. et al., 2019).

Betulinic acid is a triterpenoid found in the bark of several tree species, most notably that of the white birch (Betula pubescens Ehrh.), where it functions as a phytoalexin. This compound was used to treat breast cancer cell lines by (Mertens-Talcott et al., 2013) and (Liu et al., 2012). Both groups showed that betulinic acid displays anti-cancer activity, as reflected in lower cell survival, proliferation and increased apoptosis. Betulinic acid down-regulated the transcription factors SP1, SP3 and SP4 via miR-27a down-regulation, and the subsequent up-regulation of its target ZBTB10. Furthermore, Liu et al. demonstrated that betulinic acid effect on miR-27a-ZBTB10-Sp axis was CB1 and CB2 cannabinoid receptors dependent.

\section{Carotenoids}

Carotenoids are lipid-soluble tetraterpenoid pigments fulfilling important functions in plants, such as facilitating photosynthesis by harvesting light energy (photons) as an antenna pigment, protecting against high light-induced damage or signalizing fruit ripeness. They are often responsible for yellow, orange or red coloration in different parts of the plant (Ngamwonglumlert et al., 2019).

One of the best-known carotenoids, $\boldsymbol{\beta}$-carotene, has been tested in colon cancer stem cells, where it reduced sphere formation and proliferation and it was shown to act as an epigenetic regulator by down-regulating various miRNAs, such as miR-1260b and miR296-3p. Mechanistically, these dysregulated miRNAs stimulated the acetylation process, reflected by an increase in histones $\mathrm{H} 3$ and $\mathrm{H} 4$, as well as the reduced expression levels of the DNMT3A mRNA, resulting in DNA hypomethylation. Both these noted effects are counteracting epigenetic modifications observed in cancer cells (Kim et al., 2019).

In human diets, $\beta$-carotene functions as provitamin $\mathrm{A}$ consisting of two retinyl groups and is transformed in the digestive system into retinol, a form of vitamin A. Due to some carotenoids (including $\beta$-carotene) being sources of vitamin $A$, we will proceed to discuss the effects of a synthetic isoform of vitamin A called all-trans retinoic acid (ATRA). While it is not a natural compound itself, ATRA is synthesized 
from $\beta$-carotene (oxidative cleavage of carotenoids catalyzed by enzyme models and beta-carotene $15,15^{\prime}$-monooxygenase) and, therefore, it is a very suitable example for demonstrating the value of developing synthetic substances inspired by natural compounds in an attempt to optimize their known beneficial effects.

In a recent systematic review by Lima et al. (2019), the effects of ATRA on nine different in vitro cancer types was summarized. In this review, miRNA expression profiles, as well as phenotypical changes after ATRA treatment are well described for the nine cancer forms. However, for most of the covered studies, the mechanistic description of miRNA downstream pathways is missing.

Nevertheless, the ATRA-induced promyelocytic leukemia (PML) differentiation through miRNA is covered in different studies, numerous mechanistic explanations being available. In one study (De Marchis et al., 2009), ATRA achieved an upregulation of miR-342, while at the same time increased expression levels of granulocyte colony-stimulating factor receptor (G-CSFr) mRNA levels were noted, which in turn, were linked to promyelocytic differentiation. Likewise, in another study on AML lines, the research group (Lin K. Y. et al., 2011) showed that ATRA could down-regulate the expression of the homebox protein $\mathrm{CDX} 2$, stopping it from binding to the promoter region of the miR$125 \mathrm{~b}$ gene, hence down-regulating its expression. The downregulated miR-125b then stops binding to the core binding factor $\beta(\mathrm{CBF} \beta)$ gene, allowing it to be expressed, which also accounted for the granulocytic differentiation. Interestingly, in a different study (Zhuang et al., 2014), it was shown that CBF $\beta$ downregulates the expression of miR-181a which, in turn, regulates the adenylate cyclase 9 (AC9) levels. The latter is an enzyme which catalyzes the conversion of ATP to CAMP, which is required in the differentiation process of the promyelocytic forms. These findings are confirmed by a different study which showed that the promyelocytic differentiation is miR-181a,b-dependent. In PML, the miR-181 cluster is pathologically up-regulated because of the PML/RARa oncogene. Upon ATRA treatment, levels of the miR-181a,b are down-regulated. In this study, these miRNAs were shown to bind to the $3^{\prime} \mathrm{UTR}$ gene of RASSF1A, regulating its expression. While downregulation of RASSFA1 halted the ATRA-induced differentiation by influencing the cyclin D1 pathway, its overexpression led to apoptosis (Bräuer-Hartmann et al., 2015). In non-small-cell lung cancer (NSCLC) lines, ATRA induced the up-regulation of miR-512-5p, which in turn may be responsible for the observed p21 mRNA and protein downregulation, associated with apoptosis and lesser glucose uptake by cancer cells (Chu et al., 2016). These finding are represented in Figure 2.

\section{Saponins}

Saponins are glycosylated triterpenoids with a wide distribution in plants, where they are mainly associated with defense responses against herbivores (acting as antifeedants) and pathogens (Sawai and Saito, 2011). Most of them are amphipathic, being intercalated in the lipid bilayers where, among other functions, they influence membrane

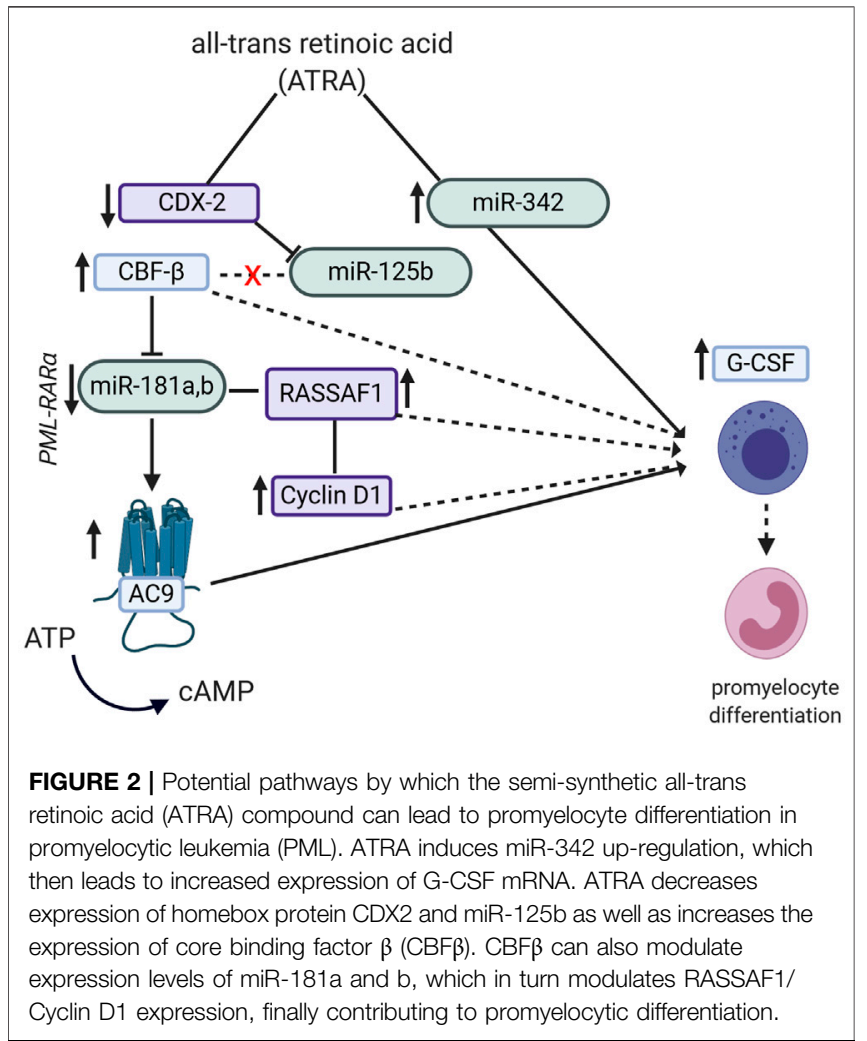

permeability (Moses et al., 2014). They have also been used for ages in traditional medicine and most compounds used in cancer-related studies featuring ncRNAs generally originate from TCM. The majority of the studies are conducted on different cancer cell lines, while others also focus on in vivo models of tumor-bearing mice.

Some of the most extensively studied saponins are derived from the ginseng genus Panax, most commonly from the species Panax ginseng C.A.Mey and Panax notoginseng (Burkill) F.H.Chen. Among these compounds, the most thoroughly investigated is Ginsenoside $\mathbf{R h} \mathbf{2}$, which has been shown to have anti-proliferative and/or apoptosis-inducing properties. In glioma cell lines, Rh2 was shown to regulate expression of different miRNAs. Especially an up-regulation of miR-128 was noted, which was then demonstrated to target the promoter region of E2F3a, reducing its expression. $\mathrm{E} 2 \mathrm{Fa}$ is a transcription factor implicated in regulating expression of key components of the cell cycle, which explains the noted anti-proliferative effects. Moreover, in the same study, increasing caspase-3 levels were noted along dose- and time-dependent induction of apoptosis through Rh2 (Wu et al., 2011). Likewise, in prostate cancer cell lines, miR-4295 was shown to be suppressed by $\mathrm{Rh} 2$, not being able to bind to the $3^{\prime} \mathrm{UTR}$ region of CDKN1. This resulted in up-regulation of $\mathrm{p} 21$, with known implications in cell cycle regulation, accounting for the observed anti-proliferative effects (Gao and Zheng, 2018).

In a study on both hepatitis B-induced HCC cell lines as well as on tumor bearing mice, $\mathrm{Rh} 2$ also showed anti-proliferative 
potential by up-regulation of miR-491, which was shown to target the epidermal growth factor receptor (EGFR) and by reducing its expression to act anti-proliferative (Chen and Qiu, 2015). In one study on NSCLC lines, Rh2 was proposed as an anti-metastatic agent. It was shown to up-regulate miR-491, which in turn might reverse the hypoxia (HIF-1 $\alpha$ )-induced up-regulation of MMP-9, contributing to the anti-migratory effect noticed in the cell lines (Chen Y. et al., 2019).

In a study on adriamycin- and docetaxel-resistant breast cancer cell lines, Wen et al. showed anti-proliferative effects after treatment with Rh2. The authors hypothesized that Rh2 could reverse chemoresistance by regulating the expression miR222, miR-34a and miR-29a, which in turn could target effectors implicated in chemoresistance reversal. However, no targets of specified miRNAs were analyzed in this study, only an unspecific increase in BAX expression levels was noted (Wen et al., 2015).

Ginsenoside Rh2 was proposed to induce apoptosis and to prolong survival in mice with AML and the miR-21/Bcl-2 pathway (Wang and Wang, 2015). In retinoblastoma cell lines it also showed anti-proliferative and apoptosis inducing properties via miR-638 via $\mathrm{PI} 3 \mathrm{~K} / \mathrm{AKT} / \mathrm{mTOR}$ pathway (Li M. et al., 2019).

A related compound, ginsenoside $\mathbf{R g 3}$ was proposed to influence the cancer cell metabolism in two studies on ovarian cell lines by reversing the Warburg effect. In one of the studies, Rg3 decreased expression of several lncRNAs including $\operatorname{lncH19}$, which was shown to target miR-324-5p. The increased miR-324$5 \mathrm{p}$ levels inhibited pyruvate kinase isozyme 2 (PKM2), which accounted for the noted metabolic change (Zheng et al., 2018). In a similar follow-up study, the same research group noted that Rg3 inhibited the expression of DNA methyltransferase $3 \mathrm{~A}$ (DNMT3A), which, in turn, reduced methylation of many genes, among these also the promoter region of miR-532-3p leading to the up-regulation of this miRNA. Further on, this miRNA was shown to target hexokinase 2 (HK2), having the same consequence, Warburg effect reversal (Zhou et al., 2018).

Another similar compound, ginsenoside Rg2 was tested also on oral squamous cell cancer (OSCC) cell lines where it showed anti-proliferative and anti-metastatic effects by down-regulating miR-221. Low levels of miR-221 up-regulate the metalloproteinase inhibitor 3 (TIMP3), which in turn acts on the PI3K/AKT and MAPK/ERK pathways. The findings were also confirmed on tumor bearing mice (Cheng and Xing, 2019).

There is also a third type of ginsenoside that has been investigated, ginsenoside Rd. This compound showed antimetastatic properties in vitro and in vivo in breast cancer via down-regulation of miR-18a, which directly targets Smad2, known to be implicated in cell migration (Wang P. et al., 2016).

One study showed that a mixture of ginsenosides could also influence angiogenesis in a tissue specific manner via miR-18a, reducing neo-vascularization in tumor tissue, while stimulating it in cardiac tissue of the same tumor-bearing mice (Yang Q. et al., 2014). Another study focused on the P. notoginseng extract (a mixture of multiple ginsenosides), showed anti-proliferative effects in vitro and in vivo also via miR-222, by targeting and up-regulating p27 and PTEN tumor suppressors, which in turn modulated the expression of several other oncogenes or tumor suppressor genes in lung cancer cell lines. Results were confirmed in vivo on inoculated mice (Yang Q. et al., 2016).

Of course, saponins known to have miRNA-dependent anticancer effects are found in other plants as well, beside ginseng species. For instance, polyphyllin VI, extracted from the Asian plant species Paris polyphylla Sm., has been tested in murine and human breast cancer lines and was shown to decrease miR-18a expression, up-regulating the Receptor expressed in lymphoid tissue (RELT)-like 2 (Rell2), which was linked to the observed anti-metastatic effects (Wang et al., 2019).

Astragaloside IV is a saponin extracted from the root of the Mongolian milkvetch (Astragalus membranaceus (Fisch.) Bunge). This compound was shown to improve tumor microenvironment (TME) disbalance and affect EMT and migratory potential in fibroblast derived from gastric cancers (in opposition to fibroblasts derived from non-cancerous gastric tissue) via miR214 and miR-301. The two miRNAs subsequently modulate M-CSF and TIMP2 levels, which, in turn, prevented the expression of the pro-oncogenic factors SRY (sex determining region Y)-box 2 (SOX2) and NANOG (Wang Z. F. et al., 2017). In CRC, it also affected EMT through miR-134/CREB1, while it also increased chemosensitivity through the same mechanism (Ye et al., 2017). Cell proliferation was also reduced in CRC via miR-29c and B7-H3 protein (Wang et al., 2018).

In another study in HCC, astragaloside IV together with curcumin, reduced angiogenesis via miR-122 and miR-212 in vivo, by influencing expression of several TME regulatory molecules (FGF2, MMP2, VEGF, HGF, TF, FVII). The data was also confirmed by microscopical vessel count (Zhang S. et al., 2017).

There are also several saponins with anti-proliferative and anti-migratory properties on NSCLC lines. For instance, NSCLC cell lines treated with Tubeimoside I, have been shown to have increased miR-126-5p expression. In turn, miR-126-5p targeted VEGF-A and VEGFR-2, leading to reduced angiogenesis and reduced metastatic potential (Shi et al., 2018). Still in NSCLC cell lines, Cyclamen pseudibericum Hildebr. extract up-regulated miR-200c which, in turn, targeted the transcriptional repressor Zinc finger E-box-binding homeobox 1 (ZEB1), resulting in decreased expression of E-cadherin, $\mathrm{N}$-cadherin and vimentin, reflecting the EMT-inhibitory properties of this extract (Karagur et al., 2018).

Other saponins were found to have anti-cancer effects in studies addressing a variety of cancer types. In hepatoma cell lines, a saponin extacted from the plant species Ornithogalum saundersiae Baker called OSW-1 (alternatively known as orsaponin), in combination with doxorubicin influenced the expression of multiple miRNAs (especially miR-142-3p), which are known to be implicated in tumor metabolism (Jin et al., 2013). In gastric cancer, another anti-proliferative saponin was Platycodin D, which regulated miR-34a/surviving levels in vitro and also in vivo (Peng et al., 2019). D Rhamnose $\boldsymbol{\beta}$-hederin from the vine Clematis ganpiniana (H.Lév. and Vaniot) Tamura reduced breast cancer tumor cell exosome production, exosomes which either carry genetic cargo coding for Docetaxel chemoresistance (Chen et al., 2018b) or simply prometastatic miRNAs, like miR-130 and miR-425 (Chen et al., 
2018a). Finally, in breast cancer cell lines, Timosaponin A-III, extracted from the plant species Anemarrhena asphodeloides Bunge, has been shown to induce the expression of miR-200c and miR-141, both of which may target c-Myc. This might lead to the down-regulation of the BMI1, a protein associated a prooncogenic phenotype in several malignancies (Gergely et al., 2018).

\section{Polyprenylated Acylphloroglucinols}

Polyprenylated acylphloroglucinols are a peculiar class of natural compounds that contain multiple isoprenyl or geranyl chains stemming from the MVA/MEP biosynthetic pathways coupled to an acylphloroglucinol core moiety derived from the polyketide pathway. These meroterpenoid compounds are very diverse in terms of structure and bioactivity. A subgroup with less complex structures, monocyclic polyprenylated acylphloroglucinols (MPAPs) is known from plant families such as Clusiaceae (Guttiferae), Myrtaceae and Cannabaceae (Ciochina and Grossman, 2006), while their more complex derivatives, the polycyclic polyprenylated acylphloroglucinols (PPAPs) have been isolated almost exclusively from the genera Hypericum and Garcinia of the family Clusiaceae. Only two exceptions from the families Rutaceae and Simaroubaceae have recently been described (Yang X. W. et al., 2018).

Garcinol is a PPAP possessing a dihydroxyphenyl moiety extracted from the fruit of the kokum tree (Garcinia indica (Thouars) Choisy). Kokum fruits are widely used in Indian cuisine as a souring agent and for the preparation of refreshing drinks (Padhye et al., 2009). In pancreatic cancer cell cultures (PANC-1SP cells), garcinol treatment effectively increased the expression of different anti-oncogenic miRNAs: miR-200c, miR-29b, miR-101 and miR-181. Only the activity of miR$200 \mathrm{c}$ was investigated in more detail. MiR-200c shows affinity for the $3^{\prime}$ UTR of the NOTCH1 mRNA, with its subsequent down-regulation leading to a reversal of cancer stemness (including reduction of self-renewal ability) and metastasis inhibition (Huang et al., 2017). Similarly, a study by Parasramka et al. found the modulation of several miRNAs by garcinol to be the mechanism behind the reduction in tumor sphere formation. Additionally, this regulation of miRNA expression was suggested to be involved in the attenuation of the drug resistance phenotype when garcinol was used alongside gemcitabine. Garcinol and gemcitabine cotreatment modulates several miRNAs involved in canonical cancer signaling pathways such as miR-21, miR-196a, miR495, miR-605, miR-638, miR-453, with gemcitabine alone modulating only miR-605. Meanwhile, garcinol itself was shown to up-regulate miR-453, miR-128, miR-1280 and miR-720 expression and down-regulate miR-21, miR-495, miR-494, miR-1977 (Parasramka et al., 2013).

The ability of garcinol to increase the sensitivity of cancer cells to other drugs was also described in a study on mesenchymal NSCLC cell lines (Farhan et al., 2019). Here, garcinol treatment resulted in drug-sensitization to cisplatin and erlotinib as well as in EMT inhibition. EMT is regulated by several important miRNAs such as miR-200b, miR-205, miR218 and let-7c, all of which were up-regulated by garcinol in these cell lines, with miR-200b and let-7c levels being the most strongly influenced.

Furthermore, in breast cancer cell cultures and xenograft mouse models, garcinol treatment facilitated the transition of EMT to MET phenotype. Several miRNAs were significantly upregulated such as let-7 family miRNAs (let-7a, let-7e, let-7f) and members of the miR-200 family (miR-200b, and miR-200c). MiR-200b and mirR-200c up-regulation is associated with decreased activity of the NF-kB signaling pathway and provides a molecular framework for how garcinol lowers cancer cell invasiveness (Ahmad et al., 2012).

\section{Cannabinoids}

Cannabinoids are a group of terpenophenols (meroterpenoids) with 21 carbon atoms naturally occurring in hemp (Cannabis sativa L.), known for their capacity to bind the cannabinoid receptors $\mathrm{CB} 1$ and $\mathrm{CB} 2$. This characteristic offers them psychoactive properties as well as the ability to modulate the immune system (Widelski et al., 2017). Two very well-known examples of natural cannabinoids are tetrahydrocannabinol (THC) and cannabidiol (CBD).

The anti-inflammatory effects of cannabinoids, particularly of cannabidiol (CBD) have been demonstrated in several studies on microglial cells exposed to CBD and lipopolysaccharide (LPS). MiR-146a, an important element of the Toll like receptor (TLR) signaling pathway (O'Neill et al., 2011), was up-regulated by LPS and down-regulated by CBD. In addition, pretreatment with CBD reduced miR-146a up-regulation after exposure to LPS (Juknat et al., 2019). A study on low-grade gliomas in a pediatric population revealed that the low expression of the CB1 receptor and high levels of hsa-miR-29b-3p are potential prognostic factors for involution or absence of progression after subtotal tumor resection (Sredni et al., 2016). These results show that further research into miR-29b-3p and exogenous and endogenous cannabinoids is needed.

\section{ALKALOIDS}

Alkaloids are a class of natural compounds with structures containing at least one nitrogen atom. These compounds are immensely structurally diverse and are primarily connected to chemical defense mechanisms developed by plants against herbivores, pathogens or competing plants. Therefore, many alkaloids show significant levels of toxicity (Michael, 2007). Many are also used for medical purposes. Some alkaloids such as vincristine and vinblastine are already being used as chemotherapeutic agents in a number of cancers such as Hodgkin's lymphoma, neuroblastoma and Wilms tumor (Moudi et al., 2013; Below and Das, 2020). Many other alkaloids have been studied in order to ascertain their effects either as direct anti-cancer agents or as adjuvants by increasing chemotherapeutic sensitivity (Mondal et al., 2019).

Neferine is an alkaloid found in the seeds of the sacred lotus (Nelumbo nucifera Gaertn.), which are used in TCM to obtain a herbal remedy known as Lotus Plumule or Plumula Nelumbinis. Liang et al. treated glioma cell lines with neferine and found 
increased apoptosis along with decreased cell proliferation and migration. Neferine down-regulated miR-10b which was found to inhibit PTEN/PI3K/AKT by targeting PTEN gene. Subsequently, PTEN expression-an important tumor-suppressive gene-was increased in U251 treated cells. p38-MAPK pathway was deactivated with lower p38 phosphorylation levels following neferine treatment via down-regulation of miR-10b (Liang et al., 2019). However, no further inquiries regarding the molecular target were formulated.

Liu Z. et al. (2019) also achieved anti-tumor effects with neferine on a breast cancer cell line through down-regulation of miR-374a. This miRNA was further shown to increase Fibroblast growth factor receptor 2 (FGFR-2) expression. Neferine inhibited the PI3K/AKT and MEK/ERK pathways through the modulation of miR-374a/FGFR-2 axis leading to reduced cell proliferation and migration and enhanced apoptosis. Neferine also inhibited the PI3K/AKT pathway in a gastrointestinal stromal tumor cell line by up-regulating miR449a levels (Xue et al., 2019).

Berbamine is an alkaloid found in the Amur barberry plant (Berberis amurensis Rupr.). A synthetic derivative (BBMD3) of berbamine was used by Yang F. et al. (2014) to treat glioblastoma cell lines. Apoptosis was increased by caspase-3 and JNK-c JUN/ AP-1 pathway activation as evidenced by increased cleavage of poly (ADP-ribose) polymerase and phosphorylation of c-Jun and c-Fos respectively. MiR-4284 was one of several upregulated miRNAs, and its inhibition resulted in diminished apoptotic effects of BBMD3. In a study on melanoma cells, BBMD3 inhibited the STAT3 pathway (Nam et al., 2012), but these results were not confirmed by Yang et al. in their studies.

Matrine, oxymatrine (matrine oxide) and sophocarpine are alkaloids found in plants of the genus Sophora of the legume family (Fabaceae). Matrine induced apoptosis and cell cycle arrest in a number of different cancer cell lines. In breast cancer, matrine acted through the miR-21/PTEN/Akt pathway by down-regulating miR-21 to induce apoptosis and cell cycle arrest in the G1/S phase (Li et al., 2012). In a study on colon cancer cells, matrine, by up-regulating miR-22 which was found to target ERBB3 and MECOM mRNA. This way, matrine induced apoptosis and G0/G1 cell cycle arrest as well as down-regulation of the $\mathrm{Wnt} / \beta$-catenin and MEK/ERK pathways (Liu J. et al., 2020). MiR-126 was also up-regulated in a NSCLC cell line treated with matrine and increased apoptosis and G0/G1 phase arrest were also observed (An et al., 2016). In melanoma cells, matrine also up-regulated PTEN and modulated the PTEN/Akt pathway to promote apoptosis, but by means of down-regulating miR-19b-3p which was also found to bind to PTEN as did miR-21 in breast cancer cells (Wei et al., 2018).

MiR-21 was also down-regulated by sophocarpine in a head and neck squamous cell carcinoma cell line by inhibition of Dicer processing and resulted in increased activity in the PTEN and p38/MAPK pathways. Beneficial effects were obtained both in vitro with increased apoptosis but also in vivo with growth inhibition in a mouse xenograft model (Li W. et al., 2017).
Anti-cancer effects were also described for oxymatrine. $\mathrm{Li}$ et al. (2015) found up-regulated levels of miR-29b with downstream inhibition of MMP-2 expression in ovarian cancer cells treated with oxymatrine. In another study on lung cancer cells, Zhou et al. (2019) also managed to lower proliferation both in vitro and in vivo by up-regulating miR520 which showed inhibitory effects on VEGF expression after oxymatrine treatment.

Solanine and solasodine are toxic alkaloids found in some very common representatives of the nightshade family (Solanaceae), including tomatoes, eggplants and the fruits of potato plants. Zhang F. et al. (2016) and Wu et al. (2018) both reported that solanine up-regulated miR-138 with anti-proliferative and chemosensitizing effects in lung adenocarcinoma cells and esophageal cancer respectively. On lung adenocarcinoma cells, solanine was cytotoxic by itself and also improved chemosensitivity to cisplatin. Focal adhesion kinase (FAK) levels, a protein involved in cellular adhesion that was investigated as a potential therapeutic target for lung (Kawashima and Kurokawa, 1983) and breast (Baraka and Serhal, 1989; Zhang S. et al., 2017) cancer (among others), were down-regulated. FAK was revealed to be a direct target of miR-138 and it was shown that upon antisense transfection, solanine manifested no anti-cancer effects.

Regarding esophageal cancer, solanine improved chemosensitivity to 5-FU and cisplatin in a miR-138 dependent manner. Survivin, a protein which inhibits apoptosis and is highly expressed in tumor tissue (Sah et al., 2006), was down-regulated by miR-138 which directly bound to its mRNA. MiR-138 antisense transfection lifted the effects of solanine on survivin expression. In a study on prostate cancer cells, solanine up-regulated GAS5, a lncRNA, which was revealed to target miR-18a directly and decrease its expression with increased radiosensitivity as a result. GAS5 was overexpressed without solanine and, indeed, the same proapoptotic effects were seen, however no target of miR-18a was mentioned (Yang et al., 2019a).

The related compound solasodine down-regulated miR-21 in a lung cancer cell line and besides inhibiting the PI3K/Akt pathway it was shown to increase that expression of RECK (reversion-inducing cystein-rich protein with kazal motifs). RECK is known target of miR-21 and acts as metastasis suppressor (Shen et al., 2017).

Capsaicin is an alkaloid that is found in Capsicum peppers, within the Solanaceae family. By binding to capsaicin receptors in our tongues, it triggers a sensation of heat or pungency, which accounts for its wide use as a spice in global cuisine. CML cells treated with capsaicin showed decreased proliferation, with capsaicin down-regulating miR-520a-5p and, by a miR-520a$5 \mathrm{p}$-dependent mechanism, also down-regulating the STAT3 pathway (Kaymaz et al., 2014). Acting as a reactive oxygen species (ROS), capsaicin damages DNA, which triggers cell apoptosis through the p53/miR-34 axis, as was show in a NSCLC cell line. It is worth mentioning that absence of p53 abolished the effects of capsaicin (Chakraborty et al., 2014). Interestingly, capsaicin also inhibited proliferation of prostate cancer cells, not through increasing apoptosis, rather through inducing cell cycle arrest in the G0/G1 phase. Capsaicin up- 
regulated miR-449a, which in turn dowregulated the androgen receptor (AR) (Zheng et al., 2015).

Ligustrazine is an alkaloid found in nattō, a traditional Japanese dish of fermented soybeans, in fermented cocoa beans and in Ligusticum wallichii Franch., a plant of the Apiaceae family used in TCM. A study (Xu D. et al., 2018) on medulloblastoma cell lines showed that ligustrazine promoted apoptosis and inhibited proliferation and invasion by inhibiting the mTOR and PI3K/Akt pathways. Ligustrazine also upregulated miR-211 and although miR-211 antisense transfection reduced ligustrazine's inhibitory effects on the above-mentioned pathways, no direct target of miR-211 was evidenced.

Sinomenine is an alkaloid found in the roots of Sinomenium acutum (Thunb.) Rehder and E.H.Wilson, a climbing plant from East Asia used in TCM. Sinomenine showed proapoptotic effects in prostate cancer cells by inhibition of the PI3K/Akt and JAK STAT pathways. MiR-23a was also up-regulated by sinomenine and antisense transfection reduced sinomenine effects on these two pathways, but no target of miR-23a was identified (Xu et al., 2019). In breast cancer cells, sinomenine suppressed invasion, proliferation and also induced apoptosis by down-regulating miR-324-5p (Song et al., 2015) and up-regulating miR-29 (Gao G. et al., 2019). Down-regulation of interleukin 4 (IL-4) resulted in decreased miR-324-5p expression and, in turn, CUEDC2, its reported target gene, was up-regulated. This resulted in increased NF-kB-IkB binding, with lowered NF-kB activity. MiR-29 up-regulation resulted in increased PDCD4 expression and downstream inhibition of the JNK and MERK/ ERK pathways.

Sanguinarine is a toxic alkaloid found in several plants of the poppy family (Papaveraceae). In gastric cancer cells, sanguinarine was found to down-regulate miR-96-5p and miR-29c-3p and subsequently increase MAP4K4, a target gene of both miRNAs, with downstream activation of MAPK/JNK pathway and decreased tumor proliferation (Dong et al., 2019). In HCC lines (Zhang B. et al., 2019), sanguinarine up-regulated miR16-2 in a p53-dependent manner with anti-proliferative effects. Moreover, mouse HCC xenografts showed reduced tumor growth in the same study. While no direct mRNA target of miR-16-2 was explored, Bcl-2 and Cyclin D1 levels, two accepted targets of miR16 (Cimmino et al., 2005; Liu et al., 2008), were found to be reduced.

Coptisine and dauricine are two alkaloids isolated from the Chinese goldthread (Coptis chinensis Franch.) and the Asian moonseed vine (Menispermum dauricum DC.), respectively. Both showed anti-tumor effects on hepatocellular carcinoma cells in vitro and in vivo. Coptisine was found to up-regulate miR-122 and lower proliferation and tumor size (Chai et al., 2018). Dauricine inhibited glycolysis via up-regulation of miR199 which directly targeted and inhibited hexokinase 2 (HK2) and pyruvate kinase muscle isozyme 2 (PKM2). Treatmend with dauricine also lead to decreased proliferation and increased chemosensitivity to sorafenib, cisplatin and isoliensinine ( $\mathrm{Li}$ W. et al., 2018).

Berberine is a further alkaloid found in C. chinensis rhizomes. This compound suppressed IL6 and STAT3 in a multiple myeloma cell line, a possible mechanism for the down-regulation of miR-21 was also observed. MiR-21 suppression was followed by PDCD4 overexpression with anti-cancer effects (Luo et al., 2014). It appears berberine also has chemosensitizing properties as shown by You et al. (2016) and Chen et al. (2015) who increased cisplatin sensitivity by upregulating miR-203 and inhibiting miR-93 in a gastric cancer cell line and ovarian cancer cell line, respectively. You et al. revealed Bcl-w as a target for miR-203 and Chen et al. showed that berberine elicited its effects through the miR-93-PTEN/ AKT pathway.

Lycorine is toxic alkaloid isolated from plants of the Amaryllidaceae family, which includes popular ornamental plants like snowdrops and daffodils. Lycorine was shown to decrease proliferation in a NSCLC cell population. It upregulated miR-186, which was found to directly inhibit the cyclin-dependent kinase 1 (CDK-1) expression with subsequent destabilization of the cellular cycle (Li L. et al., 2019).

\section{POLYSACCHARIDES}

Polysaccharides are a vast class of biogenic polymers formed by monosaccharide units connected by glycosidic bonds. These compounds consist of anywhere between 40 and 3,000 linked monosaccharides that are either connected to form linear structures or branch out into side chains (Zong et al., 2012). In plants, they are mainly involved in energy storage or they play a structural role. Many compounds have qualities that allow various medical applications. Some even have anti-cancer properties, with potential uses ranging from dietary supplements for disease prevention, to antioxidants, immunomodulators, apoptosis inducers and metastasis inhibitors (Yu et al., 2018). Polysaccharides are produced by a variety of organisms, from microorganisms (e.g., bacteria, fungi) to animals, plants and marine algae. In this section, we will only focus on the plant-derived ones, mentioning compounds which have a mechanism of action involving ncRNAs.

A homogenous polysaccharide extracted from the leaves of the tea shrub (Camellia sinensis (L.) Kuntze), referred to as green tea polysaccharide was shown to have anti-proliferative and antimigratory effects on prostatic cancer both in vitro and in vivo. Upon treatment with green tea polysaccharide, miR-93 levels were down-regulated and the $\mathrm{Bax} / \mathrm{Bcl} 2$ ratio and caspase- 3 expression were increased but no direct target of miR-93 nor any potential cellular pathways were explored (Yang et al., 2019c). However, in a follow-up study, the same author group revealed disabled homolog 2 (DAB2) as a potential target of miR-93. Upregulation of DAB2 would act in an inhibitory fashion on the Akt/ ERK1,2 pathways, accounting for the observed anti-proliferative and anti-metastatic effect (Yang et al., 2019d).

Besides the tea shrub, another source of polysaccharides with proven anti-cancer activity is the plant species Patrinia heterophylla Bunge (Lu et al., 2010), which is used in TCM in a form known as Patriniae Herba. The aqueous extract of Patrinae Herba which most probably contains polysaccharidic compounds, showed anti-proliferative, anti-metastatic properties 
in hepatocellular carcinoma cell lines, via up-regulating the $\ln$ CHTR2A-AS1 and subsequently influencing the concentration of several proteins-MMP2, P21, caspase 3, E-Cadherin (Guan et al., 2020).

Promising natural products also originate from plants of the genus Actinidia, whose most famous representative is the vine producing the kiwifruit. Experiments using Actinidia eriantha Benth. polysaccharide (AEP) on a murine leukemia virus-induced tumor, showed potential immunomodulatory properties of AEP on macrophages by influencing lncRNAs (D730047E02Rik, Gm14047, A_30_P01020139, A_30_P01026293 and A_30_P01032196), which could subsequently modulate the mRNA expression of different genes implicated in the immune response. In this study, a predicted target was the NF- $\kappa \mathrm{B}$ p65 protein, which could account for the macrophagic activation observed in the cell lines (Chen X. et al., 2019).

The only compound studied in pediatric cancers was the Angelica sinensis polysaccharide (AP). AP is a polysaccharide found in the root of Angelica sinensis (Oliv.) Diels, commonly known as dong quai or female ginseng. In a study on neuroblastoma cells, AP treatment resulted in increased apoptosis (as evidenced by higher expression of Bax, caspase-3 and -9 and lower expression of $\mathrm{Bcl}-2$ ) and reduced migration and proliferation (Yang J. et al., 2018). MiR-675 levels were downregulated and transfection with a miR-675 mimic reduced the effects of AP. Mechanistic studies were performed and miR-675 was shown to up-regulate the PI3K/AKT and JAK/STAT pathways, and AP down-regulated these pathways by downregulating miR-675. Another study treating neuroblastoma cells with AP revealed the same pro-apoptotic and antiproliferative effects already described and showed that the PI3K/AKT and ERK1/2 pathways were inhibited. MiR-205 was up-regulated and, after transfection with a miR-205 inhibitor, the effects of AP were reduced (Yang et al., 2019b). MiR-205 was shown to target the ZEB1 gene which is known to induce EMT in various cancers (Eger et al., 2005).

The Mongolian milkvetch (A. membranaceus) does not only yield the astragalosides discussed in the saponins section, but also a mixture of polysaccharides that were shown to have antiproliferative effects. Chu et al. treated osteosarcoma cell lines with Astragalus polysaccharide (APS), resulting in upregulation of miR-133a, which in turn led to decreased expression of several proteins of the JNK pathway, a member of the MAPK pathway, implicated in cell proliferation and apoptosis. In this study, the authors observed that APS also promoted cell cycle arrest in the $S$ phase and apoptosis, and the anti-migratory effect was reflected by lower measured levels of MMP-2 and -9 (Chu et al., 2018).

There is an additional plant extract worth mentioning that has been shown to contain compounds from various classes (phenols, flavonoids, triterpenes) along with polysaccharides. It is the Spica Prunellae extract (SPE), obtained from Prunella vulgaris L., a plant commonly known by the very fitting names of self-heal or heal-all. In a study on colon cancer cell lines, treatment with SPE showed anti-proliferative and apoptosis inducing properties via up-regulation of the miR-34a which, in turn, was shown to decrease the expression levels of Notch1,2 and Bcl-2 (Fang Y. et al., 2017). Moreover, in a different study using bioinformatic analysis, the same extract showed 5-FU chemo-sensitizing properties in colon cancer cell lines, supposedly via upregulation of miR-494, which could down-regulate TOP $2 \alpha$ expression, an enzyme involved in DNA transcription (Fang et al., 2019).

\section{ORGANOSULFUR COMPOUNDS}

Organosulfur compounds are a chemically heterogeneous group of organic molecules that contain sulfur. In human diets, two major sources of organosulfur compounds are represented by vegetables from Alliaceae (garlic, onions, leaks etc.) and Brassicaceae (cabbage, Brussels sprouts, kale, broccoli, cauliflower, watercress etc.) families. These organosulfur compounds, such as alliin (onions) or glucosinolates (Brassicaspecies), protect plants from pathogens and insects. A side aspect is that these compounds are key for the taste of the plant-based foods. Moreover, they have health-promoting effects as part of the human diet. In a 2016 review by Biersack (2016) the interplay between three major organosulfur compounds and miRNAs in adult anti-cancer therapy was precisely described. However, over the last four years, more insights were gained, with some few studies also focused on pediatric-age cancers.

Diallyl disulfide (DADS), a compound found in garlic and other plants in the genus Allium, showed anti-proliferative effects in gastric cancer cell lines and tumor bearing mice via up-regulation of miR-200b and miR-22 which directly target the Wntl pathway (Tang et al., 2013). Likewise, in a different study on gastric cell lines, DADS up-regulated miR-34a, which, in turn, led to down-regulation of $\mathrm{p}$-PI3K and $p$-Akt, resulting in apoptosis induction and invasiveness reduction (Wang $\mathrm{G}$. et al., 2016). In a different study employing breast cancer cell lines and tumor bearing mice, DADS also increased miR-34a expression and was shown to directly target $\mathrm{c}$-Src, affecting its downstream targets Ras/ERK. This led to reduced proliferation and invasiveness in vitro, as well as to reduced tumoral volume in mice models, compared to the control groups (Xiao et al., 2014).

A further agent with potent anti-cancer activity is sulforaphane (SFN), an organosulfur compound found in many vegetables of the Brassicaceae family. SFN showed varied anti-cancer properties, ranging from cancer cell stemness suppression, anti-proliferation and apoptosis induction to metastasis and EMT inhibition and can be used as a chemo-sensitizing co-agent in a wide range of cancers.

In a study on two colon cancer cell lines, SFN treatment has effectively decreased miR-21 and human telomerase reverse transcriptase (hTERT) mRNA levels, by means of epigenetic regulation showing anti-proliferative and apoptosis-inducing effects (Martin et al., 2018). In another recent study on colon cancer cells, the co-treatment of SFN and a miR-15b-5p inhibiting agent, showed very potent anti-apoptotic properties, compared to the two substances alone (Gasparello et al., 2020). In a study on two gastric cancer cell lines and a control cell line, SFN dose-dependently increased miR-9 and miR-326 expression in 
one cell line. These miRNAs targeted and reduced the expression of the caudal type homebox 1 and 2 (CDX1, CDX2) protein levels, which are known to act as modulators of intestinal stem cell differentiation. The observed phenotypic effect was apoptosis induction (Kiani et al., 2018).

In pancreatic cancer, one study done on different cell lines showed that SFN induced miR-135b-5p expression which, in turn, binds to the $3^{\prime} \mathrm{UTR}$ region of the Rat sarcoma (RAS) Protein Activator Like 2 (RASAL2) gene, leading to its up-regulation, having an anti-proliferative effect in vitro. These findings mirror the expression levels found in tumor tissues compared to healthy tissue (Yin et al., 2019a). In a different in vitro study on pancreatic cancer, SFN alone or in combination with other natural compounds (quercetin and green tea catechins), were shown to have anti-proliferative effects through up-regulation of the miRNA let-7 and subsequent down-regulation of its target K-Ras (Appari et al., 2014). In a different study miR-365a-3p was significantly underexpressed in pancreas cancer tissue compared to healthy pancreas tissues. The group showed the ability of SFN to induce miR-365a-3p expression and confirmed $\mathrm{c}-$ Rel as target, known to act on NF- $\kappa \mathrm{B}$ signaling. In this study, SFN treatment showed anti-metastatic and apoptosis-inducing properties in vitro, confirmed by decreased tumor size in xenograft models (Yin et al., 2019b).

Interestingly, the chemoresistance of pancreatic cancer might be partly owed to a decreased intercellular communication through gap junctions and reflected in low connexin 43 (Cx43) expression. In one study on pancreatic cancer cells, SFN treatment inhibited miR-30a-3p expression, which was shown to target $\mathrm{Cx} 43$ and increase its expression, which led to better gemcitabine chemosensitivity (Georgikou et al., 2020).

Lung cancer stem cells showed high expression rates of miR19a and mir-19b, which were significantly decreased by SFN treatment. These miRNAs were shown to target GSK3 $\beta$, which affected the downstream Wnt/ $\beta$-catenin pathway. This way, SFN showed stemness suppression, alteration of tumor sphere formation and resulted in apoptosis induction (Zhu et al., 2017). In a different study on NSCLC, SFN decreased the expression of a different miRNA, miR-616-5p which was then shown to also target GSK3 $\beta$ and influence the aforementioned pathway. In this study, treatment with SFN was effective in suppressing EMT and reducing metastatic potential (Wang D. X. et al., 2017). The SFN treatment in NSCLC cell lines was shown to also up-regulate miR-214 expression, which was shown to target the c-Myc proto-oncogene, leading to stemness inhibition, apoptosis induction and to better cisplatin chemosensitivity in vitro as well as in vivo (Li et al., 2017).

In an in vitro study on bladder cancer, SFN induced the expression of miR-200c which, in turn, targeted ZEB1, leading to increased E-cadherin expression, suggesting that SFN acts as a TME modulator in this type of cancer (Shan et al., 2013). In nasopharyngeal carcinoma, SFN increased miR-124-3p levels, which down-regulated STAT3, resulting in decreased proliferation and apoptosis inducement (Li X. et al., 2018). In a different study on gastric cancer cell lines, SFN also upregulated miR-124-3p. This miRNA in turn targeted IL-6R and STAT3 which resulted in better response to cisplatin treatment, especially by counteracting the stemness-inducing properties of the treatment with cisplatin alone (Wang $\mathrm{X}$. et al., 2016).

A study on AML showed that sulforaphane might reduce the pathologically up-regulated miR-155, and hereby induce differentiation and apoptosis, however, there is no mechanistic explanation of this effect (Koolivand et al., 2018). In GBM cell lines, SFN has been shown to repress the Wnt/ $\beta$-catenin/TCF4 pathway and indirectly decrease the miR-21 expression. This down-regulation then altered the BAX/BCL-2 ratio and increased caspase 4 and 7 levels, with pro-apoptotic consequences. This effect was especially useful in the Temozolomide treated cells, acting as chemosensitizer (Lan et al., 2015).

Effects related to lncRNAs were reported by a study which investigated a prostatic cancer cell line and compared it to a noncancerous control before and after SFN treatment using whole genome RNA sequencing. Significant differences in expression of about 100 lncRNAs involved in cancer metabolism, cell cycle regulation and signal transduction were noted. Moreover, the suppression of LINC01116 through SFN showed antiproliferative effects by modulating expression of several genes implicated in metabolism (GADPH), autophagy (MAP1LC3B2) and regulation of chromatin structure (H2AFY). The authors hypothesized that this LINC01116 could modulate target genes expression by forming ssRNA:dsDNA triplexes with them (Beaver et al., 2017).

Lastly, another organosulfur compound found in Brassicaceae, phenethyl isothiocyanate (PEITC) has been shown to increase the expression of miR-194 in prostate cancer cell lines. This miRNA, in turn, targets and decreases the expression of the bone morphogenic protein 1 (BMP-1), resulting in decreased levels of MMP2 and 9 which are associated with a lesser migratory potential (Zhang C. et al., 2016).

The presented findings regarding organosulfur compounds are summarized graphically in Figure 3.

Summing up, in this entire segment, we presented natural compounds from different chemical classes and reviewed their ncRNA-dependent anti-cancer effects. In order to visualize the most important information presented in the main body of this review, we created a table that lists most of the cancer types discussed herein, along with two or more examples of natural compounds studied for each cancer, the ncRNAs which are known to be involved in each particular case and, wherever available, with their downstream targets (Table 2). Additionally, Figure 4 summarizes our review in a graphical manner: phenolic acids and other monophenols, flavonoids and curcuminoids in Figure 4A; tannins, terpenoids, saponins, stilbenoids and carotenoids (except for ATRA, already presented in Figure 2) in Figure 4B; polyprenylated acylphloroglucinols, cannabinoids, alkaloids, polysaccharides and organosulfur compounds in Figure 4C.

\section{FUTURE PERSPECTIVES}

In this review, we summed up recent findings related to anticancer plant-derived natural compounds that have a ncRNA 


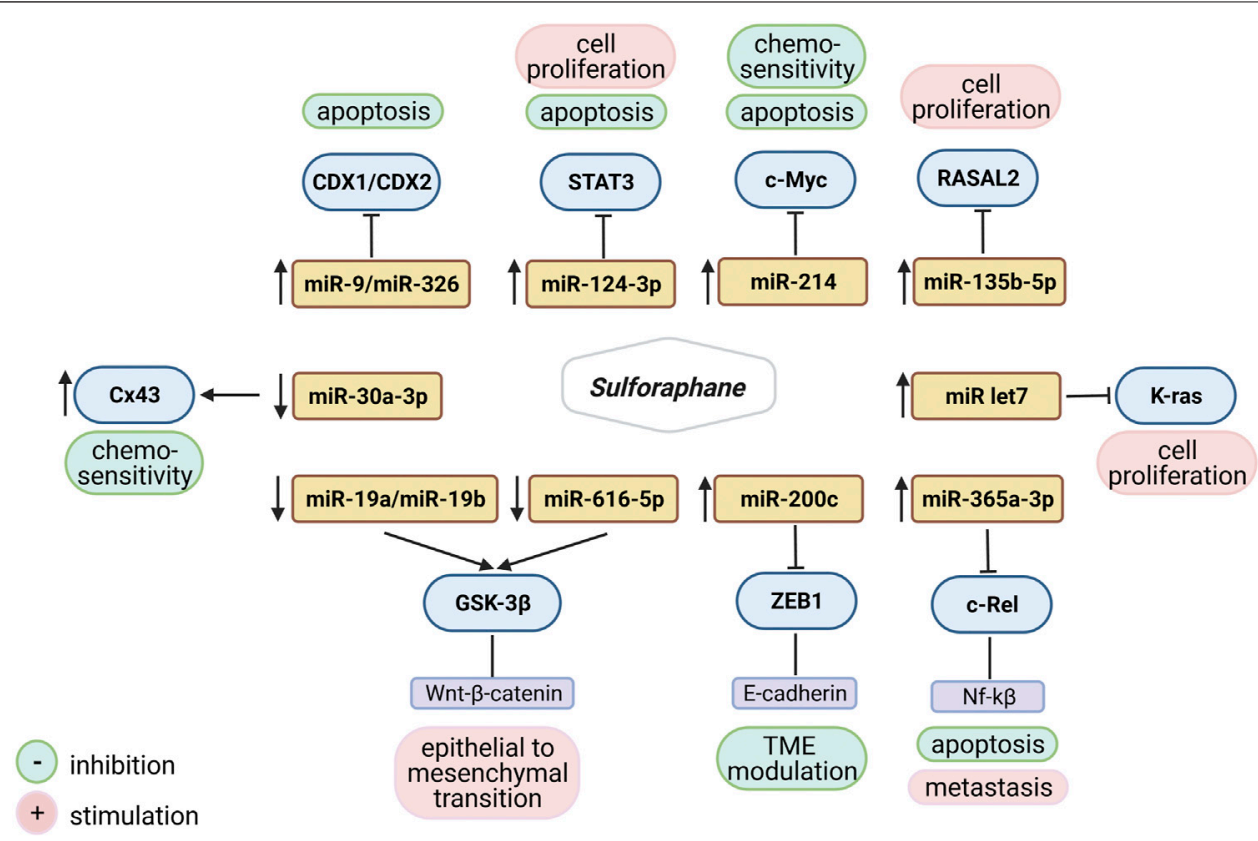

FIGURE 3 | The mechanism of action of sulforaphane by modulating expression of several miRNAs (yellow rectangles) which target specific molecules (blue ovals) and/or pathways (purple rectangles), inducing the observed phenotypical changes-inducing of apoptosis, inhibition of cell proliferation, inhibition of metastasis, inhibition of EMT, TME modulation and inducing of chemosensitivity.

(mostly miRNA)-related mechanism of action. In our search, several points raised our attention.

First, most studies were in vitro analyses, using cancer specific cell lines and researching the effects of treatment with the specific natural compound, compared to treatment with a negative control substance. Hence, only exceptionally the effect of a natural compound was compared to an already proven antitumorigenic substance. Expression levels of specific ncRNAs were then measured via microarray or PCR. Likewise, levels of potential mRNA targets and/or the corresponding proteins were subsequently analyzed. In some cases, direct targeting was confirmed via luciferase reporter assay. Rescue assays, to ensure that the noted effects were indeed induced by the studied substances via ncRNA and their downstream pathways were rarely performed. Few studies also confirmed the finding in vivo, using tumor-bearing mice models. Unfortunately, this thorough analysis was not conducted in all studies and we want to point out that in order to introduce these substances into clinical practice, comprehensive mechanistic studies are necessary.

Second, we observed that natural compounds can have heterogenous anti-cancer effects by restoring dysregulated ncRNA expression levels and, in turn, indirectly targeting numerous downstream molecules of ncRNAs. Natural compounds can act as anti-proliferative, apoptosis-inducing and anti-metastatic agents, but can also influence the TME, the energetic metabolism, angiogenesis and lastly, induce chemosensitivity (Figure 5). An important limitation of the studies we analyzed is the fact that only exceptionally the mechanism through which the natural compound regulates the ncRNA expression was researched. We can envision several possibilities: the natural compound directly/indirectly regulates the transcription of the ncRNA; the natural compound inhibits the biogenesis of ncRNAs, in a similar way to small-molecule inhibitors of miRNA (Vo et al., 2014); or the natural compound binds the mature form of ncRNA prolonging its half-life or accelerating its degradation. Apart from these putative mechanisms, many of the reviewed compounds are known to have effects on membrane fluidity and permeability (Tsuchiya, 2015). As already described for terpenoids, this could account for certain, presumably unspecific effects of phytochemicals on miRNA function by influencing membrane association of AGO proteins. Deciphering these aspects is of great importance in order to understand the mechanism of action of natural compounds on ncRNAs in cancer and could help in improving the efficacy of semi-synthetic natural compound analogs or derivatives.

Third, we only focused on pharmacological products that where directly derived from natural compounds, excluding those synthetically designed based on natural compounds. However, there are compounds derived from plants, which are further synthetically adjusted (for example ATRA), which have shown solid anti-oncogenic capacities and some of which are also clinically used. This observation clearly outlines that after the initial confirmation of the anti-cancer effect of natural compounds, subsequent synthetic modifications that improve the pharmacokinetics and pharmacodynamics of the compound are necessary in order to translate the findings into clinical practice. Of note, in order to purposefully make synthetic modifications that improve the pharmacodynamics of the natural 
TABLE 2 | Types of cancers covered in this review and some of the most representative examples of natural compounds/derivatives acting on ncRNAs, the type of material studied on (cell lines, i.e., in vitro or mouse models i.e., in vivo), the mechanistic pathway downstream of the ncRNA and the phenotypic effect achieved.

\begin{tabular}{|c|c|c|c|c|c|c|}
\hline Cancer & Natural compound & $\begin{array}{l}\text { In vitro }{ }^{1 /} \\
\text { In vivo }\end{array}$ & ncRNA & $\begin{array}{c}\text { Targets and/or } \\
\text { downstream effectors }\end{array}$ & $\begin{array}{l}\text { Phenotypic } \\
\text { effects }^{a}\end{array}$ & Reference \\
\hline \multirow{2}{*}{$\begin{array}{l}\text { Hepatocellular } \\
\text { cancer }\end{array}$} & Apigenin & 1 & miR-520b & ATG7 & CS & Gao et al. (2018) \\
\hline & Dauricine & 1, 2 & miR-199a & HK2, PKM2 & $A, C S, E$ & Li W. et al. (2018) \\
\hline \multirow[t]{2}{*}{ Gastric cancer } & Luteolin & 1 & miR-34a & $\mathrm{BCL}-2$ & A & Wu et al. (2015a) \\
\hline & Sulforaphane & 1 & miR-124-3p & IL-6r, STAT3 & CS & Wang X. et al. (2016) \\
\hline \multirow[t]{2}{*}{ Colorectal cancer } & Astragaloside IV & 1 & $\mathrm{miR}-29 \mathrm{c}$ & $\mathrm{B} 7-\mathrm{H} 3$ & $\mathrm{P}$ & Wang et al. (2018) \\
\hline & Astragaloside IV & 1 & miR-134 & CREB1 & EMT, CS & Ye et al. (2017) \\
\hline \multirow[t]{2}{*}{ Pancreatic cancer } & Luteolin & 1 & miR-301-3p & Caspase-8 & $\mathrm{P}$ & Moeng et al. (2020) \\
\hline & Sulforaphane & 1,2 & $m i R-135 b-5 p$ & RASAL2 & $\mathrm{P}$ & Yin et al. (2019a) \\
\hline \multirow{2}{*}{$\begin{array}{l}\text { Non small-cell lung } \\
\text { cancer }\end{array}$} & Garcinol & 1 & miR-200b let7 & E-cadherin, vimentin, ZEB1 & EMT, CS & Farhan et al. (2019) \\
\hline & ATRA & 1 & $m i R-512-5 p$ & p21 & $A, E$ & Chu et al. (2016) \\
\hline \multirow{2}{*}{$\begin{array}{l}\text { Oral squamous cell } \\
\text { cancer }\end{array}$} & Sophocarpine & 1,2 & $\operatorname{miR}-21$ & PTEN, p38/MAPK & $\mathrm{P}, \mathrm{A}, \mathrm{EMT}$ & Li W. et al. (2017) \\
\hline & Ginsenoside Rg3 & 1,2 & miR-221 & TIMP3, PI3K/AKT, MAPK/ERK & $\mathrm{P}, \mathrm{EMT}$ & Cheng and Xing (2019) \\
\hline \multirow{2}{*}{$\begin{array}{l}\text { Nasopharyngeal } \\
\text { cancer }\end{array}$} & EGCG & 1 & miR-296 & STAT3 & $\mathrm{M}$ & Lin et al. (2020) \\
\hline & Sulforaphane & 1 & miR-124-3p & STAT3 & $\mathrm{P}, \mathrm{A}, \mathrm{TME}$ & Li X. et al. (2018) \\
\hline \multirow[t]{2}{*}{ Prostatic cancer } & Sulforaphane & 1 & LINC01116 & GADPH, MAP1LCD3B H2AFY & E, GS, A & Beaver et al. (2017) \\
\hline & PEITC & 1 & miR-194 & BMP-1 MMP2, -9 & M & Zhang C. et al. (2016) \\
\hline \multirow[t]{2}{*}{ Breast cancer } & Betulinic acid & 1 & $\mathrm{miR}-27 \mathrm{a}$ & ZBTB10, Sp-1, -3, -4 & $P, A, A G$ & $\begin{array}{l}\text { Liu et al. (2012); } \\
\text { Mertens-Talcott et al. (2013) }\end{array}$ \\
\hline & Ailanthone & 1 & $\mathrm{miR}-148 \mathrm{a}$ & $\begin{array}{l}\text { CyclinD1, p53 and p21 Caspase-3, -9 } \\
\text { AMPK, Wnt/ } \beta \text {-catenin }\end{array}$ & $\mathrm{P}, \mathrm{M}$ & Gao W. et al. (2019) \\
\hline \multirow[t]{2}{*}{ Neuroblastoma } & $\begin{array}{l}\text { Angelica sinensis } \\
\text { polysaccharide }\end{array}$ & 1 & miR-675 & KIF1B $\beta$, CD44, IncRNA-H19 & $P, A, M$ & Yang J. et al. (2018) \\
\hline & EGC, EGCG & 1 & $\operatorname{miR}-7-1$ & & $A$ & Chakrabarti et al. (2013) \\
\hline CML & Capsaicin & 1 & $m i R-520 a-5 p$ & STAT3 & $\mathrm{P}, \mathrm{A}$ & Kaymaz et al. (2014) \\
\hline AML & Ginsenoside Rh2 & 1,2 & $\mathrm{miR}-21$ & BCL-2 & A & Wang and Wang (2015) \\
\hline Osteosarcoma & Resveratrol & 1 & $\operatorname{miR}-139-5 p$ & $\mathrm{NOTCH} 1$ & A & Xiao et al. (2020) \\
\hline \multirow[t]{2}{*}{ Nephroblastoma } & Triptolide & 1 & $\operatorname{miR}-193 b-3 p$ & KLF4, PI3K/AKT, ERK & $A, M$ & Hang et al. (2019) \\
\hline & Salidroside & 1 & $\mathrm{miR}-891 \mathrm{~b}$ & $\begin{array}{l}\text { Cyclin D1, MMP-2, vimentin, p53, p21, } \\
\text { caspase-3, -9 PI3KJAKT/mTOR }\end{array}$ & $P, A, M$ & Li H. et al. (2019) \\
\hline \multirow[t]{2}{*}{ Retinoblastoma } & Curcumin & 1 & miR-22 & Erbb3 & $P, M$ & Sreenivasan et al. (2012) \\
\hline & Shikonin & 1 & $\begin{array}{l}\text { miR-34a, } \\
\text { miR-202 }\end{array}$ & MYCN & $\mathrm{P}$ & Su et al. (2018) \\
\hline \multirow[t]{2}{*}{ Medulloblastoma } & Ligustrazine & 1 & miR-211 & PI3K/AKT and mTOR & $\mathrm{P}, \mathrm{M}$ & Xu D. et al., 2018 \\
\hline & Triptolide & 1 & $\mathrm{miR}-138$ & CDK6 & $\mathrm{P}, \mathrm{M}$ & Zhang H. et al., 2018 \\
\hline \multirow[t]{4}{*}{ Glioma/GBM } & Xanthohumol & 1 & $\mathrm{miR}-4725-3 p$ & STIM1 & $\mathrm{P}, \mathrm{EMT}$ & Ho et al. (2018) \\
\hline & Apigenin & 1 & $\mathrm{miR}-16$ & BCL-2 - NFkB/MMP9 & A & Chen X. J. et al. (2016) \\
\hline & Resveratrol & 1 & $\mathrm{miR}-21$ & |кB/p50-p65 & $\mathrm{P}$ & Li H. et al. (2013) \\
\hline & BBMD3 & 1 & $\mathrm{miR}-4284$ & JNK/AP-1 & A & Yang F. et al. (2014) \\
\hline
\end{tabular}

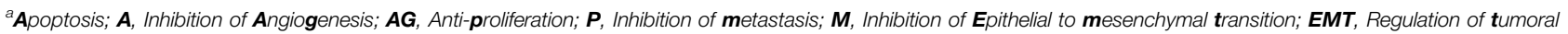
microenvironment; TME, Regulation of cellular energetics; E, Promotion of genomic stability; GS, Inducing chemo-sensitivity; CS.

compound, it is crucial to understand its biomolecular mechanism of action. Therefore, in-depth mechanistic studies are highly necessary.

Fourth, we noticed that some of the reported substances were used in phase I-III clinical trials, with sometimes inconclusive and sometimes favorable results. While there are several phase I trials that proved the therapeutic efficacy of natural compounds, only few phase II trials reported favorable outcomes. Many of the phase II clinical studies were terminated due to lack of safety, funding, or lack of efficacy. Nevertheless, there are also a few phase III clinical trials that are either completed or currently recruiting. Data regarding some very popular compounds that potentially also function via ncRNAs is already available. A phase II clinical study on curcumin showed beneficial effects on reducing radiation-induced dermatitis in breast cancer patients (Ryan et al., 2013). A phase III study on the same topic was completed by the same study group, but no results have been published (NCT01246973). In contrast, a phase II clinical study on resveratrol (SRT501) in combination with bortezomib on refractory multiple myeloma patients showed no efficacy and several concerning adverse side effects (nausea, vomiting, and renal failure), having an unacceptable safety profile (Popat et al., 2013). Two phase III clinical trials regarding treatment with curcumin in prostatic cancer are currently recruiting. One of them measures the progression of low-risk prostatic cancer (NCT03769766), while the other assesses recurrence post radical prostatectomy (NCT02064673). A phase II clinical trial on curcumin in advanced inoperable pancreatic cancer has been completed in 2020, results are still to be published (NCT00094445). Unfortunately, only scarcely do these studies report mechanistic analyses regarding the anti-tumorigenic effect of the natural compounds. We can only speculate that natural 


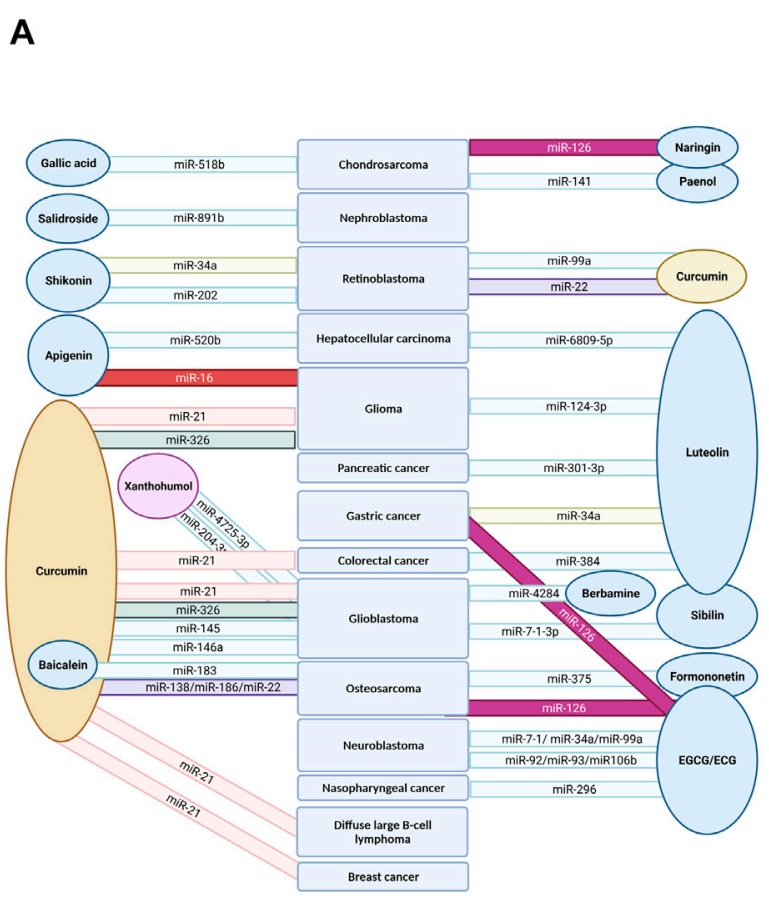

B

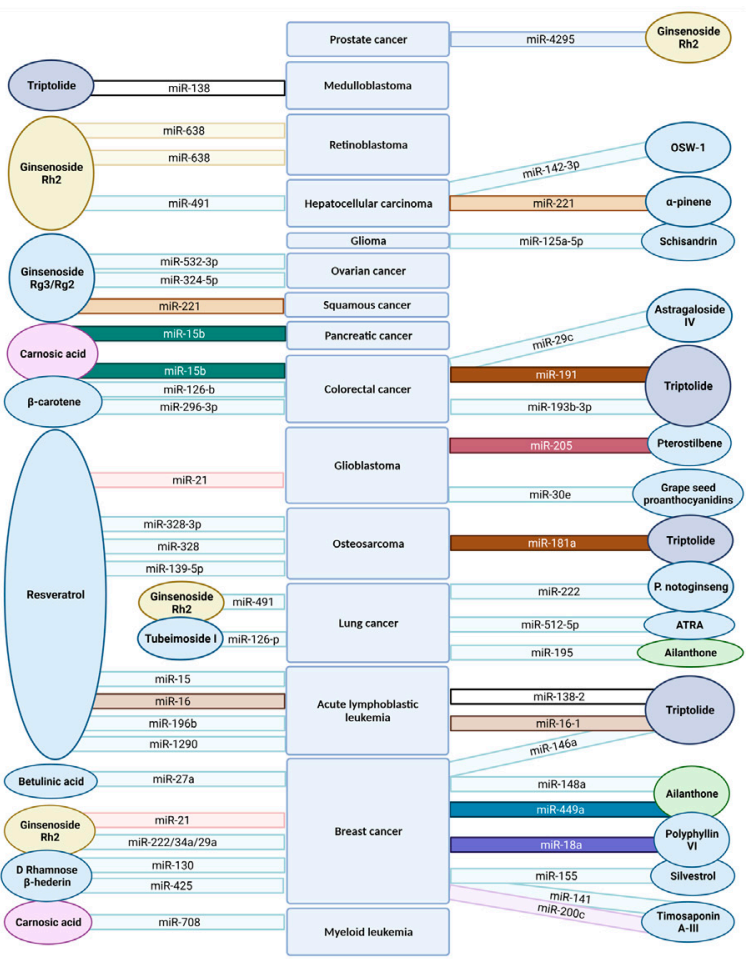

\section{C}

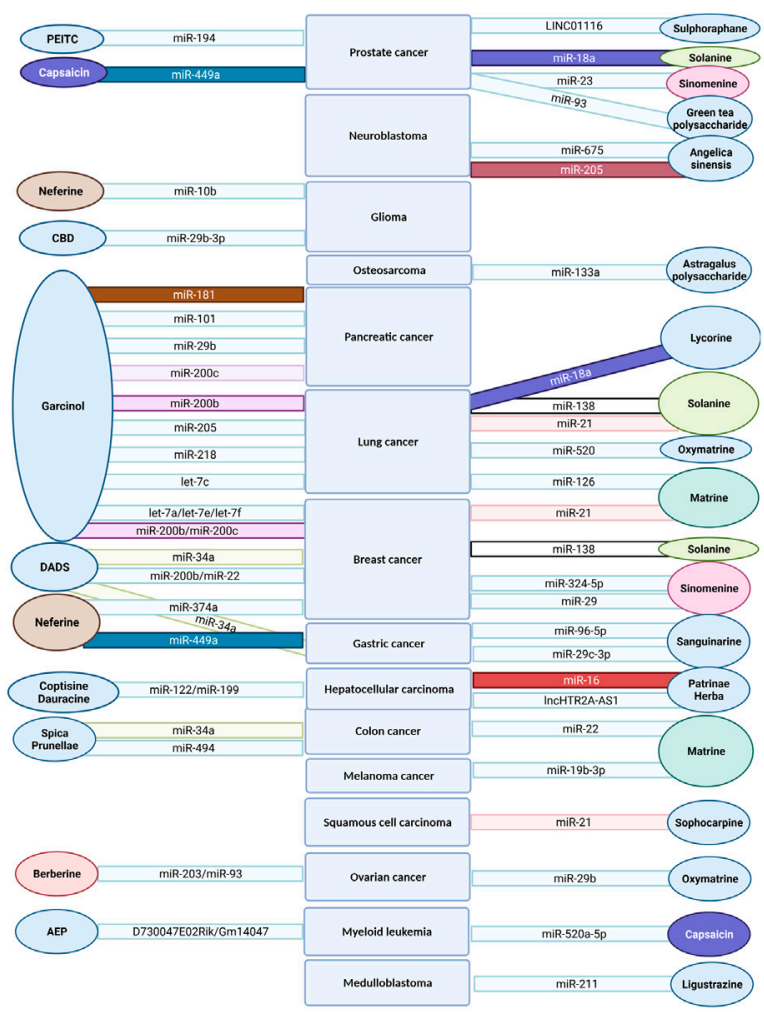

FIGURE 4 | Summarized in this figure are natural compounds (ovals), which influence specific cancers (big rectangles) through specific ncRNAs (long rectangles): (A) phenolic acids and other monophenols, flavonoids and curcuminoids; (B) tannins, terpenoids, saponins, stilbenoids, carotenoids (except for ATRA, already presented in Figure 2); and (C) polyprenylated acylphloroglucinols, cannabinoids, alkaloids, polysaccharides and organosulfur compounds. 


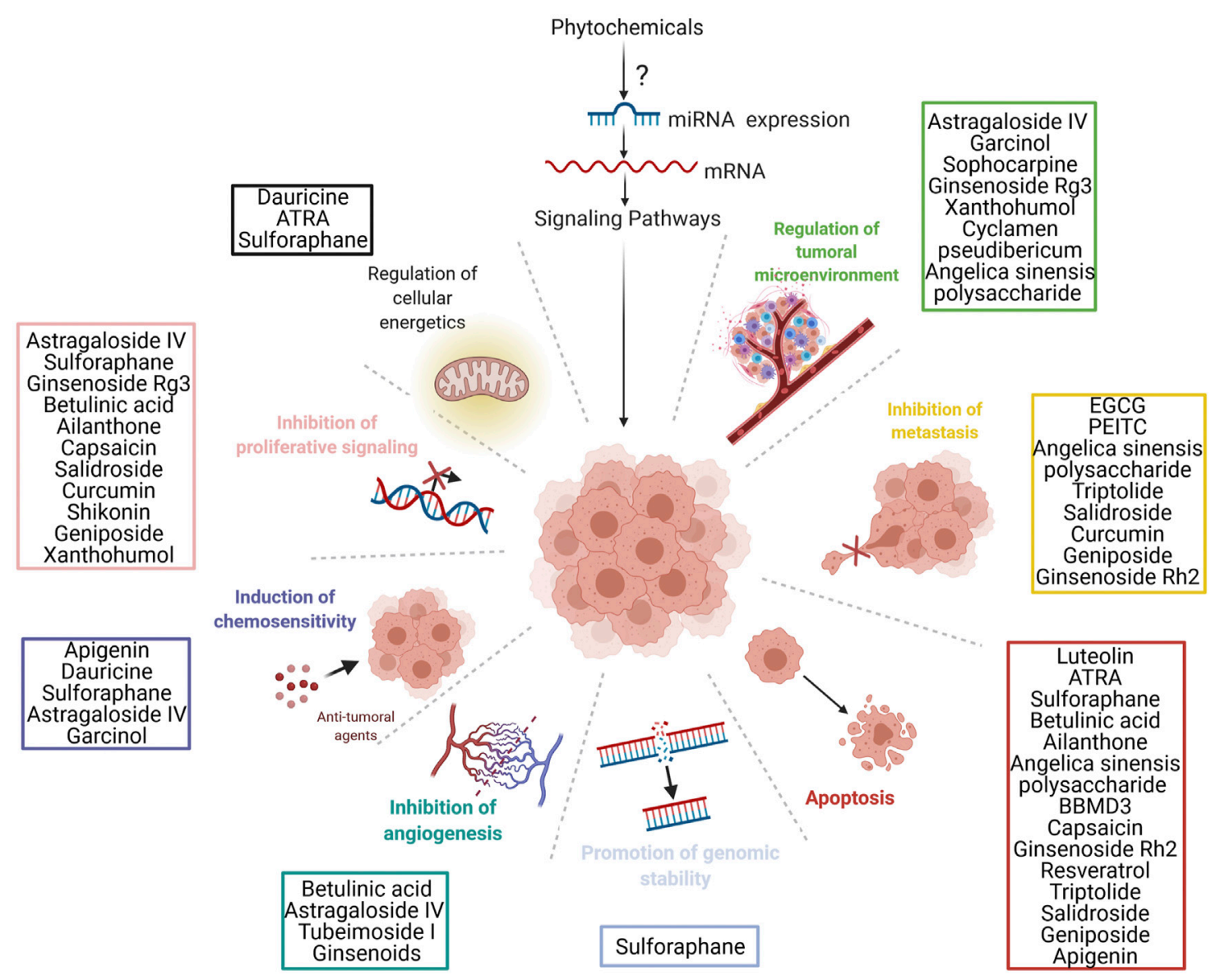

FIGURE 5 | The general mechanisms by which plant-derived natural compounds (phytochemicals) influence miRNA expression. In turn, these miRNAs can alter the expression of different proteins implicated in several cancer signaling pathways by binding to target mRNA. This alteration at the molecular level then leads to the phenotypical changes observed in vitro and in vivo. The major phenotypical changes are represented in the figure. Lastly, the major types of natural compounds and their pathways of action are summarized in the figure.

compounds function in clinical setting via ncRNAs. Meanwhile, methodological tools for investigating molecular interactions of natural compounds with ncRNAs are readily available. For instance, we highly recommend the analysis of ncRNA expression on tumor biopsies after neoadjuvant treatment/ palliative treatment with natural compounds and/or the analysis of the circulating ncRNAs from the different bodily fluids before and after treatment with natural compounds.

The future and the role of natural compounds in medicine and more precisely in oncology remains undetermined. In a recent critical publication Grollman and Marcus (2020) presented the historical development and the current status quo regarding the use of "botanical medicine". Mainly, the use of herbal remedies is rooted in ignorance or lack of knowledge regarding potential side effects or rejection of evidence-based medicine, especially in western societies. Most concerningly, the authors emphasized the complex financial interests regarding regulation of dietary supplements. Funding of the WHO through the Chinese government, lack of regulation regarding safety profiles, the planned introduction of TCM and alternative medicine in the 2021 ICD-11 are all current critical problems and raising awareness regarding this topic is essential. While the authors emphasized the hazardous effects in the unregulated use of "herbal remedies", the intrinsic effects and potentiality of these compounds is presented in many of the studies mentioned above. That being said, we do not advocate for the uncontrolled use of such compounds as "health boosters". We do support, however, an evidence-based approach in the use of such compounds mainly as adjuvant treatments in specific cancer types where the effect is proven, with acceptable safety profiles documented in phase III and IV clinical trials. Surely, many further mechanistic investigations regarding such compounds are needed until official clinical approval of one such substance will take place.

Taking a look toward the future, we would like to conclude with noting the auspicious coexistence of three aspects: the overwhelming diversity of chemical compounds produced throughout the plant kingdom, the accumulating evidence linking several such compounds to ncRNA-mediated anticancer effects and the availability of the proper methodological 
tools for investigating their exact mechanism of action. In this combination, we recognize promising circumstances for the development of reliable, evidence-based cancer treatments starting from natural compounds. There are good reasons to expect that scientific efforts invested in this topic, while still abundantly needed, will eventually prove to be worthwhile.

\section{AUTHOR CONTRIBUTIONS}

AAS, MD, GLC and MPD: conception and design. AAS, MD, GLC, TCP, C-MG, AN, and MPD: provision of study materials. AAS, MD, GLC, and TCP: collection and assembly of data. AAS, MD, GLC, TCP, C-MG, AN, and MPD: manuscript writing. MD: figure design. AN and MPD: supervision. All authors gave the final approval of the manuscript.

\section{REFERENCES}

Acunzo, M., and Croce, C. M. (2016). Downregulation of miR-15a and miR-16-1 at 13q14 in Chronic Lymphocytic Leukemia. Clin. Chem. 62 (4), 655-656. doi:10.1373/clinchem.2015.240036

Ahmad, A., Sarkar, S. H., Bitar, B., Ali, S., Aboukameel, A., Sethi, S., et al. (2012). Garcinol Regulates EMT and Wnt Signaling Pathways In Vitro and In Vivo, Leading to Anticancer Activity against Breast Cancer Cells. Mol. Cancer Ther. 11 (10), 2193-2201. doi:10.1158/1535-7163.MCT-12-0232-T

Akinwumi, B. C., Bordun, K. M., and Anderson, H. D. (2018). Biological Activities of Stilbenoids. Int. J. Mol. Sci. 19 (3), 792. doi:10.3390/ ijms 19030792

Alachkar, H., Santhanam, R., Harb, J. G., Lucas, D. M., Oaks, J. J., Hickey, C. J., et al. (2013). Silvestrol Exhibits Significant In Vivo and In Vitro Antileukemic Activities and Inhibits FLT3 and miR-155 Expressions in Acute Myeloid Leukemia. J. Hematol. Oncol. 6, 21. doi:10.1186/1756-8722-6-21

Amit, M., Takahashi, H., Dragomir, M. P., Lindemann, A., Gleber-Netto, F. O., Pickering, C. R., et al. (2020). Loss of P53 Drives Neuron Reprogramming in Head and Neck Cancer. Nature 578 (7795), 449-454. doi:10.1038/s41586-0201996-3

An, Q., Han, C., Zhou, Y., Li, F., Li, D., Zhang, X., et al. (2016). Matrine Induces Cell Cycle Arrest and Apoptosis with Recovery of the Expression of miR-126 in the A549 Non-small Cell Lung Cancer Cell Line. Mol. Med. Rep. 14 (5), 4042-4048. doi:10.3892/mmr.2016.5753

Appari, M., Babu, K. R., Kaczorowski, A., Gross, W., and Herr, I. (2014). Sulforaphane, Quercetin and Catechins Complement Each Other in Elimination of Advanced Pancreatic Cancer by miR-Let-7 Induction and K-Ras Inhibition. Int. J. Oncol. 45 (4), 1391-1400. doi:10.3892/ ijo.2014.2539

Asangani, I. A., Rasheed, S. A., Nikolova, D. A., Leupold, J. H., Colburn, N. H., Post, S., et al. (2008). MicroRNA-21 (miR-21) post-transcriptionally Downregulates Tumor Suppressor Pdcd4 and Stimulates Invasion, Intravasation and Metastasis in Colorectal Cancer. Oncogene 27 (15), 2128-2136. doi:10.1038/ sj.onc. 1210856

Baer, C., Oakes, C. C., Ruppert, A. S., Claus, R., Kim-Wanner, S. Z., Mertens, D., et al. (2015). Epigenetic Silencing of miR-708 Enhances NF-Kb Signaling in Chronic Lymphocytic Leukemia. Int. J. Cancer 137 (6), 1352-1361. doi:10.1002/ ijc.29491

Bao, J., and Dai, S. M. (2011). A Chinese Herb Tripterygium Wilfordii Hook F in the Treatment of Rheumatoid Arthritis: Mechanism, Efficacy, and Safety. Rheumatol. Int. 31 (9), 1123-1129. doi:10.1007/s00296-011-1841-y

Baraka, A., and Serhal, A. (1989). Lateral Decubitus Improves Oxygenation during Conventional Ventilation in Unilateral Lung Injury. Middle East. J. Anaesthesiol 10 (3), 329-332.

Beaver, L. M., Kuintzle, R., Buchanan, A., Wiley, M. W., Glasser, S. T., Wong, C. P., et al. (2017). Long Noncoding RNAs and Sulforaphane: a Target for

\section{FUNDING}

This work was supported by Compagnia di San Paolo and the Oncobiome European H2020 research project (Grant number 825410) (to AN).

\section{ACKNOWLEDGMENTS}

We thank Prof. Pascual Ángel Gargiulo from the National University of Cuyo, Argentina for proofreading the manuscript and providing suggestions for improvement. Moreover, we would like to thank our colleague Ing. Vlad Buzică from Technische Universität Berlin, Germany for the helpful remarks provided during the preparation of the manuscript. The authors used BioRender software to create the figures.

Chemoprevention and Suppression of Prostate Cancer. J. Nutr. Biochem. 42, 72-83. doi:10.1016/j.jnutbio.2017.01.001

Below, J., and Das, J. M (2020). Vincristine. Treasure Island (FL): StatPearls.

Bergman, M. E., Davis, B., and Phillips, M. A. (2019). Medically Useful Plant Terpenoids: Biosynthesis, Occurrence, and Mechanism of Action. Molecules 24 (21), 3961. doi:10.3390/molecules24213961

Bhattacharya, A., Sood, P., and Citovsky, V. (2010). The Roles of Plant Phenolics in Defence and Communication during Agrobacterium and Rhizobium Infection. Mol. Plant Pathol. 11 (5), 705-719. doi:10.1111/j.1364-3703.2010.00625.x

Biersack, B. (2016). Non-coding RNA/microRNA-modulatory Dietary Factors and Natural Products for Improved Cancer Therapy and Prevention: Alkaloids, Organosulfur Compounds, Aliphatic Carboxylic Acids and Water-Soluble Vitamins. Noncoding RNA Res. 1 (1), 51-63. doi:10.1016/j.ncrna.2016.09.001

Brasó-Maristany, F., Filosto, S., Catchpole, S., Marlow, R., Quist, J., FranceschDomenech, E., et al. (2016). PIM1 Kinase Regulates Cell Death, Tumor Growth and Chemotherapy Response in Triple-Negative Breast Cancer. Nat. Med. 22 (11), 1303-1313. doi:10.1038/nm.4198

Bräuer-Hartmann, D., Hartmann, J. U., Wurm, A. A., Gerloff, D., Katzerke, C. Verga Falzacappa, M. V., et al. (2015). PML/RARa-Regulated miR-181a/b Cluster Targets the Tumor Suppressor RASSF1A in Acute Promyelocytic Leukemia. Cancer Res. 75 (16), 3411-3424. doi:10.1158/0008-5472.CAN-143521

Brodersen, P., Sakvarelidze-Achard, L., Schaller, H., Khafif, M., Schott, G., Bendahmane, A., et al. (2012). Isoprenoid Biosynthesis Is Required for miRNA Function and Affects Membrane Association of ARGONAUTE 1 in Arabidopsis. Proc. Natl. Acad. Sci. U S A. 109 (5), 1778-1783. doi:10.1073/ pnas.1112500109

Budisan, L., Gulei, D., Zanoaga, O. M., Irimie, A. I., Sergiu, C., Braicu, C., et al. (2017). Dietary Intervention by Phytochemicals and Their Role in Modulating Coding and Non-coding Genes in Cancer. Int. J. Mol. Sci. 18 (6), 1178. doi:10.3390/ijms18061178

Calin, G. A., Dumitru, C. D., Shimizu, M., Bichi, R., Zupo, S., Noch, E., et al. (2002). Frequent Deletions and Down-Regulation of Micro- RNA Genes miR15 and miR16 at 13q14 in Chronic Lymphocytic Leukemia. Proc. Natl. Acad. Sci. US A. 99 (24), 15524-15529. doi:10.1073/pnas.242606799

Cao, L. L., Xie, J. W., Lin, Y., Zheng, C. H., Li, P., Wang, J. B., et al. (2014). miR-183 Inhibits Invasion of Gastric Cancer by Targeting Ezrin. Int. J. Clin. Exp. Pathol. 7 (9), 5582-5594.

Cao, S., Cui, Y., Xiao, H., Mai, M., Wang, C., Xie, S., et al. (2016). Upregulation of Flotillin-1 Promotes Invasion and Metastasis by Activating TGF- $\beta$ Signaling in Nasopharyngeal Carcinoma. Oncotarget 7 (4), 4252-4264. doi:10.18632/ oncotarget.6483

Carter, L. G., D’Orazio, J. A., and Pearson, K. J. (2014). Resveratrol and Cancer: Focus on In Vivo Evidence. Endocr. Relat. Cancer 21 (3), R209-R225. doi:10.1530/ERC-13-0171

Cech, T. R., and Steitz, J. A. (2014). The Noncoding RNA Revolution-Trashing Old Rules to Forge New Ones. Cell 157 (1), 77-94. doi:10.1016/j.cell.2014.03.008 
Chai, F. N., Ma, W. Y., Zhang, J., Xu, H. S., Li, Y. F., Zhou, Q. D., et al. (2018). Coptisine from Rhizoma Coptidis Exerts an Anti-cancer Effect on Hepatocellular Carcinoma by Up-Regulating miR-122. Biomed. Pharmacother. 103, 1002-1011. doi:10.1016/j.biopha.2018.04.052

Chakrabarti, M., Ai, W., Banik, N. L., and Ray, S. K. (2013). Overexpression of miR7-1 Increases Efficacy of green tea Polyphenols for Induction of Apoptosis in Human Malignant Neuroblastoma SH-Sy5y and SK-N-DZ Cells. Neurochem. Res. 38 (2), 420-432. doi:10.1007/s11064-012-0936-5

Chakrabarti, M., Khandkar, M., Banik, N. L., and Ray, S. K. (2012). Alterations in Expression of Specific microRNAs by Combination of 4-HPR and EGCG Inhibited Growth of Human Malignant Neuroblastoma Cells. Brain Res. 1454, 1-13. doi:10.1016/j.brainres.2012.03.017

Chakrabarti, M., Klionsky, D. J., and Ray, S. K. (2016). miR-30e Blocks Autophagy and Acts Synergistically with Proanthocyanidin for Inhibition of AVEN and BIRC6 to Increase Apoptosis in Glioblastoma Stem Cells and Glioblastoma SNB19 Cells. PLoS One 11 (7), e0158537. doi:10.1371/journal.pone.0158537

Chakrabarti, M., and Ray, S. K. (2016). Anti-tumor Activities of Luteolin and Silibinin in Glioblastoma Cells: Overexpression of miR-7-1-3p Augmented Luteolin and Silibinin to Inhibit Autophagy and Induce Apoptosis in Glioblastoma In Vivo. Apoptosis 21 (3), 312-328. doi:10.1007/s10495-015-1198-x

Chakraborty, S., Khare, S., Dorairaj, S. K., Prabhakaran, V. C., Prakash, D. R., and Kumar, A. (2007). Identification of Genes Associated with Tumorigenesis of Retinoblastoma by Microarray Analysis. Genomics 90 (3), 344-353. doi:10.1016/j.ygeno.2007.05.002

Chakraborty, S., Mazumdar, M., Mukherjee, S., Bhattacharjee, P., Adhikary, A., Manna, A., et al. (2014). Restoration of p53/miR-34a Regulatory axis Decreases Survival Advantage and Ensures Bax-dependent Apoptosis of Non-small Cell Lung Carcinoma Cells. FEBS Lett. 588 (4), 549-559. doi:10.1016/j.febslet.2013.11.040

Chen, J., Zhao, X., Ye, Y., Wang, Y., and Tian, J. (2013). Estrogen Receptor BetaMediated Proliferative Inhibition and Apoptosis in Human Breast Cancer by Calycosin and Formononetin. Cell Physiol. Biochem. 32 (6), 1790-1797. doi:10.1159/000356612

Chen, P. H., Chang, C. K., Shih, C. M., Cheng, C. H., Lin, C. W., Lee, C. C., et al. (2016). The miR-204-3p-Targeted IGFBP2 Pathway Is Involved in Xanthohumol-Induced Glioma Cell Apoptotic Death. Neuropharmacology 110 (Pt A), 362-375. doi:10.1016/j.neuropharm.2016.07.038

Chen, Q., Qin, R., Fang, Y., and Li, H. (2015). Berberine Sensitizes Human Ovarian Cancer Cells to Cisplatin through miR-93/PTEN/Akt Signaling Pathway. Cel. Physiol. Biochem. 36 (3), 956-965. doi:10.1159/000430270

Chen, W., and Qiu, Y. (2015). Ginsenoside Rh2 Targets EGFR by Up-Regulation of miR-491 to Enhance Anti-tumor Activity in Hepatitis B Virus-Related Hepatocellular Carcinoma. Cell Biochem. Biophys. 72 (2), 325-331. doi:10.1007/s12013-014-0456-9

Chen, W. X., Cheng, L., Pan, M., Qian, Q., Zhu, Y. L., Xu, L. Y., et al. (2018a). D Rhamnose $\beta$-Hederin against Human Breast Cancer by Reducing TumorDerived Exosomes. Oncol. Lett. 16 (4), 5172-5178. doi:10.3892/ol.2018.9254

Chen, W. X., Xu, L. Y., Qian, Q., He, X., Peng, W. T., Fan, W. Q., et al. (2018b). d Rhamnose $\beta$-hederin Reverses Chemoresistance of Breast Cancer Cells by Regulating Exosome-Mediated Resistance Transmission. Biosci. Rep. 38 (5), BSR20180110. doi:10.1042/BSR20180110

Chen, X., Du, J., Zhu, Y., Zhang, C., and Sun, H. (2019). Comprehensive Analysis of lncRNA and mRNA Expression Profiles in Macrophages Activated by Actinidia Eriantha Polysaccharide. Int. J. Biol. Macromol. 136, 980-993. doi:10.1016/ j.ijbiomac.2019.06.091

Chen, X. J., Wu, M. Y., Li, D. H., and You, J. (2016). Apigenin Inhibits Glioma Cell Growth through Promoting microRNA-16 and Suppression of BCL-2 and Nuclear Factor-Kb/mmp-9. Mol. Med. Rep. 14 (3), 2352-2358. doi:10.3892/ mmr.2016.5460

Chen, Y., Zhang, Y., Song, W., Zhang, Y., Dong, X., and Tan, M. (2019). Ginsenoside Rh2 Inhibits Migration of Lung Cancer Cells under Hypoxia via Mir-491. Anticancer Agents Med. Chem. 19 (13), 1633-1641. doi:10.2174/ 1871520619666190704165205

Cheng, J., Wu, Q., Lv, R., Huang, L., Xu, B., Wang, X., et al. (2018). MicroRNA449a Inhibition Protects H9C2 Cells against Hypoxia/Reoxygenation-Induced Injury by Targeting the Notch-1 Signaling Pathway. Cel. Physiol. Biochem. 46 (6), 2587-2600. doi:10.1159/000489686

Cheng, Z., and Xing, D. (2019). Ginsenoside Rg3 Inhibits Growth and EpithelialMesenchymal Transition of Human Oral Squamous Carcinoma Cells by
Down-Regulating miR-221. Eur. J. Pharmacol. 853, 353-363. doi:10.1016/ j.ejphar.2019.03.040

Chivukula, R. R., and Mendell, J. T. (2009). Abate and Switch: miR-145 in Stem Cell Differentiation. Cell 137 (4), 606-608. doi:10.1016/j.cell.2009.04.059

Chu, K., Gao, G., Yang, X., Ren, S., Li, Y., Wu, H., et al. (2016). MiR-512-5p Induces Apoptosis and Inhibits Glycolysis by Targeting P21 in Non-small Cell Lung Cancer Cells. Int. J. Oncol. 48 (2), 577-586. doi:10.3892/ ijo.2015.3279

Chu, Y., Fang, Y., Chi, J., Li, J., Zhang, D., Zou, Y., et al. (2018). Astragalus Polysaccharides Decrease Proliferation, Migration, and Invasion but Increase Apoptosis of Human Osteosarcoma Cells by Up-Regulation of microRNA-133a. Braz. J. Med. Biol. Res. 51 (12), e7665. doi:10.1590/ 1414-431X20187665

Cimmino, A., Calin, G. A., Fabbri, M., Iorio, M. V., Ferracin, M., Shimizu, M., et al. (2005). miR-15 and miR-16 Induce Apoptosis by Targeting BCL2. Proc. Natl. Acad. Sci. U S A. 102 (39), 13944-13949. doi:10.1073/pnas.0506654102

Ciochina, R., and Grossman, R. B. (2006). Polycyclic Polyprenylated Acylphloroglucinols. Chem. Rev. 106 (9), 3963-3986. doi:10.1021/ cr0500582

Cirino, G., Cicala, C., Sorrentino, L., and Regoli, D. (1991). Effect of Bradykinin Antagonists, NG-Monomethyl-L-Arginine and L-NG-nitro Arginine on Phospholipase A2 Induced Oedema in Rat Paw. Gen. Pharmacol. 22 (5), 801-804. doi:10.1016/0306-3623(91)90209-o

Cragg, G. M., and Pezzuto, J. M. (2016). Natural Products as a Vital Source for the Discovery of Cancer Chemotherapeutic and Chemopreventive Agents. Med. Princ. Pract. 25 (Suppl. 2), 41-59. doi:10.1159/000443404

Crone, S. G., Jacobsen, A., Federspiel, B., Bardram, L., Krogh, A., Lund, A. H., et al. (2012). microRNA-146a Inhibits G Protein-Coupled Receptor-Mediated Activation of NF-Kb by Targeting CARD10 and COPS8 in Gastric Cancer. Mol. Cancer 11, 71. doi:10.1186/1476-4598-11-71

Da Fonseca, B. H. R., Domingues, D. S., and Paschoal, A. R. (2019). mirtronDB: a Mirtron Knowledge Base. Bioinformatics 35 (19), 3873-3874. doi:10.1093/ bioinformatics/btz153

De Marchis, M. L., Ballarino, M., Salvatori, B., Puzzolo, M. C., Bozzoni, I., and Fatica, A. (2009). A New Molecular Network Comprising PU.1, Interferon Regulatory Factor Proteins and miR-342 Stimulates ATRA-Mediated Granulocytic Differentiation of Acute Promyelocytic Leukemia Cells. Leukemia 23 (5), 856-862. doi:10.1038/leu.2008.372

de Souza Rocha Simonini, P., Breiling, A., Gupta, N., Malekpour, M., Youns, M., Omranipour, R., et al. (2010). Epigenetically Deregulated microRNA-375 Is Involved in a Positive Feedback Loop with Estrogen Receptor Alpha in Breast Cancer Cells. Cancer Res. 70 (22), 9175-9184. doi:10.1158/0008-5472.CAN-101318

DellaGreca, M., Zuppolini, S., and Zarrelli, A. (2013). Isolation of Lignans as Seed Germination and Plant Growth Inhibitors from Mediterranean Plants and Chemical Synthesis of Some Analogues. Phytochem. Rev. 12, 717-731. doi:10.1007/s11101-013-9311-7

DeVita, V. T., Jr., and Chu, E. (2008). A History of Cancer Chemotherapy. Cancer Res. 68 (21), 8643-8653. doi:10.1158/0008-5472.CAN-07-6611

Diaz-Moralli, S., Tarrado-Castellarnau, M., Miranda, A., and Cascante, M. (2013). Targeting Cell Cycle Regulation in Cancer Therapy. Pharmacol. Ther. 138 (2), 255-271. doi:10.1016/j.pharmthera.2013.01.011

Dong, X. Z., Song, Y., Lu, Y. P., Hu, Y., Liu, P., and Zhang, L. (2019). Sanguinarine Inhibits the Proliferation of BGC-823 Gastric Cancer Cells via Regulating miR96-5p/miR-29c-3p and the MAPK/JNK Signaling Pathway. J. Nat. Med. 73 (4), 777-788. doi:10.1007/s11418-019-01330-7

Dragomir, M., Mafra, A. C. P., Dias, S. M. G., Vasilescu, C., and Calin, G. A. (2018). Using microRNA Networks to Understand Cancer. Int. J. Mol. Sci. 19 (7), 1871. doi:10.3390/ijms19071871

Dragomir, M. P., Knutsen, E., and Calin, G. A. (2018). SnapShot: Unconventional miRNA Functions. Cell 174 (4), 1038.e1. doi:10.1016/j.cell.2018.07.040

Dragomir, M. P., Kopetz, S., Ajani, J. A., and Calin, G. A. (2020a). Non-coding RNAs in GI Cancers: from Cancer Hallmarks to Clinical Utility. Gut 69 (4), 748-763. doi:10.1136/gutjnl-2019-318279

Dragomir, M. P., Manyam, G. C., Ott, L. F., Berland, L., Knutsen, E., Ivan, C., et al. (2020b). FuncPEP: A Database of Functional Peptides Encoded by Non-coding RNAs. Noncoding RNA 6 (4), 41. doi:10.3390/ ncrna6040041 
Du, W., Liu, X., Chen, L., Dou, Z., Lei, X., Chang, L., et al. (2015). Targeting the SMO Oncogene by miR-326 Inhibits Glioma Biological Behaviors and Stemness. Neuro. Oncol. 17 (2), 243-253. doi:10.1093/neuonc/nou217

Du, W. Z., Feng, Y., Wang, X. F., Piao, X. Y., Cui, Y. Q., Chen, L. C., et al. (2013). Curcumin Suppresses Malignant Glioma Cells Growth and Induces Apoptosis by Inhibition of SHH/GLI1 Signaling Pathway In Vitro and Vivo. CNS Neurosci. Ther. 19 (12), 926-936. doi:10.1111/cns.12163

Dvorakova, M., and Landa, P. (2017). Anti-inflammatory Activity of Natural Stilbenoids: A Review. Pharmacol. Res. 124, 126-145. doi:10.1016/ j.phrs.2017.08.002

Eger, A., Aigner, K., Sonderegger, S., Dampier, B., Oehler, S., Schreiber, M., et al. (2005). DeltaEF1 Is a Transcriptional Repressor of E-Cadherin and Regulates Epithelial Plasticity in Breast Cancer Cells. Oncogene 24 (14), 2375-2385. doi:10.1038/sj.onc.1208429

El-Seedi, H. R., Taher, E. A., Sheikh, B. Y., Anjum, S., Saeed, A., AlAjmi, M. F., et al. (2018). "Chapter 8 - Hydroxycinnamic Acids: Natural Sources, Biosynthesis, Possible Biological Activities, and Roles in Islamic Medicine," in Studies in Natural Products Chemistry. Editor R Atta ur (Amsterdam, The Netherlands: Elsevier), 55, 269-292. doi:10.1016/b978-0-444-64068-0.00008-5

Erdman, J. W., Jr., Balentine, D., Arab, L., Beecher, G., Dwyer, J. T., Folts, J., et al. (2007). Flavonoids and Heart Health: Proceedings of the ILSI North America Flavonoids Workshop, May 31-June 1, 2005, Washington, DC. J. Nutr. 137 (3 Suppl. 1), 718S-737S. doi:10.1093/jn/137.3.718S

Esmatabadi, M. J. D., Farhangi, B., Montazeri, M., Monfared, H., Sistani, R. N., and Sadeghizadeh, M. (2017). Up-regulation of miR-21 Decreases Chemotherapeutic Effect of Dendrosomal Curcumin in Breast Cancer Cells. Iran J. Basic Med. Sci. 20 (4), 350-359. doi:10.22038/IJBMS.2017.8574

Fabbri, M., Paone, A., Calore, F., Galli, R., Gaudio, E., Santhanam, R., et al. (2012). MicroRNAs Bind to Toll-like Receptors to Induce Prometastatic Inflammatory Response. Proc. Natl. Acad. Sci. U S A. 109 (31), E2110-E2116. doi:10.1073/ pnas.1209414109

Fang, J., Morsalin, S., Rao, V., and Reddy, E. S. (2017). Decoding of Non-coding DNA and Non-coding RNA: Pri-Micro RNA-Encoded Novel Peptides Regulate Migration of Cancer Cells. J. Pharmaceut. Sci. Pharmacol. 3, 23-27. doi:10.1166/jpsp.2017.1070

Fang, Y., Yang, C., Zhang, L., Wei, L., Lin, J., Zhao, J., et al. (2019). Spica Prunellae Extract Enhances Fluorouracil Sensitivity of 5-Fluorouracil-Resistant Human Colon Carcinoma HCT-8/5-FU Cells via TOP2 $\alpha$ and miR-494. Biomed. Res. Int. 2019, 5953619. doi:10.1155/2019/5953619

Fang, Y., Zhang, L., Feng, J., Lin, W., Cai, Q., and Peng, J. (2017). Spica Prunellae Extract Suppresses the Growth of Human colon Carcinoma Cells by Targeting Multiple Oncogenes via Activating miR-34a. Oncol. Rep. 38 (3), 1895-1901. doi:10.3892/or.2017.5792

Farhan, M., Malik, A., Ullah, M. F., Afaq, S., Faisal, M., Farooqi, A. A., et al. (2019). Garcinol Sensitizes NSCLC Cells to Standard Therapies by Regulating EMTModulating miRNAs. Int. J. Mol. Sci. 20 (4), 800. doi:10.3390/ijms20040800

Franco-Zorrilla, J. M., Valli, A., Todesco, M., Mateos, I., Puga, M. I., RubioSomoza, I., et al. (2007). Target Mimicry Provides a New Mechanism for Regulation of microRNA Activity. Nat. Genet. 39 (8), 1033-1037. doi:10.1038/ ng2079

Gao, A. M., Zhang, X. Y., Hu, J. N., and Ke, Z. P. (2018). Apigenin Sensitizes Hepatocellular Carcinoma Cells to Doxorubic through Regulating miR520b/ATG7 axis. Chem. Biol. Interact 280, 45-50. doi:10.1016/ j.cbi.2017.11.020

Gao, G., Liang, X., and Ma, W. (2019). Sinomenine Restrains Breast Cancer Cells Proliferation, Migration and Invasion via Modulation of miR-29/PDCD-4 axis. Artif. Cell Nanomed. Biotechnol. 47 (1), 3839-3846. doi:10.1080/ 21691401.2019.1666861

Gao, Q., and Zheng, J. (2018). Ginsenoside Rh2 Inhibits Prostate Cancer Cell Growth through Suppression of microRNA-4295 that Activates CDKN1A. Cell Prolif. 51 (3), e12438. doi:10.1111/cpr.12438

Gao, W., Ge, S., and Sun, J. (2019). Ailanthone Exerts Anticancer Effect by UpRegulating miR-148a Expression in MDA-MB-231 Breast Cancer Cells and Inhibiting Proliferation, Migration and Invasion. Biomed. Pharmacother. 109, 1062-1069. doi:10.1016/j.biopha.2018.10.114

Gasparello, J., Gambari, L., Papi, C., Rozzi, A., Manicardi, A., Corradini, R., et al. (2020). High Levels of Apoptosis Are Induced in the Human Colon Cancer HT29 Cell Line by Co-administration of Sulforaphane and a Peptide Nucleic Acid
Targeting miR-15b-5p. Nucleic Acid Ther. 30 (3), 164-174. doi:10.1089/ nat.2019.0825

Geilfus, C. M. (2019). Controlled Environment Horticulture. 1 ed. Cham, Switzerland: Springer International Publishing.

Georgikou, C., Yin, L., Gladkich, J., Xiao, X., Sticht, C., Torre, C., et al. (2020). Inhibition of miR30a-3p by Sulforaphane Enhances gap junction Intercellular Communication in Pancreatic Cancer. Cancer Lett. 469, 238-245. doi:10.1016/ j.canlet.2019.10.042

Gergely, J. E., Dorsey, A. E., Dimri, G. P., and Dimri, M. (2018). Timosaponin A-III Inhibits Oncogenic Phenotype via Regulation of PcG Protein BMI1 in Breast Cancer Cells. Mol. Carcinog. 57 (7), 831-841. doi:10.1002/mc.22804

Giménez Martínez, R., De La Serrana, H. L. G., Mir, M. V., Alarcón, M. N., Herrera, M. O., Vique, C. C., et al. (2001). Study of Vanillin, Syringaldehyde and Gallic Acid Content in Oak Wood and Wine Spirit Mixtures: Influence of Heat Treatment and Chip Size. J. Wine Res. 12 (3), 175-182. doi:10.1080/ 09571260120106811

González-Vallinas, M., Molina, S., Vicente, G., Zarza, V., Martín-Hernández, R., García-Risco, M. R., et al. (2014). Expression of microRNA-15b and the Glycosyltransferase GCNT3 Correlates with Antitumor Efficacy of Rosemary Diterpenes in colon and Pancreatic Cancer. PLoS One 9 (6), e98556. doi:10.1371/journal.pone.0098556

Grollman, A. P., and Marcus, D. M. (2020). Is There a Role for Botanical Medicines in the Twenty-First century?: Promotion of Untested Traditional Therapies by the World Health Organization and China Endangers Global Public Health. EMBO Rep. 21 (11), e51376. doi:10.15252/embr.202051376

Guan, Z., Chen, J., and Li, X. (2020). Patrinia Herba Aqueous Extract on the Proliferation, Apoptosis, Invasion and Migration of Hepatocellular Carcinoma Cells. Cel. Mol. Biol. (Noisy-le-grand) 66 (3), 119-124. doi:10.14715/cmb/ 2020.66.3.18

Gullett, N. P., Ruhul Amin, A. R., Bayraktar, S., Pezzuto, J. M., Shin, D. M., Khuri, F. R., et al. (2010). Cancer Prevention with Natural Compounds. Semin. Oncol. 37 (3), 258-281. doi:10.1053/j.seminoncol.2010.06.014

Gupta, S., Hussain, T., and Mukhtar, H. (2003). Molecular Pathway for (-)-Epigallocatechin-3-Gallate-Induced Cell Cycle Arrest and Apoptosis of Human Prostate Carcinoma Cells. Arch. Biochem. Biophys. 410 (1), 177-185. doi:10.1016/s0003-9861(02)00668-9

Hang, S., Wang, X., and Li, H. (2019). Triptolide Inhibits Viability and Migration while Promotes Apoptosis in Nephroblastoma Cells by Regulation of miR-193b-3p. Exp. Mol. Pathol. 108, 80-88. doi:10.1016/ j.yexmp.2019.04.006

Harakeh, S., Abu-El-Ardat, K., Diab-Assaf, M., Niedzwiecki, A., El-Sabban, M., and Rath, M. (2008). Epigallocatechin-3-gallate Induces Apoptosis and Cell Cycle Arrest in HTLV-1-Positive and -negative Leukemia Cells. Med. Oncol. 25 (1), 30-39. doi:10.1007/s12032-007-0036-6

Ho, K. H., Chang, C. K., Chen, P. H., Wang, Y. J., Chang, W. C., and Chen, K. C. (2018). miR-4725-3p Targeting Stromal Interacting Molecule 1 Signaling Is Involved in Xanthohumol Inhibition of Glioma Cell Invasion. J. Neurochem. 146 (3), 269-288. doi:10.1111/jnc.14459

Horng, C. T., Shieh, P. C., Tan, T. W., Yang, W. H., and Tang, C. H. (2014). Paeonol Suppresses Chondrosarcoma Metastasis through Up-Regulation of miR-141 by Modulating PKC $\delta$ and C-Src Signaling Pathway. Int. J. Mol. Sci. 15 (7), 11760-11772. doi:10.3390/ijms150711760

Hou, S., Cheng, Z., Wang, W., Wang, X., and Wu, Y. (2019). Ailanthone Exerts an Antitumor Function on the Development of Human Lung Cancer by Upregulating microRNA-195. J. Cell Biochem. 120 (6), 10444-10451. doi: $10.1002 / j \mathrm{jcb} .28329$

Hu, W., and Xiao, Z. (2015). Formononetin Induces Apoptosis of Human Osteosarcoma Cell Line U2OS by Regulating the Expression of Bcl-2, Bax and MiR-375 In Vitro and In Vivo. Cell Physiol. Biochem. 37 (3), 933-939. doi:10.1159/000430220

Huang, C. C., Lin, C. M., Huang, Y. J., Wei, L., Ting, L. L., Kuo, C. C., et al. (2017). Garcinol Downregulates Notch1 Signaling via Modulating miR-200c and Suppresses Oncogenic Properties of PANC-1 Cancer Stem-like Cells. Biotechnol. Appl. Biochem. 64 (2), 165-173. doi:10.1002/bab.1446

Huang, W., Wang, W. T., Fang, K., Chen, Z. H., Sun, Y. M., Han, C., et al. (2018). MIR-708 Promotes Phagocytosis to Eradicate T-ALL Cells by Targeting CD47. Mol. Cancer 17 (1), 12. doi:10.1186/s12943-018-0768-2

Huynh, T. T., Lin, C. M., Lee, W. H., Wu, A. T., Lin, Y. K., Lin, Y. F., et al. (2015). Pterostilbene Suppressed Irradiation-Resistant Glioma Stem Cells by 
Modulating GRP78/miR-205 axis. J. Nutr. Biochem. 26 (5), 466-475. doi:10.1016/j.jnutbio.2014.11.015

Izzotti, A., Cartiglia, C., Steele, V. E., and De Flora, S. (2012). MicroRNAs as Targets for Dietary and Pharmacological Inhibitors of Mutagenesis and Carcinogenesis. Mutat. Res. 751 (2), 287-303. doi:10.1016/j.mrrev.2012.05.004

Javanmardi, S., Aghamaali, M. R., Abolmaali, S. S., Mohammadi, S., and Tamaddon, A. M. (2017). miR-21, an Oncogenic Target miRNA for Cancer Therapy: Molecular Mechanisms and Recent Advancements in Chemo and Radio-Resistance. Curr. Gene Ther. 16 (6), 375-389. doi:10.2174/ 1566523217666170102105119

Jee, Y. H., Sadowski, S. M., Celi, F. S., Xi, L., Raffeld, M., Sacks, D. B., et al. (2016). Increased Pleiotrophin Concentrations in Papillary Thyroid Cancer. PLoS One 11 (2), e0149383. doi:10.1371/journal.pone.0149383

Jiang, C., Fang, X., Zhang, H., Wang, X., Li, M., Jiang, W., et al. (2017). Triptolide Inhibits the Growth of Osteosarcoma by Regulating microRNA-181a via Targeting PTEN Gene In Vivo and Vitro. Tumour Biol. 39 (4), 1010428317697556. doi:10.1177/1010428317697556

Jiang, L., Tao, C., He, A., and He, X. (2014). Overexpression of miR-126 Sensitizes Osteosarcoma Cells to Apoptosis Induced by Epigallocatechin-3-Gallate. World J. Surg. Oncol. 12, 383. doi:10.1186/1477-7819-12-383

Jiang, Y., Zhang, Q., Bao, J., Du, C., Wang, J., Tong, Q., et al. (2017). Schisandrin B Inhibits the Proliferation and Invasion of Glioma Cells by Regulating the HOTAIR-micoRNA-125a-mTOR Pathway. Neuroreport 28 (2), 93-100. doi:10.1097/WNR.0000000000000717

Jiang, Y., Zhang, Q., Bao, J., Du, C., Wang, J., Tong, Q., et al. (2015). Schisandrin B Suppresses Glioma Cell Metastasis Mediated by Inhibition of mTOR/MMP-9 Signal Pathway. Biomed. Pharmacother. 74, 77-82. doi:10.1016/ j.biopha.2015.07.006

Jiang, Z., Cushing, L., Ai, X., and Lü, J. (2014). miR-326 Is Downstream of Sonic Hedgehog Signaling and Regulates the Expression of Gli2 and Smoothened. Am. J. Respir. Cel. Mol. Biol. 51 (2), 273-283. doi:10.1165/rcmb.2013-0127OC

Jin, J. C., Jin, X. L., Zhang, X., Piao, Y. S., and Liu, S. P. (2013). Effect of OSW-1 on microRNA Expression Profiles of Hepatoma Cells and Functions of Novel microRNAs. Mol. Med. Rep. 7 (6), 1831-1837. doi:10.3892/mmr.2013.1428

Juknat, A., Gao, F., Coppola, G., Vogel, Z., and Kozela, E. (2019). miRNA Expression Profiles and Molecular Networks in Resting and LPS-Activated BV-2 Microglia-Effect of Cannabinoids. PLoS One 14 (2), e0212039. doi:10.1371/journal.pone.0212039

Karagur, E. R., Ozay, C., Mammadov, R., and Akca, H. (2018). Anti-invasive Effect of Cyclamen Pseudibericum Extract on A549 Non-small Cell Lung Carcinoma Cells via Inhibition of ZEB1 Mediated by miR-200c. J. Nat. Med. 72 (3), 686-693. doi:10.1007/s11418-018-1204-z

Karpinski, T. M., and Adamczak, A. (2018). Anticancer Activity of Bacterial Proteins and Peptides. Pharmaceutics 10 (2), 54 . doi:10.3390/ pharmaceutics10020054

Kaurinovic, B., and Vastag, G. (2019). Flavonoids and Phenolic Acids as Potential Natural Antioxidants. Editors E. Shalaby and G. M. Azzam London: IntechOpen.

Kawashima, H., and Kurokawa, K. (1983). Unique Hormonal Regulation of Vitamin D Metabolism in the Mammalian Kidney. Miner Electrolyte Metab. 9 (4-6), 227-235.

Kaymaz, B. T., Cetintaş, V. B., Aktan, C., and Kosova, B. (2014). MicroRNA-520a$5 p$ Displays a Therapeutic Effect upon Chronic Myelogenous Leukemia Cells by Targeting STAT3 and Enhances the Anticarcinogenic Role of Capsaicin. Tumour Biol. 35 (9), 8733-8742. doi:10.1007/s13277-014-2138-z

Khanbabaee, K., and van Ree, T. (2001). Tannins: Classification and Definition. Nat. Prod. Rep. 18 (6), 641-649. doi:10.1039/b101061l

Kiani, S., Akhavan-Niaki, H., Fattahi, S., Kavoosian, S., Babaian Jelodar, N., Bagheri, N., et al. (2018). Purified Sulforaphane from Broccoli (Brassica oleracea Var. Italica) Leads to Alterations of CDX1 and CDX2 Expression and Changes in miR-9 and miR-326 Levels in Human Gastric Cancer Cells. Gene 678, 115-123. doi:10.1016/j.gene.2018.08.026

Kim, D., Kim, Y., and Kim, Y. (2019). Effects of $\beta$-carotene on Expression of Selected MicroRNAs, Histone Acetylation, and DNA Methylation in Colon Cancer Stem Cells. J. Cancer Prev. 24 (4), 224-232. doi:10.15430/ JCP.2019.24.4.224

Kim, M. K., Choi, G. J., and Lee, H. S. (2003). Fungicidal Property of Curcuma Longa L. Rhizome-Derived Curcumin against Phytopathogenic Fungi in a
Greenhouse. J. Agric. Food Chem. 51 (6), 1578-1581. doi:10.1021/ jf0210369

Koolivand, M., Ansari, M., Piroozian, F., Moein, S., and MalekZadeh, K. (2018). Alleviating the Progression of Acute Myeloid Leukemia (AML) by Sulforaphane through Controlling miR-155 Levels. Mol. Biol. Rep. 45 (6), 2491-2499. doi:10.1007/s11033-018-4416-0

Kosuru, R., Rai, U., Prakash, S., Singh, A., and Singh, S. (2016). Promising Therapeutic Potential of Pterostilbene and its Mechanistic Insight Based on Preclinical Evidence. Eur. J. Pharmacol. 789, 229-243. doi:10.1016/ j.ejphar.2016.07.046

Kumar, N., and Goel, N. (2019). Phenolic Acids: Natural Versatile Molecules with Promising Therapeutic Applications. Biotechnol. Rep. (Amst) 24, e00370. doi:10.1016/j.btre.2019.e00370

Lan, F., Pan, Q., Yu, H., and Yue, X. (2015). Sulforaphane Enhances Temozolomide-Induced Apoptosis Because of Down-Regulation of miR-21 via Wnt/ $\beta$-Catenin Signaling in Glioblastoma. J. Neurochem. 134 (5), 811-818. doi:10.1111/jnc.13174

Lauressergues, D., Couzigou, J. M., Clemente, H. S., Martinez, Y., Dunand, C., Bécard, G., et al. (2015). Primary Transcripts of microRNAs Encode Regulatory Peptides. Nature 520 (7545), 90-93. doi:10.1038/nature14346

Lavon, I., Fuchs, D., Zrihan, D., Efroni, G., Zelikovitch, B., Fellig, Y., et al. (2007). Novel Mechanism Whereby Nuclear Factor kappaB Mediates DNA Damage Repair through Regulation of $\mathrm{O}(6)$-methylguanine-DNAmethyltransferase. Cancer Res. 67 (18), 8952-8959. doi:10.1158/00085472.CAN-06-3820

Lee, R. C., Feinbaum, R. L., and Ambros, V. (1993). The C. elegans Heterochronic Gene Lin-4 Encodes Small RNAs with Antisense Complementarity to Lin-14. Cell 75 (5), 843-854. doi:10.1016/0092-8674(93)90529-y

Li, H., Huang, D., and Hang, S. (2019). Salidroside Inhibits the Growth, Migration and Invasion of Wilms' Tumor Cells through Down-Regulation of miR-891b. Life Sci. 222, 60-68. doi:10.1016/j.lfs.2019.02.052

Li, H., Jia, Z., Li, A., Jenkins, G., Yang, X., Hu, J., et al. (2013). Resveratrol Repressed Viability of U251 Cells by miR-21 Inhibiting of NF-Kb Pathway. Mol. Cel. Biochem. 382 (1-2), 137-143. doi:10.1007/s11010-013-1728-1

Li, J., Jiang, K., and Zhao, F. (2015). Oxymatrine Suppresses Proliferation and Facilitates Apoptosis of Human Ovarian Cancer Cells through Upregulating microRNA-29b and D-ownregulating M-atrix M-etalloproteinase2 E-xpression. Mol. Med. Rep. 12 (4), 5369-5374. doi:10.3892/mmr.2015.3977

Li, J., Lei, L., Ye, F., Zhou, Y., Chang, H., and Zhao, G. (2019). Nutritive Implications of Dietary microRNAs: Facts, Controversies, and Perspectives. Food Funct. 10 (6), 3044-3056. doi:10.1039/c9fo00216b

Li, L., Zhang, Z., Yang, Q., and Ning, M. (2019). Lycorine Inhibited the Cell Growth of Non-small Cell Lung Cancer by Modulating the miR-186/CDK1 axis. Life Sci. 231, 116528. doi:10.1016/j.lfs.2019.06.003

Li, L. Q., Li, X. L., Wang, L., Du, W. J., Guo, R., Liang, H. H., et al. (2012). Matrine Inhibits Breast Cancer Growth via miR-21/PTEN/Akt Pathway in MCF-7 Cells. Cel. Physiol. Biochem. 30 (3), 631-641. doi:10.1159/000341444

Li, M., Zhang, D., Cheng, J., Liang, J., and Yu, F. (2019). Ginsenoside Rh2 Inhibits Proliferation but Promotes Apoptosis and Autophagy by Down-Regulating microRNA-638 in Human Retinoblastoma Cells. Exp. Mol. Pathol. 108, 17-23. doi:10.1016/j.yexmp.2019.03.004

Li, Q. Q., Xie, Y. K., Wu, Y., Li, L. L., Liu, Y., Miao, X. B., et al. (2017). Sulforaphane Inhibits Cancer Stem-like Cell Properties and Cisplatin Resistance through miR-214-Mediated Downregulation of C-MYC in Non-small Cell Lung Cancer. Oncotarget 8 (7), 12067-12080. doi:10.18632/oncotarget.14512

Li, W., Qiu, Y., Hao, J., Zhao, C., Deng, X., and Shu, G. (2018). Dauricine Upregulates the Chemosensitivity of Hepatocellular Carcinoma Cells: Role of Repressing Glycolysis via miR-199a:HK2/PKM2 Modulation. Food Chem. Toxicol. 121, 156-165. doi:10.1016/j.fct.2018.08.030

Li, X., Li, D., Zhuang, Y., Shi, Q., Wei, W., Zhang, H., et al. (2013). [The Expression and Regulatory Mechanism of microRNA-708 in Pediatric Common B-Cell Acute Lymphoblastic Leukemia]. Zhonghua Xue Ye Xue Za Zhi 34 (2), 138-143.

Li, X., Zhao, Z., Li, M., Liu, M., Bahena, A., Zhang, Y., et al. (2018). Sulforaphane Promotes Apoptosis, and Inhibits Proliferation and Self-Renewal of Nasopharyngeal Cancer Cells by Targeting STAT Signal through miRNA124-3p. Biomed. Pharmacother. 103, 473-481. doi:10.1016/ j.biopha.2018.03.121 
Li, Y., Sun, W., Han, N., Zou, Y., and Yin, D. (2018). Curcumin Inhibits Proliferation, Migration, Invasion and Promotes Apoptosis of Retinoblastoma Cell Lines through Modulation of miR-99a and JAK/STAT Pathway. BMC Cancer 18 (1), 1230. doi:10.1186/s12885-018-5130-y

Liang, H. X., Sun, L. B., and Liu, N. J. (2019). Neferine Inhibits Proliferation, Migration and Invasion of U251 Glioma Cells by Down-Regulation of miR-10b. Biomed. Pharmacother. 109, 1032-1040. doi:10.1016/j.biopha.2018.10.122

Liang, W., Li, X., Li, Y., Li, C., Gao, B., Gan, H., et al. (2014). Gallic Acid Induces Apoptosis and Inhibits Cell Migration by Upregulating miR-518b in SW1353 Human Chondrosarcoma Cells. Int. J. Oncol. 44 (1), 91-98. doi:10.3892/ ijo.2013.2155

Lima, L., de Melo, T. C. T., Marques, D., de Araújo, J. N. G., Leite, I. S. F., Alves, C. X., et al. (2019). Modulation of All-Trans Retinoic Acid-Induced MiRNA Expression in Neoplastic Cell Lines: a Systematic Review. BMC Cancer 19 (1), 866. doi:10.1186/s12885-019-6081-7

Lin, C., Wu, Z., Lin, X., Yu, C., Shi, T., Zeng, Y., et al. (2011). Knockdown of FLOT1 Impairs Cell Proliferation and Tumorigenicity in Breast Cancer through Upregulation of FOXO3a. Clin. Cancer Res. 17 (10), 3089-3099. doi:10.1158/1078-0432.CCR-10-3068

Lin, C. H., Wang, H. H., Chen, T. H., Chiang, M. C., Hung, P. H., and Chen, Y. J. (2020). Involvement of MicroRNA-296 in the Inhibitory Effect of Epigallocatechin Gallate against the Migratory Properties of AnoikisResistant Nasopharyngeal Carcinoma Cells. Cancers (Basel) 12 (4), 973. doi:10.3390/cancers 12040973

Lin, K. Y., Zhang, X. J., Feng, D. D., Zhang, H., Zeng, C. W., Han, B. W., et al. (2011). miR-125b, a Target of CDX2, Regulates Cell Differentiation through Repression of the Core Binding Factor in Hematopoietic Malignancies. J. Biol. Chem. 286 (44), 38253-38263. doi:10.1074/jbc.M111.269670

Lin, Y., Shi, R., Wang, X., and Shen, H. M. (2008). Luteolin, a Flavonoid with Potential for Cancer Prevention and Therapy. Curr. Cancer Drug Targets 8 (7), 634-646. doi:10.2174/156800908786241050

Liu, D., Wang, B., Zhu, Y., Yan, F., and Dong, W. (2018). Carnosic Acid Regulates Cell Proliferation and Invasion in Chronic Myeloid Leukemia Cancer Cells via Suppressing microRNA-708. J. BUON 23 (3), 741-746.

Liu, H., Hughes, J. D., Rollins, S., Chen, B., and Perkins, E. (2011). Calcium Entry via ORAI1 Regulates Glioblastoma Cell Proliferation and Apoptosis. Exp. Mol. Pathol. 91 (3), 753-760. doi:10.1016/j.yexmp.2011.09.005

Liu, H., Zhou, X., Yuan, M., Zhou, S., Huang, Y. E., Hou, F., et al. (2020). ncEP: A Manually Curated Database for Experimentally Validated ncRNA-Encoded Proteins or Peptides. J. Mol. Biol. 432 (11), 3364-3368. doi:10.1016/ j.jmb.2020.02.022

Liu, J., Guo, Y., and Cao, J. (2020). Matrine Triggers colon Cancer Cell Apoptosis and G0/G1 Cell Cycle Arrest via Mediation of microRNA-22. Phytother Res. 34 (7), 1619-1628. doi:10.1002/ptr.6626

Liu, K., Du, J., and Ruan, L. (2017). MicroRNA-21 Regulates the Viability and Apoptosis of Diffuse Large B-Cell Lymphoma Cells by Upregulating B Cell Lymphoma-2. Exp. Ther. Med. 14 (5), 4489-4496. doi:10.3892/etm.2017.5021

Liu, L. Y., Wang, W., Zhao, L. Y., Guo, B., Yang, J., Zhao, X. G., et al. (2014). Mir126 Inhibits Growth of SGC-7901 Cells by Synergistically Targeting the Oncogenes PI3KR2 and Crk, and the Tumor Suppressor PLK2. Int. J. Oncol. 45 (3), 1257-1265. doi:10.3892/ijo.2014.2516

Liu, Q., Fu, H., Sun, F., Zhang, H., Tie, Y., Zhu, J., et al. (2008). miR-16 Family Induces Cell Cycle Arrest by Regulating Multiple Cell Cycle Genes. Nucleic Acids Res. 36 (16), 5391-5404. doi:10.1093/nar/gkn522

Liu, Q., Wang, W., Li, F., Yu, D., Xu, C., and Hu, H. (2019). Triptolide Inhibits Breast Cancer Cell Metastasis through Inducing the Expression of miR-146a, a Negative Regulator of Rho GTPase. Oncol. Res. 27 (9), 1043-1050. doi:10.3727/ 096504019X15560124931900

Li, W., Zhang, B., Chen, G., Wu, W., Zhou, L., Shi, Y., et al. (2017). Targeting miR21 with Sophocarpine Inhibits Tumor Progression and Reverses EpithelialMesenchymal Transition in Head and Neck Cancer. Mol. Ther. 25 (9), 2129-2139. doi:10.1016/j.ymthe.2017.05.008

Liu, X., Jutooru, I., Lei, P., Kim, K., Lee, S. O., Brents, L. K., et al. (2012). Betulinic Acid Targets YY1 and ErbB2 through Cannabinoid Receptor-dependent Disruption of microRNA-27a:ZBTB10 in Breast Cancer. Mol. Cancer Ther. 11 (7), 1421-1431. doi:10.1158/1535-7163.MCT-12-0026

Liu, X., Zhang, L., Liu, Y., Cui, J., Che, S., An, X., et al. (2018). Circ-8073 Regulates CEP55 by Sponging miR-449a to Promote Caprine Endometrial Epithelial Cells
Proliferation via the PI3K/AKT/mTOR Pathway. Biochim. Biophys. Acta Mol. Cel Res 1865 (8), 1130-1147. doi:10.1016/j.bbamcr.2018.05.011

Liu, Z., Zhang, S., Wang, T., Shao, H., Gao, J., Wang, Y., et al. (2019). Neferine Inhibits MDA-MB-231 cells Growth and Metastasis by Regulating miR-374a/ FGFR-2. Chem. Biol. Interact 309, 108716. doi:10.1016/j.cbi.2019.06.029

Lodygin, D., Tarasov, V., Epanchintsev, A., Berking, C., Knyazeva, T., Körner, H., et al. (2008). Inactivation of miR-34a by Aberrant CpG Methylation in Multiple Types of Cancer. Cell Cycle 7 (16), 2591-2600. doi:10.4161/cc.7.16.6533

Lu, W. Z., Geng, G. X., Li, Q. W., Li, J., Liu, F. Z., and Han, Z. S. (2010). Antitumor Activity of Polysaccharides Isolated from Patrinia Heterophylla. Pharm. Biol. 48 (9), 1012-1017. doi:10.3109/13880200903437852

Luo, X., Gu, J., Zhu, R., Feng, M., Zhu, X., Li, Y., et al. (2014). Integrative Analysis of Differential miRNA and Functional Study of miR-21 by Seed-Targeting Inhibition in Multiple Myeloma Cells in Response to Berberine. BMC Syst. Biol. 8, 82. doi:10.1186/1752-0509-8-82

Ma, J., Kong, Y., Nan, H., Qu, S., Fu, X., Jiang, L., et al. (2017). Pleiotrophin as a Potential Biomarker in Breast Cancer Patients. Clin. Chim. Acta 466, 6-12. doi:10.1016/j.cca.2016.12.030

Manach, C., Scalbert, A., Morand, C., Rémésy, C., and Jiménez, L. (2004). Polyphenols: Food Sources and Bioavailability. Am. J. Clin. Nutr. 79 (5), 727-747. doi:10.1093/ajen/79.5.727

Mann, J. (2002). Natural Products in Cancer Chemotherapy: Past, Present and Future. Nat. Rev. Cancer 2 (2), 143-148. doi:10.1038/nrc723

Maracaja-Coutinho, V., Paschoal, A. R., Caris-Maldonado, J. C., Borges, P. V., Ferreira, A. J., and Durham, A. M. (2019). Noncoding RNAs Databases: Current Status and Trends. Methods Mol. Biol. 1912, 251-285. doi:10.1007/978-1-49398982-9_10

Martin, S. L., Kala, R., and Tollefsbol, T. O. (2018). Mechanisms for the Inhibition of Colon Cancer Cells by Sulforaphane through Epigenetic Modulation of MicroRNA-21 and Human Telomerase Reverse Transcriptase (hTERT) DownRegulation. Curr. Cancer Drug Targets 18 (1), 97-106. doi:10.2174/ 1568009617666170206104032

Meng, H. T., Zhu, L., Ni, W. M., You, L. S., Jin, J., and Qian, W. B. (2011). Triptolide Inhibits the Proliferation of Cells from Lymphocytic Leukemic Cell Lines in Association with Downregulation of NF-Kb Activity and miR-16-1*. Acta Pharmacol. Sin 32 (4), 503-511. doi:10.1038/aps.2010.237

Mertens-Talcott, S. U., Noratto, G. D., Li, X., Angel-Morales, G., Bertoldi, M. C., and Safe, S. (2013). Betulinic Acid Decreases ER-Negative Breast Cancer Cell Growth In Vitro and In Vivo: Role of Sp Transcription Factors and microRNA27a:ZBTB10. Mol. Carcinog. 52 (8), 591-602. doi:10.1002/mc.21893

Michael, W. (2007). Modern Alkaloids: Structure, Isolation, Synthesis and Biology (Weinheim: Wiley-VCH Verlag GmbH \& Co. KGaA), 1-24.

Moeng, S., Son, S. W., Seo, H. A., Lee, J. S., Kim, C. K., Kuh, H. J., et al. (2020). Luteolin-regulated MicroRNA-301-3p Targets Caspase-8 and Modulates TRAIL Sensitivity in PANC-1 Cells. Anticancer Res. 40 (2), 723-731. doi:10.21873/anticanres. 14003

Mondal, A., Gandhi, A., Fimognari, C., Atanasov, A. G., and Bishayee, A. (2019). Alkaloids for Cancer Prevention and Therapy: Current Progress and Future Perspectives. Eur. J. Pharmacol. 858, 172472. doi:10.1016/j.ejphar.2019.172472

Montaser, R., and Luesch, H. (2011). Marine Natural Products: a New Wave of Drugs? Future Med. Chem. 3 (12), 1475-1489. doi:10.4155/fmc.11.118

Monteleone, N. J., and Lutz, C. S. (2020). miR-708-5p Targets Oncogenic Prostaglandin E2 Production to Suppress a Pro-tumorigenic Phenotype in Lung Cancer Cells. Oncotarget 11 (26), 2464-2483. doi:10.18632/ oncotarget.27614

Moore, B. D., Andrew, R. L., Külheim, C., and Foley, W. J. (2014). Explaining Intraspecific Diversity in Plant Secondary Metabolites in an Ecological Context. New Phytol. 201 (3), 733-750. doi:10.1111/nph.12526

Moses, T., Papadopoulou, K. K., and Osbourn, A. (2014). Metabolic and Functional Diversity of Saponins, Biosynthetic Intermediates and Semi-synthetic Derivatives. Crit. Rev. Biochem. Mol. Biol. 49 (6), 439-462. doi:10.3109/ 10409238.2014.953628

Moudi, M., Go, R., Yien, C. Y., and Nazre, M. (2013). Vinca Alkaloids. Int. J. Prev. Med. 4 (11), 1231-1235.

Mudduluru, G., George-William, J. N., Muppala, S., Asangani, I. A., Kumarswamy, R., Nelson, L. D., et al. (2011). Curcumin Regulates miR-21 Expression and Inhibits Invasion and Metastasis in Colorectal Cancer. Biosci. Rep. 31 (3), 185-197. doi:10.1042/BSR20100065 
Nam, S., Xie, J., Perkins, A., Ma, Y., Yang, F., Wu, J., et al. (2012). Novel Synthetic Derivatives of the Natural Product Berbamine Inhibit Jak2/Stat3 Signaling and Induce Apoptosis of Human Melanoma Cells. Mol. Oncol. 6 (5), 484-493. doi:10.1016/j.molonc.2012.05.002

Ngamwonglumlert, L., and Devahastin, S. (2019). "Carotenoids," in Encyclopedia of Food Chemistry. Editors L Melton, F Shahidi, and P Varelis (Oxford: Academic Press), 40-52. doi:10.1016/b978-0-08-100596-5.21608-9

Novikova, I. V., Hennelly, S. P., and Sanbonmatsu, K. Y. (2012). Sizing up Long Non-coding RNAs: Do lncRNAs Have Secondary and Tertiary Structure? Bioarchitecture 2 (6), 189-199. doi:10.4161/bioa.22592

O'Neill, L. A., Sheedy, F. J., and McCoy, C. E. (2011). MicroRNAs: the fine-tuners of Toll-like Receptor Signalling. Nat. Rev. Immunol. 11 (3), 163-175. doi:10.1038/nri2957

Othoum, G., Coonrod, E., Zhao, S., Dang, H. X., and Maher, C. A. (2020). Pancancer Proteogenomic Analysis Reveals Long and Circular Noncoding RNAs Encoding Peptides. NAR Cancer 2 (3), zcaa015. doi:10.1093/narcan/zcaa015

Padhye, S., Ahmad, A., Oswal, N., and Sarkar, F. H. (2009). Emerging Role of Garcinol, the Antioxidant Chalcone from Garcinia Indica Choisy and its Synthetic Analogs. J. Hematol. Oncol. 2, 38. doi:10.1186/1756-8722-2-38

Palazzo, A. F., and Lee, E. S. (2015). Non-coding RNA: what Is Functional and what Is Junk? Front. Genet. 6, 2. doi:10.3389/fgene.2015.00002

Pan, L., Acuña, U. M., Li, J., Jena, N., Ninh, T. N., Pannell, C. M., et al. (2013). Bioactive Flavaglines and Other Constituents Isolated from Aglaia Perviridis. J. Nat. Prod. 76 (3), 394-404. doi:10.1021/np3007588

Panche, A. N., Diwan, A. D., and Chandra, S. R. (2016). Flavonoids: an Overview. J. Nutr. Sci. 5, e47. doi:10.1017/jns.2016.41

Parasramka, M. A., Ali, S., Banerjee, S., Deryavoush, T., Sarkar, F. H., and Gupta, S. (2013). Garcinol Sensitizes Human Pancreatic Adenocarcinoma Cells to Gemcitabine in Association with microRNA Signatures. Mol. Nutr. Food Res. 57 (2), 235-248. doi:10.1002/mnfr.201200297

Pardini, B., and Calin, G. A. (2019). MicroRNAs and Long Non-coding RNAs and Their Hormone-like Activities in Cancer. Cancers (Basel) 11 (3), 378. doi:10.3390/cancers11030378

Pardini, B., Sabo, A. A., Birolo, G., and Calin, G. A. (2019). Noncoding RNAs in Extracellular Fluids as Cancer Biomarkers: The New Frontier of Liquid Biopsies. Cancers (Basel) 11 (8), 1170. doi:10.3390/cancers11081170

Paschoal, A. R., Lozada-Chávez, I., Domingues, D. S., and Stadler, P. F. (2018). ceRNAs in Plants: Computational Approaches and Associated Challenges for Target Mimic Research. Brief Bioinform 19 (6), 1273-1289. doi:10.1093/bib/ bbx058

Patel, J. B., Appaiah, H. N., Burnett, R. M., Bhat-Nakshatri, P., Wang, G., Mehta, R., et al. (2011). Control of EVI-1 Oncogene Expression in Metastatic Breast Cancer Cells through microRNA miR-22. Oncogene 30 (11), 1290-1301. doi:10.1038/onc.2010.510

Peng, Y., Fan, J. Y., Xiong, J., Lou, Y., and Zhu, Y. (2019). miR-34a Enhances the Susceptibility of Gastric Cancer to Platycodin D by Targeting Survivin. Pathobiology 86 (5-6), 296-305. doi:10.1159/000502913

Petrescu, G. E. D., Sabo, A. A., Torsin, L. I., Calin, G. A., and Dragomir, M. P. (2019). MicroRNA Based Theranostics for Brain Cancer: Basic Principles. J. Exp. Clin. Cancer Res. 38 (1), 231. doi:10.1186/s13046-019-1180-5

Poliseno, L., Salmena, L., Zhang, J., Carver, B., Haveman, W. J., and Pandolfi, P. P. (2010). A Coding-independent Function of Gene and Pseudogene mRNAs Regulates Tumour Biology. Nature 465 (7301), 1033-1038. doi:10.1038/ nature09144

Popat, R., Plesner, T., Davies, F., Cook, G., Cook, M., Elliott, P., et al. (2013). A Phase 2 Study of SRT501 (Resveratrol) with Bortezomib for Patients with Relapsed and or Refractory Multiple Myeloma. Br. J. Haematol. 160 (5), 714-717. doi:10.1111/bjh.12154

Qi, Y., and Li, J. (2019). Triptolide Inhibits the Growth and Migration of colon Carcinoma Cells by Down-Regulation of miR-191. Exp. Mol. Pathol. 107, 23-31. doi:10.1016/j.yexmp.2019.01.008

Quideau, S., Deffieux, D., Douat-Casassus, C., and Pouységu, L. (2011). Plant Polyphenols: Chemical Properties, Biological Activities, and Synthesis. Angew. Chem. Int. Ed. Engl. 50 (3), 586-621. doi:10.1002/anie.201000044

Reinhart, B. J., Weinstein, E. G., Rhoades, M. W., Bartel, B., and Bartel, D. P. (2002). MicroRNAs in Plants. Genes Dev. 16 (13), 1616-1626. doi:10.1101/gad.1004402

Rigoutsos, I., Lee, S. K., Nam, S. Y., Anfossi, S., Pasculli, B., Pichler, M., et al. (2017). N-BLR, a Primate-specific Non-coding Transcript Leads to Colorectal Cancer
Invasion and Migration. Genome Biol. 18 (1), 98. doi:10.1186/s13059-0171224-0

Rivière, C., Pawlus, A. D., and Mérillon, J. M. (2012). Natural Stilbenoids: Distribution in the Plant Kingdom and Chemotaxonomic Interest in Vitaceae. Nat. Prod. Rep. 29 (11), 1317-1333. doi:10.1039/c2np20049j

RNAcentral Consortium. (2021). RNAcentral 2021: Secondary Structure Integration, Improved Sequence Search and New Member Databases. Nucleic Acids Res. 49 (D1), D212-D220. doi:10.1093/nar/gkaa921

Ryan, J. L., Heckler, C. E., Ling, M., Katz, A., Williams, J. P., Pentland, A. P., et al. (2013). Curcumin for Radiation Dermatitis: a Randomized, Double-Blind, Placebo-Controlled Clinical Trial of Thirty Breast Cancer Patients. Radiat. Res. 180 (1), 34-43. doi:10.1667/RR3255.1

Sah, N. K., Khan, Z., Khan, G. J., and Bisen, P. S. (2006). Structural, Functional and Therapeutic Biology of Survivin. Cancer Lett. 244 (2), 164-171. doi:10.1016/ j.canlet.2006.03.007

Sak, K. (2012). Chemotherapy and Dietary Phytochemical Agents. Chemother. Res. Pract. 2012, 282570. doi:10.1155/2012/282570

Salehi, B., Venditti, A., Sharifi-Rad, M., Kręgiel, D., Sharifi-Rad, J., Durazzo, A., et al. (2019). The Therapeutic Potential of Apigenin. Int. J. Mol. Sci. 20 (6), 1305. doi:10.3390/ijms20061305

Sawai, S., and Saito, K. (2011). Triterpenoid Biosynthesis and Engineering in Plants. Front. Plant Sci. 2, 25. doi:10.3389/fpls.2011.00025

Sha, M., Ye, J., Zhang, L. X., Luan, Z. Y., and Chen, Y. B. (2013). Celastrol Induces Apoptosis of Gastric Cancer Cells by miR-146a Inhibition of NF-Kb Activity. Cancer Cel. Int. 13 (1), 50. doi:10.1186/1475-2867-13-50

Shahidi, F., and Yeo, J. (2018). Bioactivities of Phenolics by Focusing on Suppression of Chronic Diseases: A Review. Int. J. Mol. Sci. 19 (6), 1573. doi:10.3390/ijms19061573

Shan, Y., Zhang, L., Bao, Y., Li, B., He, C., Gao, M., et al. (2013). Epithelialmesenchymal Transition, a Novel Target of Sulforaphane via COX-2/MMP2, 9/ Snail, ZEB1 and miR-200c/ZEB1 Pathways in Human Bladder Cancer Cells. J. Nutr. Biochem. 24 (6), 1062-1069. doi:10.1016/j.jnutbio.2012.08.004

Shen, K. H., Hung, J. H., Chang, C. W., Weng, Y. T., Wu, M. J., and Chen, P. S. (2017). Solasodine Inhibits Invasion of Human Lung Cancer Cell through Downregulation of miR-21 and MMPs Expression. Chem. Biol. Interact 268, 129-135. doi:10.1016/j.cbi.2017.03.005

Shi, H., Bi, H., Sun, X., Dong, H., Jiang, Y., Mu, H., et al. (2018). Antitumor Effects of Tubeimoside-1 in NCI-H1299 Cells Are Mediated by microRNA-126-5pInduced Inactivation of VEGF-A/VEGFR-2/ERK Signaling Pathway. Mol. Med. Rep. 17 (3), 4327-4336. doi:10.3892/mmr.2018.8459

Song, C., Lu, P., Sun, G., Yang, L., Wang, Z., and Wang, Z. (2017). miR-34a Sensitizes Lung Cancer Cells to Cisplatin via p53/miR-34a/MYCN axis. Biochem. Biophys. Res. Commun. 482 (1), 22-27. doi:10.1016/ j.bbrc.2016.11.037

Song, L., Liu, D., Zhao, Y., He, J., Kang, H., Dai, Z., et al. (2015). Sinomenine Inhibits Breast Cancer Cell Invasion and Migration by Suppressing NF-Kb Activation Mediated by IL-4/miR-324-5p/CUEDC2 axis. Biochem. Biophys. Res. Commun. 464 (3), 705-710. doi:10.1016/j.bbrc.2015.07.004

Sredni, S. T., Huang, C. C., Suzuki, M., Pundy, T., Chou, P., and Tomita, T. (2016). Spontaneous Involution of Pediatric Low-Grade Gliomas: High Expression of Cannabinoid Receptor 1 (CNR1) at the Time of Diagnosis May Indicate Involvement of the Endocannabinoid System. Childs Nerv. Syst. 32 (11), 2061-2067. doi:10.1007/s00381-016-3243-7

Sreenivasan, S., Thirumalai, K., Danda, R., and Krishnakumar, S. (2012). Effect of Curcumin on miRNA Expression in Human Y79 Retinoblastoma Cells. Curr. Eye Res. 37 (5), 421-428. doi:10.3109/02713683.2011.647224

Statello, L., Guo, C. J., Chen, L. L., and Huarte, M. (2021). Gene Regulation by Long Non-coding RNAs and its Biological Functions. Nat. Rev. Mol. Cel. Biol. 22 (2), 96-118. doi:10.1038/s41580-020-00315-9

$\mathrm{Su}$, Y., Lu, S., Li, J., and Deng, L. (2018). Shikonin-mediated Up-Regulation of miR34a and miR-202 Inhibits Retinoblastoma Proliferation. Toxicol. Res. (Camb) 7 (5), 907-912. doi:10.1039/c8tx00079d

Sui, X. Q., Xu, Z. M., Xie, M. B., and Pei, D. A. (2014). Resveratrol Inhibits Hydrogen Peroxide-Induced Apoptosis in Endothelial Cells via the Activation of PI3K/Akt by miR-126. J. Atheroscler. Thromb. 21 (2), 108-118. doi:10.5551/ jat.19257

Tahmasebi Mirgani, M., Isacchi, B., Sadeghizadeh, M., Marra, F., Bilia, A. R., Mowla, S. J., et al. (2014). Dendrosomal Curcumin Nanoformulation 
Downregulates Pluripotency Genes via miR-145 Activation in U87MG Glioblastoma Cells. Int. J. Nanomedicine 9, 403-417. doi:10.2147/IJN.S48136

Tan, T. W., Chou, Y. E., Yang, W. H., Hsu, C. J., Fong, Y. C., and Tang, C. H. (2014). Naringin Suppress Chondrosarcoma Migration through Inhibition Vascular Adhesion Molecule-1 Expression by Modulating miR-126. Int. Immunopharmacol. 22 (1), 107-114. doi:10.1016/j.intimp.2014.06.029

Tan, X., Kim, G., Lee, D., Oh, J., Kim, M., Piao, C., et al. (2018). A CurcuminLoaded Polymeric Micelle as a Carrier of a microRNA-21 AntisenseOligonucleotide for Enhanced Anti-tumor Effects in a Glioblastoma Animal Model. Biomater. Sci. 6 (2), 407-417. doi:10.1039/c7bm01088e

Tang, H., Kong, Y., Guo, J., Tang, Y., Xie, X., Yang, L., et al. (2013). Diallyl Disulfide Suppresses Proliferation and Induces Apoptosis in Human Gastric Cancer through Wnt-1 Signaling Pathway by Up-Regulation of miR200b and miR-22. Cancer Lett. 340 (1), 72-81. doi:10.1016/j.canlet.2013.06.027

Tang, L., Shen, H., Li, X., Li, Z., Liu, Z., Xu, J., et al. (2016). MiR-125a-5p Decreases after Long Non-coding RNA HOTAIR Knockdown to Promote Cancer Cell Apoptosis by Releasing Caspase 2. Cell Death Dis. 7, e2137. doi:10.1038/ cddis. 2016.41

Tetali, S. D. (2019). Terpenes and Isoprenoids: a Wealth of Compounds for Global Use. Planta. 249 (1), 1-8. doi:10.1007/s00425-018-3056-x

The ENCODE Project Consortium. (2012). An Integrated Encyclopedia of DNA Elements in the Human Genome. Nature 489, 57-74. doi:10.1038/nature11247

Tian, B., and Liu, J. (2020). Resveratrol: a Review of Plant Sources, Synthesis, Stability, Modification and Food Application. J. Sci. Food Agric. 100 (4), 1392-1404. doi:10.1002/jsfa.10152

Tsuchiya, H. (2015). Membrane Interactions of Phytochemicals as Their Molecular Mechanism Applicable to the Discovery of Drug Leads from Plants. Molecules 20 (10), 18923-18966. doi:10.3390/molecules201018923

Tursynbay, Y., Zhang, J., Li, Z., Tokay, T., Zhumadilov, Z., Wu, D., et al. (2016). Pim-1 Kinase as Cancer Drug Target: An Update. Biomed. Rep. 4 (2), 140-146. doi:10.3892/br.2015.561

Valanciene, E., Jonuskiene, I., Syrpas, M., Augustiniene, E., Matulis, P., Simonavicius, A., et al. (2020). Advances and Prospects of Phenolic Acids Production, Biorefinery and Analysis. Biomolecules 10 (6), 874. doi:10.3390/ biom 10060874

Velderrain-Rodríguez, G. R., Palafox-Carlos, H., Wall-Medrano, A., Ayala-Zavala, J. F., Chen, C. Y., Robles-Sánchez, M., et al. (2014). Phenolic Compounds: Their Journey after Intake. Food Funct. 5 (2), 189-197. doi:10.1039/c3fo60361j

Victor, S. P., and Sharma, C. P. (2015). Anti-inflammatory Drug Delivery Systems Using marine Products. Functional Marine Biomater. (Elsevier, Cambridge: Woodhead Publishing Ltd., 137-147. doi:10.1016/b978-1-78242-086-6.00009-1

Vo, D. D., Staedel, C., Zehnacker, L., Benhida, R., Darfeuille, F., and Duca, M. (2014). Targeting the Production of Oncogenic microRNAs with Multimodal Synthetic Small Molecules. ACS Chem. Biol. 9 (3), 711-721. doi:10.1021/ cb400668h

Wang, D. X., Zou, Y. J., Zhuang, X. B., Chen, S. X., Lin, Y., Li, W. L., et al. (2017). Sulforaphane Suppresses EMT and Metastasis in Human Lung Cancer through miR-616-5p-Mediated GSK3 $3 / \beta$-Catenin Signaling Pathways. Acta Pharmacol. Sin 38 (2), 241-251. doi:10.1038/aps.2016.122

Wang, G., Liu, G., Ye, Y., Fu, Y., and Zhang, X. (2016). Upregulation of miR-34a by Diallyl Disulfide Suppresses Invasion and Induces Apoptosis in SGC-7901 Cells through Inhibition of the PI3K/Akt Signaling Pathway. Oncol. Lett. 11 (4), 2661-2667. doi:10.3892/ol.2016.4266

Wang, P., Du, X., Xiong, M., Cui, J., Yang, Q., Wang, W., et al. (2016). Ginsenoside Rd Attenuates Breast Cancer Metastasis Implicating Derepressing microRNA-18a-Regulated Smad2 Expression. Sci. Rep. 6, 33709. doi:10.1038/srep33709

Wang, P., Yang, Q., Du, X., Chen, Y., and Zhang, T. (2019). Targeted Regulation of Rell2 by microRNA-18a Is Implicated in the Anti-metastatic Effect of Polyphyllin VI in Breast Cancer Cells. Eur. J. Pharmacol. 851, 161-173. doi:10.1016/j.ejphar.2019.02.041

Wang, S., Mou, J., Cui, L., Wang, X., and Zhang, Z. (2018). Astragaloside IV Inhibits Cell Proliferation of Colorectal Cancer Cell Lines through DownRegulation of B7-H3. Biomed. Pharmacother. 102, 1037-1044. doi:10.1016/ j.biopha.2018.03.127

Wang X., X., Hang, Y., Liu, J., Hou, Y., Wang, N., and Wang, M. (2017). Anticancer Effect of Curcumin Inhibits Cell Growth through miR-21/PTEN/Akt Pathway in Breast Cancer Cell. Oncol. Lett. 13 (6), 4825-4831. doi:10.3892/ol.2017.6053
Wang, X., Li, Y., Dai, Y., Liu, Q., Ning, S., Liu, J., et al. (2016). Sulforaphane Improves Chemotherapy Efficacy by Targeting Cancer Stem Cell-like Properties via the miR-124/IL-6R/STAT3 axis. Sci. Rep. 6, 36796. doi:10.1038/srep36796

Wang, X., and Wang, Y. (2015). Ginsenoside Rh2 Mitigates Pediatric Leukemia through Suppression of Bcl-2 in Leukemia Cells. Cel. Physiol. Biochem. 37 (2), 641-650. doi:10.1159/000430383

Wang, Z. F., Ma, D. G., Zhu, Z., Mu, Y. P., Yang, Y. Y., Feng, L., et al. (2017). Astragaloside IV Inhibits Pathological Functions of Gastric Cancer-Associated Fibroblasts. World J. Gastroenterol. 23 (48), 8512-8525. doi:10.3748/ wjg.v23.i48.8512

Wei, Y. P., Wang, X. H., Liu, G., Zhang, J. F., Yang, Y. X., Zhang, J., et al. (2018). Matrine Exerts Inhibitory Effects in Melanoma through the Regulation of miR19b-3p/PTEN. Int. J. Oncol. 53 (2), 791-800. doi:10.3892/ijo.2018.4414

Wen, X., Zhang, H. D., Zhao, L., Yao, Y. F., Zhao, J. H., and Tang, J. H. (2015). Ginsenoside Rh2 Differentially Mediates microRNA Expression to Prevent Chemoresistance of Breast Cancer. Asian Pac. J. Cancer Prev. 16 (3), 1105-1109. doi:10.7314/apjcp.2015.16.3.1105

Widelski, J., and Kukula-Koch, W. A. (2017). "Chapter 17 - Psychoactive Drugs," in Pharmacognosy. Editors S Badal and R Delgoda (Boston: Academic Press), 363-374. doi:10.1016/b978-0-12-802104-0.00017-2

Wightman, B., Ha, I., and Ruvkun, G. (1993). Posttranscriptional Regulation of the Heterochronic Gene Lin-14 by Lin-4 Mediates Temporal Pattern Formation in C. elegans. Cell 75 (5), 855-862. doi:10.1016/0092-8674(93)90530-4

Wong, S. H. M., Kong, W. Y., Fang, C. M., Loh, H. S., Chuah, L. H., Abdullah, S., et al. (2019). The TRAIL to Cancer Therapy: Hindrances and Potential Solutions. Crit. Rev. Oncol. Hematol. 143, 81-94. doi:10.1016/ j.critrevonc.2019.08.008

Wu, H., Huang, M., Liu, Y., Shu, Y., and Liu, P. (2015a). Luteolin Induces Apoptosis by Up-Regulating miR-34a in Human Gastric Cancer Cells. Technol. Cancer Res. Treat. 14 (6), 747-755. doi:10.7785/tcrt.2012.500434

Wu, H., Liu, Q., Cai, T., Chen, Y. D., and Wang, Z. F. (2015b). Induction of microRNA-146a Is Involved in Curcumin-Mediated Enhancement of Temozolomide Cytotoxicity against Human Glioblastoma. Mol. Med. Rep. 12 (4), 5461-5466. doi:10.3892/mmr.2015.4087

Wu, J., Wang, L., Du, X., Sun, Q., Wang, Y., Li, M., et al. (2018). $\alpha$-Solanine Enhances the Chemosensitivity of Esophageal Cancer Cells by Inducing microRNA-138 E-xpression. Oncol. Rep. 39 (3), 1163-1172. doi:10.3892/ or.2018.6187

Wu, N., Wu, G. C., Hu, R., Li, M., and Feng, H. (2011). Ginsenoside Rh2 Inhibits Glioma Cell Proliferation by Targeting microRNA-128. Acta Pharmacol. Sin. 32 (3), 345-353. doi:10.1038/aps.2010.220

Wu, X., Liu, T., Fang, O., Dong, W., Zhang, F., Leach, L., et al. (2016). MicroRNA708-5p Acts as a Therapeutic Agent against Metastatic Lung Cancer. Oncotarget 7 (3), 2417-2432. doi:10.18632/oncotarget.6594

Xiao, X., Chen, B., Liu, X., Liu, P., Zheng, G., Ye, F., et al. (2014). Diallyl Disulfide Suppresses SRC/Ras/ERK Signaling-Mediated Proliferation and Metastasis in Human Breast Cancer by Up-Regulating miR-34a. PLoS One 9 (11), el12720. doi:10.1371/journal.pone.0112720

Xiao, X., Zhang, Y., Pan, W., and Chen, F. (2020). miR-139-mediated NOTCH1 Regulation Is Crucial for the Inhibition of Osteosarcoma Progression Caused by Resveratrol. Life Sci. 242, 117215. doi:10.1016/j.lfs.2019.117215

Xu, D., Chi, G., Zhao, C., and Li, D. (2018). Ligustrazine Inhibits Growth, Migration and Invasion of Medulloblastoma Daoy Cells by Up-Regulation of miR-211. Cel Physiol. Biochem. 49 (5), 2012-2021. doi:10.1159/000493712

Xu, F., Li, Q., Wang, Z., and Cao, X. (2019). Sinomenine Inhibits Proliferation, Migration, Invasion and Promotes Apoptosis of Prostate Cancer Cells by Regulation of miR-23a. Biomed. Pharmacother. 112, 108592. doi:10.1016/ j.biopha.2019.01.053

Xu, N., Papagiannakopoulos, T., Pan, G., Thomson, J. A., and Kosik, K. S. (2009). MicroRNA-145 Regulates OCT4, SOX2, and KLF4 and Represses Pluripotency in Human Embryonic Stem Cells. Cell 137 (4), 647-658. doi:10.1016/ j.cell.2009.02.038

Xu, Q., Li, M., Yang, M., Yang, J., Xie, J., Lu, X., et al. (2018). $\alpha$-Pinene Regulates miR-221 and Induces G2/M Phase Cell Cycle Arrest in Human Hepatocellular Carcinoma Cells. Biosci. Rep. 38 (6), BSR20180980. doi:10.1042/BSR20180980

Xue, F., Liu, Z., Xu, J., Xu, X., Chen, X., and Tian, F. (2019). Neferine Inhibits Growth and Migration of Gastrointestinal Stromal Tumor Cell Line GIST-T1 
by Up-Regulation of miR-449a. Biomed. Pharmacother. 109, 1951-1959. doi:10.1016/j.biopha.2018.11.029

Yang, F., Nam, S., Brown, C. E., Zhao, R., Starr, R., Ma, Y., et al. (2014). A Novel Berbamine Derivative Inhibits Cell Viability and Induces Apoptosis in Cancer Stem-like Cells of Human Glioblastoma, via Up-Regulation of miRNA-4284 and JNK/AP-1 Signaling. PLoS One 9 (4), e94443. doi:10.1371/ journal.pone.0094443

Yang, J., Hao, T., Sun, J., Wei, P., and Zhang, H. (2019a). Long Noncoding RNA GAS5 Modulates $a$-Solanine-induced Radiosensitivity by Negatively Regulating miR-18a in Human Prostate Cancer Cells. Biomed. Pharmacother. 112, 108656. doi:10.1016/j.biopha.2019.108656

Yang, J., Shao, X., Jiang, J., Sun, Y., Wang, L., and Sun, L. (2018). Angelica Sinensis Polysaccharide Inhibits Proliferation, Migration, and Invasion by Downregulating microRNA-675 in Human Neuroblastoma Cell Line SHSy5y. Cell Biol. Int. 42 (7), 867-876. doi:10.1002/cbin.10954

Yang, J., Shao, X., Wang, L., Xu, H., Sun, Y., Jiang, J., et al. (2019b). Angelica Polysaccharide Exhibits Antitumor Effect in Neuroblastoma Cell Line SH-Sy5y by Up-Regulation of miR-205. Biofactors 1-10. doi:10.1002/biof.1586

Yang, J. B., Li, M., Xie, J. J., Yang, M. D., Lu, X. S., Wang, F., et al. (2016). [Effects of a-pinene Extracted from pine Needle on Expression of miR-221 and its Potential Target Genes in Human Hepatocellular Carcinoma Cells]. Zhongguo Zhong Yao Za Zhi 41 (21), 3996-3999. doi:10.4268/ cjcmm 20162118

Yang, K., Gao, Z. Y., Li, T. Q., Song, W., Xiao, W., Zheng, J., et al. (2019a). Antitumor Activity and the Mechanism of a green tea (Camellia Sinensis) Polysaccharide on Prostate Cancer. Int. J. Biol. Macromol. 122, 95-103. doi:10.1016/j.ijbiomac.2018.10.101

Yang, K., Li, Y. W., Gao, Z. Y., Xiao, W., Li, T. Q., Song, W., et al. (2019d). MiR-93 Functions as a Tumor Promoter in Prostate Cancer by Targeting Disabled Homolog 2 (DAB2) and an Antitumor Polysaccharide from green tea (Camellia Sinensis) on Their Expression. Int. J. Biol. Macromol. 125, 557-565. doi:10.1016/j.ijbiomac.2018.12.088

Yang, M., Liu, B., Jin, L., Tao, H., and Yang, Z. (2017). Estrogen Receptor $\beta$ Exhibited Anti-tumor Effects on Osteosarcoma Cells by Regulating Integrin, IAP, NF-kB/BCL-2 and PI3K/Akt Signal Pathway. J. Bone Oncol. 9, 15-20. doi:10.1016/j.jbo.2017.09.005

Yang, P., Sun, D., and Jiang, F. (2018). Ailanthone Promotes Human Vestibular Schwannoma Cell Apoptosis and Autophagy by Downregulation of miR-21. Oncol. Res. 26 (6), 941-948. doi:10.3727/096504018X15149775533331

Yang, P. W., Lu, Z. Y., Pan, Q., Chen, T. T., Feng, X. J., Wang, S. M., et al. (2019). MicroRNA-6809-5p Mediates Luteolin-Induced Anticancer Effects against Hepatoma by Targeting Flotillin 1. Phytomedicine 57, 18-29. doi:10.1016/ j.phymed.2018.10.027

Yang, Q., Wang, P., Cui, J., Wang, W., Chen, Y., and Zhang, T. (2016). Panax Notoginseng Saponins Attenuate Lung Cancer Growth in Part through Modulating the Level of Met/miR-222 axis. J. Ethnopharmacol. 193, 255-265. doi:10.1016/j.jep.2016.08.040

Yang, Q., Wang, X., Cui, J., Wang, P., Xiong, M., Jia, C., et al. (2014). Bidirectional Regulation of Angiogenesis and miR-18a Expression by PNS in the Mouse Model of Tumor Complicated by Myocardial Ischemia. BMC Complement. Altern. Med. 14, 183. doi:10.1186/1472-6882-14-183

Yang, S. F., Lee, W. J., Tan, P., Tang, C. H., Hsiao, M., Hsieh, F. K., et al. (2015). Upregulation of miR-328 and Inhibition of CREB-DNA-Binding Activity Are Critical for Resveratrol-Mediated Suppression of Matrix Metalloproteinase-2 and Subsequent Metastatic Ability in Human Osteosarcomas. Oncotarget 6 (5), 2736-2753. doi:10.18632/oncotarget.3088

Yang, X. W., Grossman, R. B., and Xu, G. (2018). Research Progress of Polycyclic Polyprenylated Acylphloroglucinols. Chem. Rev. 118 (7), 3508-3558. doi:10.1021/acs.chemrev.7b00551

Yang, Z. M., Yang, M. F., Yu, W., and Tao, H. M. (2019). Molecular Mechanisms of Estrogen Receptor $\beta$-induced Apoptosis and Autophagy in Tumors: Implication for Treating Osteosarcoma. J. Int. Med. Res. 47 (10), 4644-4655. doi:10.1177/0300060519871373

Yao, Y., Rao, C., Zheng, G., and Wang, S. (2019). Luteolin Suppresses Colorectal Cancer Cell Metastasis via Regulation of the miR-384/pleiotrophin axis. Oncol. Rep. 42 (1), 131-141. doi:10.3892/or.2019.7136

Ye, Q., Su, L., Chen, D., Zheng, W., and Liu, Y. (2017) Astragaloside IV Induced miR-134 Expression Reduces EMT and Increases Chemotherapeutic Sensitivity by Suppressing CREB1 Signaling in Colorectal Cancer Cell Line SW-480. Cell Physiol. Biochem. 43 (4), 1617-1626. doi:10.1159/000482025

Yeh, W. L., Lin, H. Y., Huang, C. Y., Huang, B. R., Lin, C., Lu, D. Y., et al. (2015). Migration-prone Glioma Cells Show Curcumin Resistance Associated with Enhanced Expression of miR-21 and Invasion/anti-Apoptosis-Related Proteins. Oncotarget 6 (35), 37770-37781. doi:10.18632/oncotarget.6092

Yin, L., Xiao, X., Georgikou, C., Luo, Y., Liu, L., Gladkich, J., et al. (2019a). Sulforaphane Induces miR135b-5p and its Target Gene, RASAL2, Thereby Inhibiting the Progression of Pancreatic Cancer. Mol. Ther. Oncolytics 14, 74-81. doi:10.1016/j.omto.2019.03.011

Yin, L., Xiao, X., Georgikou, C., Yin, Y., Liu, L., Karakhanova, S., et al. (2019b). MicroRNA-365a-3p Inhibits C-Rel-Mediated NF-Kb Signaling and the Progression of Pancreatic Cancer. Cancer Lett. 452, 203-212. doi:10.1016/ j.canlet.2019.03.025

Yin, S., Du, W., Wang, F., Han, B., Cui, Y., Yang, D., et al. (2018). MicroRNA-326 Sensitizes Human Glioblastoma Cells to Curcumin via the SHH/GLI1 Signaling Pathway. Cancer Biol. Ther. 19 (4), 260-270. doi:10.1080/ 15384047.2016.1250981

You, H. Y., Xie, X. M., Zhang, W. J., Zhu, H. L., and Jiang, F. Z. (2016). Berberine Modulates Cisplatin Sensitivity of Human Gastric Cancer Cells by Upregulation of miR-203. In Vitro Cel. Dev. Biol. Anim. 52 (8), 857-863. doi:10.1007/s11626-016-0044-y

You, Y., Wang, R., Shao, N., Zhi, F., and Yang, Y. (2019). Luteolin Suppresses Tumor Proliferation through Inducing Apoptosis and Autophagy via MAPK Activation in Glioma. Onco Targets Ther. 12, 2383-2396. doi:10.2147/ OTT.S191158

Yu, D., An, F., He, X., and Cao, X. (2015). Curcumin Inhibits the Proliferation and Invasion of Human Osteosarcoma Cell Line MG-63 by Regulating miR-138. Int. J. Clin. Exp. Pathol. 8 (11), 14946-14952.

Yu, Y., Shen, M., Song, Q., and Xie, J. (2018). Biological Activities and Pharmaceutical Applications of Polysaccharide from Natural Resources: A Review. Carbohydr. Polym. 183, 91-101. doi:10.1016/j.carbpol.2017.12.009

Zhang, B., Wang, X., Deng, J., Zheng, H., Liu, W., Chen, S., et al. (2019). p53dependent Upregulation of miR-16-2 by Sanguinarine Induces Cell Cycle Arrest and Apoptosis in Hepatocellular Carcinoma. Cancer Lett. 459, 50-58. doi:10.1016/j.canlet.2019.05.042

Zhang, C., Shu, L., Kim, H., Khor, T. O., Wu, R., Li, W., et al. (2016). Phenethyl Isothiocyanate (PEITC) Suppresses Prostate Cancer Cell Invasion Epigenetically through Regulating microRNA-194. Mol. Nutr. Food Res. 60 (6), 1427-1436. doi:10.1002/mnfr.201500918

Zhang, F., Yang, R., Zhang, G., Cheng, R., Bai, Y., Zhao, H., et al. (2016). Anticancer Function of $\alpha$-solanine in Lung Adenocarcinoma Cells by Inducing microRNA138 Expression. Tumour Biol. 37 (5), 6437-6446. doi:10.1007/s13277-0154528-2

Zhang, H., Li, H., Liu, Z., Ge, A., Guo, E., Liu, S., et al. (2018). Triptolide Inhibits the Proliferation and Migration of Medulloblastoma Daoy Cells by Upregulation of microRNA-138. J. Cel. Biochem. 119 (12), 9866-9877. doi:10.1002/jcb.27307

Zhang, J., Yang, W., Zhou, Y. B., Xiang, Y. X., Wang, L. S., Hu, W. K., et al. (2018). Baicalein Inhibits Osteosarcoma Cell Proliferation and Invasion through the miR-183/Ezrin P-athway. Mol. Med. Rep. 18 (1), 1104-1112. doi:10.3892/ mmr.2018.9036

Zhang, J., Zuo, J., Lei, M., Wu, S., Zang, X., and Zhang, C. (2014). Ezrin Promotes Invasion and Migration of the MG63 Osteosarcoma Cell. Chin. Med. J. (Engl) 127 (10), 1954-1959. doi:10.3760/cma.j.issn.0366-6999.20132225

Zhang, L., Hou, D., Chen, X., Li, D., Zhu, L., Zhang, Y., et al. (2012). Exogenous Plant MIR168a Specifically Targets Mammalian LDLRAP1: Evidence of CrossKingdom Regulation by microRNA. Cell Res. 22 (1), 107-126. doi:10.1038/ cr.2011.158

Zhang, L., Liao, Y., and Tang, L. (2019). MicroRNA-34 Family: a Potential Tumor Suppressor and Therapeutic Candidate in Cancer. J. Exp. Clin. Cancer Res. 38 (1), 53. doi:10.1186/s13046-019-1059-5

Zhang, M., Zhang, J., and Zhou, Q. (2019). Elevated Expression of microRNA-328$3 \mathrm{p}$ Suppresses Aggressive Malignant Behaviors via Targeting Matrix Metalloprotease 16 in Osteosarcoma. Onco Targets Ther. 12, 2063-2070. doi:10.2147/OTT.S195022

Zhang, S., Tang, D., Zang, W., Yin, G., Dai, J., and Sun, Y. (2017b). Synergistic Inhibitory Effect of Traditional Chinese Medicine Astragaloside IV and 
Curcumin on Tumor Growth and Angiogenesis in an Orthotopic Nude-Mouse Model of Human Hepatocellular Carcinoma. Anticancer Res. 37 (2), 465-473. doi:10.21873/anticanres.11338

Zhang, Y., Li, H., Cao, R., Sun, L., Wang, Y., Fan, S., et al. (2017a). Suppression of miR-708 Inhibits the Wnt/ $\beta$-Catenin Signaling Pathway by Activating DKK3 in Adult B-All. Oncotarget 8 (38), 64114-64128. doi:10.18632/ oncotarget.19342

Zhang, Y., Zhang, C., and Min, D. (2019). Ailanthone Up-Regulates miR-449a to Restrain Acute Myeloid Leukemia Cells Growth, Migration and Invasion. Exp. Mol. Pathol. 108, 114-120. doi:10.1016/j.yexmp.2019.04.011

Zheng, L., Chen, J., Ma, Z., Liu, W., Yang, F., Yang, Z., et al. (2015). Capsaicin Causes Inactivation and Degradation of the Androgen Receptor by Inducing the Restoration of miR-449a in Prostate Cancer. Oncol. Rep. 34 (2), 1027-1034. doi:10.3892/or.2015.4055

Zheng, X., Zhou, Y., Chen, W., Chen, L., Lu, J., He, F., et al. (2018). Ginsenoside 20(S)-Rg3 Prevents PKM2-Targeting miR-324-5p from H19 Sponging to Antagonize the Warburg Effect in Ovarian Cancer Cells. Cel. Physiol. Biochem 51 (3), 1340-1353. doi:10.1159/000495552

Zhou, W., Wang, S., Ying, Y., Zhou, R., and Mao, P. (2017). miR-196b/miR-1290 Participate in the Antitumor Effect of Resveratrol via Regulation of IGFBP3 Expression in Acute Lymphoblastic Leukemia. Oncol. Rep. 37 (2), 1075-1083. doi:10.3892/or.2016.5321

Zhou, W., Wu, Y., Pan, M., Liu, D., and Liu, B. (2019). Proliferation and Migration of Lung Cancer Could Be Inhibited by Oxymatrine through the Regulation for miR-520/VEGF. Am. J. Chin. Med. 47 (4), 865-878. doi:10.1142/ S0192415X19500459

Zhou, Y., Zheng, X., Lu, J., Chen, W., Li, X., and Zhao, L. (2018). Ginsenoside 20(S)-Rg3 Inhibits the Warburg Effect via Modulating DNMT3A/MiR-532-3p/
HK2 Pathway in Ovarian Cancer Cells. Cel. Physiol. Biochem. 45 (6), 2548-2559. doi:10.1159/000488273

Zhu, J., Feng, Y., Ke, Z., Yang, Z., Zhou, J., Huang, X., et al. (2012). Downregulation of miR-183 Promotes Migration and Invasion of Osteosarcoma by Targeting Ezrin. Am. J. Pathol. 180 (6), 2440-2451. doi:10.1016/ j.ajpath.2012.02.023

Zhu, J., Wang, S., Chen, Y., Li, X., Jiang, Y., Yang, X., et al. (2017). miR-19 Targeting of GSK3 $\beta$ Mediates Sulforaphane Suppression of Lung Cancer Stem Cells. J. Nutr. Biochem. 44, 80-91. doi:10.1016/j.jnutbio.2017.02.020

Zhuang, L. K., Xu, G. P., Pan, X. R., Lou, Y. J., Zou, Q. P., Xia, D., et al. (2014). MicroRNA-181a-mediated Downregulation of AC9 Protein Decreases Intracellular cAMP Level and Inhibits ATRA-Induced APL Cell Differentiation. Cel. Death Dis. 5, e1161. doi:10.1038/cddis.2014.130

Zong, A., Cao, H., and Wang, F. (2012). Anticancer Polysaccharides from Natural Resources: a Review of Recent Research. Carbohydr. Polym. 90 (4), 1395-1410. doi:10.1016/j.carbpol.2012.07.026

Conflict of Interest: The authors declare that the research was conducted in the absence of any commercial or financial relationships that could be construed as a potential conflict of interest.

Copyright (C) 2021 Sabo, Dudau, Constantin, Pop, Geilfus, Naccarati and Dragomir. This is an open-access article distributed under the terms of the Creative Commons Attribution License (CC BY). The use, distribution or reproduction in other forums is permitted, provided the original author(s) and the copyright owner(s) are credited and that the original publication in this journal is cited, in accordance with accepted academic practice. No use, distribution or reproduction is permitted which does not comply with these terms. 